José Geraldo Barreto Monteiro de Andrade

\title{
Uma contribuição ao estudo da estabilidade de tensão em sistemas elétricos de potência: novos aspectos relacionados à representação da carga
}

Tese apresentada à Escola Politécnica da Universidade de São Paulo para obtenção do Título de Doutor em Engenharia Elétrica. 
José Geraldo Barreto Monteiro de Andrade

\section{Uma contribuição ao estudo da estabilidade de tensão em sistemas elétricos de potência: novos aspectos relacionados à representação da carga}

Tese apresentada à Escola Politécnica da Universidade de São Paulo para obtenção do Título de Doutor em Engenharia Elétrica.

Área de concentração:

Sistemas de Potência

Orientador:

Prof. Dr. Hernán Prieto Schmidt 
Esse exemplar foi revisado e alterado em relação a versão original, sob responsabilidade única do autor e com anuência de seu orientador.

São Paulo, 7 de novembro de 2007

Assinatura do autor

Assinatura do orientador

\section{Ficha Catalográfica - Edição Revisada}

Andrade, José Geraldo Barreto Monteiro de

Uma contribuição ao estudo da estabilidade de tensão em sistemas elétricos de potência: novos aspectos relacionados à representação da carga. São Paulo, 2007.

$117 \mathrm{p}$.

Tese (Doutorado) - Escola Politécnica da Universidade de São Paulo. Departamento de Engenharia de Energia e Automação Elétricas.

1. Modelagem da Carga. 2. Estabilidade de Tensão. 3. Análise Modal. 4. Modelagem Multimáquina I. Universidade de São Paulo. Escola Politécnica. Departamento de Engenharia de Energia e Automação Elétricas. II. Título. 
À minha noiva Daniela pelo carinho e compreensão. Aos meus pais e à minha irmã. 


\section{Agradecimentos}

Ao professor Hernán Prieto Schmidt pelo apoio, crédito e estímulo durante a execução desse trabalho.

Ao professor Clóvis Goldemberg pela ajuda no entendimento, modelagem e implementação dos dispositivos de controle utilizados nesse trabalho.

Aos professores Carlos Márcio Vieira Tahan e José Antônio Jardini pelo envolvimento em projetos de pesquisa.

Ao amigo Eduardo Lorenzetti Pellini pelas discussões relacionadas à modelagem da máquina síncrona.

Ao Departamento de Engenharia de Energia e Automação Elétricas pelo suporte financeiro concedido à publicação e apresentação de parte desse trabalho no exterior.

Aos amigos Adriano, Chicão, Giovanni, Mikio, Ricardo e Su.

Aos demais amigos e colegas cujos nomes deixaram de ser citados por inteira culpa e esquecimento do autor. 


\section{Resumo}

Esse trabalho investiga o impacto do comportamento transitório e em regime permanente da carga sobre a estabilidade de tensão do sistema elétrico. Para isso, utiliza-se uma modelagem detalhada da rede elétrica, capaz de representar os principais eventos inerentes aos fenômenos de instabilidade e colapso de tensão. A simulação numérica do sistema algébrico-diferencial resultante é realizada utilizando-se o solver $D A S S L C$. Ao final desse trabalho, faz-se uma análise da resposta dos diferentes modelos de carga sobre a estabilidade de tensão do sistema de 14 barras do IEEE. 


\section{Abstract}

This work investigates the impact of transient and steady state load behavior on power systems voltage stability. In order to do this, a detailed electric power system model is used to reproduce the main aspects of voltage instability and collapse phenomena. The numerical solution of the resulting non-linear differential-algebraic equations is carried out by using the DASSLC solver. An analysis of different load models behaviour for some voltage instability situations is presented for IEEE 14 bus system. 


\section{Sumário}

\section{Lista de Figuras}

Lista de Tabelas

Lista de Abreviaturas

1 Introdução 1

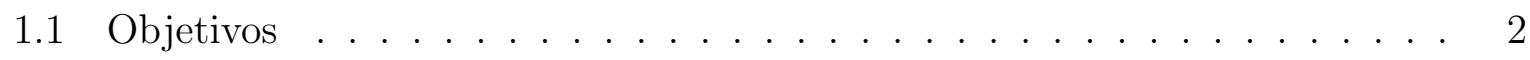

1.2 Contribuições . . . . . . . . . . . . . . . . . . 3

1.3 Organização da tese . . . . . . . . . . . . . . . . . . . . . 3

2 O Problema da Estabilidade de Tensão 5

2.1 Introdução . . . . . . . . . . . . . . . . . . . . . . 5

2.2 Descrição e causas do Colapso de Tensão . . . . . . . . . . . . . . . 5

2.3 Um exemplo de colapso de tensão . . . . . . . . . . . . . . . . . . . . 7

2.4 Escopo do presente trabalho . . . . . . . . . . . . . . . . . . . . . . 9

3 Revisão Bibliográfica $\quad 12$

3.1 Introdução . . . . . . . . . . . . . . . . . . . . . . . . 12

3.2 Controle de Segurança . . . . . . . . . . . . . . . . . . . . 12

3.3 Monitoramento de Segurança . . . . . . . . . . . . . . . . . 13

3.4 Análise de Segurança . . . . . . . . . . . . . . . . . . . . . . . 14

3.4.1 Avaliação de Contingências . . . . . . . . . . . . . . . 15

3.4.2 Metodologias baseadas no fluxo de potência pós-contingência . . . 16 
3.4.3 Metodologias baseadas no Fluxo de Potência para casos não-resolvíveis 17

3.4.4 Metodologia baseada em Curvas VQ . . . . . . . . . . . . . . . 18

3.4.5 Metodologias baseadas na simulação temporal . . . . . . . . . . . . 19

3.5 Metodologias para Determinação da Margem de Segurança . . . . . . . . . 20

3.5.1 Métodos de Continuação . . . . . . . . . . . . . . . . . . . . . 21

3.5.2 Métodos de Otimização . . . . . . . . . . . . . . . . . . . 22

3.5.3 Métodos baseados nas múltiplas soluções do fluxo de potência . . . 25

3.5.4 Métodos baseados na análise de bifurcações . . . . . . . . . . . 25

3.5.5 Simulação temporal acoplada com análise de sensibilidade . . . . 26

3.6 Determinação dos Limites de Segurança . . . . . . . . . . . . . . . . . 28

4 Modelagem dinâmica do sistema elétrico voltada para o problema da estabilidade de tensão.

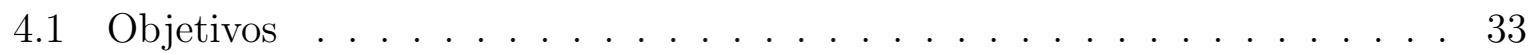

4.2 Modelagem dinâmica do sistema elétrico . . . . . . . . . . . . . . . 33

4.2 .1 Unidade Geradora . . . . . . . . . . . . . . . . . . . . . 34

4.2.1.1 Máquina Síncrona . . . . . . . . . . . . . . . . 34

4.2.1.2 Controle de Excitação (Regulador de Tensão) . . . . . . 36

4.2.1.3 Limitador de Sobre-Excitação . . . . . . . . . . . . . . . . 37

4.2.2 Transformadores com Controle Automático de Tape . . . . . . . . . 38

4.2 .3 Modelos de cargas . . . . . . . . . . . . . . . . . . . 38

4.2.3.1 Modelos estáticos das cargas . . . . . . . . . . . . . 38

4.2.3.2 Modelos dinâmicos das cargas . . . . . . . . . . . . . . . 39

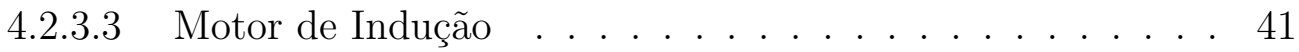

4.2.4 Demais elementos da rede elétrica . . . . . . . . . . . . . . . . . 42

4.2.5 O equacionamento multi-máquina . . . . . . . . . . . . . . . . . 42

4.3 A Representação Genérica do Sistema Elétrico . . . . . . . . . . . . . . . . 43 
4.4 O integrador algébrico-diferencial DASSLC . . . . . . . . . . . . . . 44

4.4.1 Uma visão geral sobre métodos de integração numérica . . . . . . . 44

4.4.2 Uma análise breve da estabilidade dos métodos de integração . . . . 45

4.4.3 Sobre sistemas de equações rígidas $($ stiff $)$. . . . . . . . . . . . 46

4.4 .4 O método de Diferenciação Regressiva . . . . . . . . . . . . . . . . 47

4.5 Ferramentas desenvolvidas neste trabalho . . . . . . . . . . . . . . . . 48

4.5.1 O programa de fluxo de potência FLOW . . . . . . . . . . . . . . 49

4.5.1.1 Solução do fluxo de potência . . . . . . . . . . . . . . . 49

4.5.1.2 Análise modal . . . . . . . . . . . . . . . . . 52

4.5 .2 O programa DSIM . . . . . . . . . . . . . 55

4.5.2.1 Recursos disponíveis . . . . . . . . . . . . . . . 55

4.5.2.2 Tratamento dos limites nos controles . . . . . . . . . . . 56

4.6 Resultados para o sistema de 10 barras da BPA . . . . . . . . . . . 58

5 Análise de estabilidade de tensão utilizando modelos de carga estáticos e dinâmicos $\quad 63$

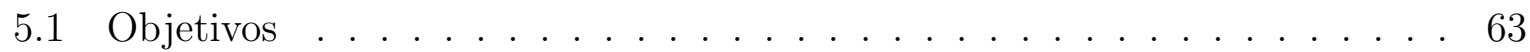

5.2 Alguns aspectos sobre o comportamento da carga . . . . . . . . . . 63

5.3 Impacto das sensibilidades da carga sobre a estabilidade de tensão . . . . . 67

5.3.1 Impacto das sensibilidades em regime permanente $\left(\alpha_{S}\right.$ e $\left.\beta_{S}\right) \ldots \ldots 8$

5.3.2 Impacto das sensibilidades transitórias $\left(\alpha_{T}\right.$ e $\left.\beta_{T}\right) \ldots \ldots$. . . . . . 69

5.4 Impacto dos controles sobre a resposta transitória da carga . . . . . . . . . 71

5.5 Impacto das cargas dinâmicas sobre a estabilidade de tensão . . . . . . . 74

5.5.1 Avaliação do ponto de máximo carregamento . . . . . . . . . . 75

5.5.2 Avaliação do limite de carregamento pós-contingência . . . . . . . . 80

5.5.3 Impacto sobre o "alívio de carga" . . . . . . . . . . . . . . . 82 
6.1 Resumo geral . . . . . . . . . . . . . . . . . . . . 84

6.2 Principais contribuições . . . . . . . . . . . . . . . . . . . . . . 84

6.2.1 Análise do impacto dos modelos de carga sobre as margens de estabilidade de tensão. . . . . . . . . . . . . . . . . . . . . . . . . 84

6.2.2 Aplicação do solver DASSLC para análise dinâmica da estabilidade de tensão . . . . . . . . . . . . . . . . . . . . 85

6.2 .3 Outras contribuições . . . . . . . . . . . . . . . . 85

6.3 Trabalhos futuros . . . . . . . . . . . . . . . . 86

6.3.1 Investigação de modelos de carga mais realistas . . . . . . . . . . . 86

6.3.2 Inclusão de mais modelos de controle no simulador . . . . . . . . . 86

6.3.3 Determinação de ações corretivas . . . . . . . . . . . . . . . . 86

$\begin{array}{lr}\text { Anexo A - Dados dos Sistemas Simulados } & 88\end{array}$

A.1 Sistema Exemplo - Capítulo $2 \ldots \ldots$. . . . . . . . . . . 88

A.2 Sistema BPA de 10 barras - Capítulo $4 \ldots \ldots$. . . . . . . . 90

A.3 Sistema de 2 barras - Capítulo $5 \ldots \ldots . \ldots . \ldots . \ldots 9$

A.4 Sistema IEEE de 14 barras - Capítulo 5 . . . . . . . . . . . . . . . . 94

Anexo B - Uma introdução breve à DASSLC $\quad 97$

Referências 


\section{Lista de Figuras}

2.1 Sistema Exemplo para ilustrar um Colapso de Tensão. . . . . . . . . . . . 8

2.2 Tensão nas barras do sistema exemplo. . . . . . . . . . . . . . . . . . . . . . 8

2.3 Tensão de Campo do Gerador utilizado no sistema exemplo. . . . . . . . . . 9

3.1 Subdivisões do Controle de Segurança. . . . . . . . . . . . . . . . . . . . . 12

3.2 Princípio do Iterative Filtering. . . . . . . . . . . . . . . . . . . . . . 17

3.3 Curva VQ . . . . . . . . . . . . . . . . . . . . . . . . . 18

3.4 Conceito de Limite de Carregamento. . . . . . . . . . . . . . . . 21

3.5 Cenários possíveis para um gerador e seus controles. . . . . . . . . . . . . 23

3.6 Distância entre os pontos de equilíbrio Estável e Instável. . . . . . . . . . . 25

3.7 Restauração de cargas com potência constante. . . . . . . . . . . . . . 27

3.8 Sistema exemplo para ilustrar o conceito de limite de operação seguro. 28

3.9 Efeito das ações de pré e pós contingência. . . . . . . . . . . . . . . . . . 29

3.10 Relação entre o limite de carregamento (pós-contingência) e o limite de operação seguro. . . . . . . . . . . . . . . . . . . . . . 30

3.11 Funcionamento do Binary Search. . . . . . . . . . . . . . . . . 30

3.12 Funcionamento do Simultaneous Binary Search. . . . . . . . . . . . . . 31

4.1 Sistema de controle de excitação. . . . . . . . . . . . . . . . . . . . . 34

4.2 Modelo de $1^{a}$ ordem do Regulador de Tensão. . . . . . . . . . . . . . . . . 36

4.3 Modelo do Limitador de Sobre-Excitação. . . . . . . . . . . . . . . . . . . 37

4.4 Circuito equivalente para o modelo transitório do motor. . . . . . . . . . . 41

4.5 Escalas de tempo dos componentes do sistema elétrico. . . . . . . . . . . . 44

4.6 Curva de capacidade do gerador. . . . . . . . . . . . . . . . 51 
4.7 Controlador com limites. . . . . . . . . . . . . . . . . . . 56

4.8 Anti-windup: técnica Tracking. . . . . . . . . . . . . . . 57

4.9 Anti-windup: técnica FeedBack-Reset. . . . . . . . . . . . . . . . 57

4.10 Sistema de 10 barras da BPA . . . . . . . . . . . . . . . . . 58

4.11 Tensão barra 11 - Casos A e B. . . . . . . . . . . . . . . . . . . . . 59

4.12 Tensões nas barra 10 e 11 - caso C . . . . . . . . . . . . . . . . 60

4.13 Tape do LTC 1011 - caso C. . . . . . . . . . . . . . . . . . . . 60

4.14 Correntes de campo geradores 2 e 3 - caso C. . . . . . . . . . . . . 61

4.15 Tensão na barra 11 - casos C e D. . . . . . . . . . . . . . . . . . . . . 61

4.16 Torque e corrente do motor - caso D. . . . . . . . . . . . . . . 62

4.17 Escorregamento do motor - caso D. . . . . . . . . . . . . . . . 62

5.1 Diagrama unifilar simplificado de um transformador de subestação. . . . . 63

5.2 Comportamento dinâmico da carga. . . . . . . . . . . . . . . . . . 64

5.3 Load Recovery - Modelo Hill. . . . . . . . . . . . . . . . . . . . . . . 65

5.4 Comportamento da Potência ativa para $\Delta \mathrm{V}=30 \% \ldots \ldots$. . . . . . 66

5.5 Comportamento da Potência reativa para $\Delta \mathrm{V}=30 \% \ldots \ldots$. . . . . 67

5.6 Sistema de duas barras. . . . . . . . . . . . . . . . . . 68

5.7 Impacto das sensibilidades em regime permanente $\left(\alpha_{S}\right) \ldots \ldots \ldots$

5.8 Impacto das sensibilidades em regime transitório $\left(\alpha_{T}\right) \ldots \ldots \ldots$. . . . . . 69

5.9 Potência absorvida pela carga para diferentes valores de $\alpha_{T} . \quad \ldots$. . . . . 70

5.10 Análise estática vs dinâmica do mecanismo de load recovery. . . . . . . . . 71

5.11 Mecanismo de load recovery da potência ativa - ação irrestrita do AVR. . . 72

5.12 Mecanismo de load recovery da potência reativa - ação irrestrita do AVR. . 72

5.13 Mecanismo de load recovery da potência ativa - ação limitada do AVR. . 73

5.14 Mecanismo de load recovery da potência reativa - ação limitada do AVR. . 73

5.15 Fatores de participação - modo EigJRQV1 (IEEE 14 barras). . . . . . . . . 75 
5.16 PMC - barra14: diferentes modelos de carga. . . . . . . . . . . . . 76

5.17 Curvas PV - barra14: diferentes modelos de carga. . . . . . . . . . . . 76

5.18 Curvas QV - barra14: diferentes modelos de carga. . . . . . . . . . . 77

5.19 Curvas PV - barra14: impacto dos limites nos AVRs . . . . . . . . . . . 77

5.20 Curvas QV - barra14: impacto dos limites nos AVRs . . . . . . . . . 78

5.21 Motor (barra 14): Relação entre os torques eletromagnético e mecânico. . . 78

5.22 Motor (barra 14): Evolução temporal do comportamento. . . . . . . . . . . 79

5.23 Curvas ZV pós contingência (barra14). . . . . . . . . . . . . . 81

5.24 Curvas PV pós contingência (barra14). . . . . . . . . . . . . 81

5.25 Curvas QV pós contingência (barra14) . . . . . . . . . . . . . . 82

5.26 Aumento na margem de carregamento devido ao corte de carga (barra14). 83 


\section{Lista de Tabelas}

4.1 Equacionamento multi-máquina do sistema elétrico. . . . . . . . . . . . . . 43

4.2 coeficientes das fórmulas BDF até ordem $6 \ldots \ldots \ldots$. . . . . . . 47

4.3 Tipos de barra considerados no programa FLOW. . . . . . . . . . . . . . . 49

4.4 Eventos contemplados no programa DSIM. . . . . . . . . . . . . . 56

4.5 Hipóteses adotadas na simulação do sistema BPA de 10 barras. . . . . . . . 59

5.1 Parâmetros utilizados nos modelos Hill e Ihara. . . . . . . . . . . . . . . 67

5.2 Autovalores JRQV - IEEE 14 barras. . . . . . . . . . . . . . . . . . 74

5.3 Modelos dinâmicos para carga localizada na barra 14. . . . . . . . . . 75

5.4 Avaliação das Contingências - IEEE 14 barras. . . . . . . . . . . . . . . . . 80 


\title{
Lista de Abreviaturas
}

\author{
AVRs Automatic Voltage Regulators \\ EADs Equações Algébrico-Diferenciais \\ LTCs Load Tap Changers \\ OXLs Over-Excitation Limiters
}




\section{Introdução}

No mundo inteiro os sistemas elétricos de potência estão enfrentando um processo de reestruturação devido, principalmente, a fatores de ordem econômica e ambiental. Sob a ótica da economia, a nova realidade imposta aos sistemas elétricos de potência caracterizase por um ambiente competitivo, entre outros fatores, oriundo da dispersão da capacidade geradora em muitas companhias. Sob a ótica ambiental, os recursos naturais necessários à expansão desses sistemas se tornam cada vez mais escassos e existem pressões sociais para que esses recursos sejam economizados ao máximo com o intuito de minimizar as agressões ao meio ambiente.

Como conseqüência direta dos fatores supracitados a possibilidade de atendimento de novas demandas através da expansão física dos sistemas elétricos de potência, com a implantação de novas unidades geradoras e linhas de transmissão, fica significativamente reduzida. Além disso, as reservas de geração e transmissão devem ser cada vez menores para minimizar os custos de produção e transmissão da energia de forma a garantir a competitividade das empresas e economizar os recursos naturais escassos. Esses fatos fazem com que os sistemas de potência tenham de operar com margens de estabilidade cada vez mais reduzidas.

Para que os sistemas de potência sigam operando com padrões adequados de qualidade e segurança faz-se necessário conhecer muito bem seus limites de operação viável e, em muitos casos, adotar medidas capazes de aumentar artificialmente suas margens de estabilidade. Nesse contexto, a preocupação com a análise de segurança passa a assumir um papel de destaque nas etapas de planejamento, operação e controle (em tempo real) dos sistemas elétricos de potência.

Em particular os dois fatores anteriores, juntamente com o comportamento da carga, são citados por diversos autores (CUTSEM; VOURNAS, 1998; TAYLOR, 1994; KUNDUR, 1994) como causas principais para a ocorrência dos fenômenos conhecidos como Instabilidade de Tensão e Colapso de Tensão. Esses fenômenos foram responsáveis por incidentes, em diversas partes do mundo, documentados em várias publicações (COUNAN et al., 1993; 
MILLER et al., 1993; AJJARAPU; LEE, 1992) e por isso passaram a ser considerados como um dos aspectos mais importantes na análise de segurança de sistemas de potência altamente carregados (CUTSEM; VOURNAS, 1998).

Nesse contexto, o presente trabalho aborda o problema da estabilidade de tensão sob um ponto de vista dinâmico analisando alguns aspectos relacionados à modelagem da carga que podem resultar em aumento ou redução das margens de estabilidade de tensão do sistema elétrico.

\subsection{Objetivos}

Esse trabalho tem como principal objetivo investigar o impacto dos diferentes modelos de carga propostos sobre os principais índices adotados para aferir as margens de estabilidade de tensão do sistema elétrico, a citar: limites de carregamento pré-contingência e limites de carregamento pós-contingência.

Além disso, podem-se mencionar uma série de objetivos secundários cuja investigação fez-se necessária para concluir esse trabalho, a citar:

- Técnicas para inclusão de dispositivos de controle no modelo do fluxo de potência, como: reguladores de tensão dos geradores (KLUMP; OVERBYE, 2000) e transformadores com controle automático de tape (PETTERSON; MEYER, 1971; POWELL, 2005);

- Técnicas "anti-windup" (FERNANDES, 2001) para inclusão dos limites dos reguladores automáticos de tensão (AVRs) e limitadores de sobreexcitação (OXLs) no modelo dinâmico dos geradores;

- Métodos numéricos multi-passo para solução de sistemas de equações algébricodiferenciais rígidas (E. CAMPBELL S. L., 1996; ASCHER; PETZOLD, 1998; F. VIEIRA R. C., 2003);

- Métodos numéricos para cálculo dos autovalores e dos autovetores esquerdos e direitos em sistemas matriciais assimétricos (ANDERSON et al., 1999);

- Métodos numéricos recentes para solução de sistemas matriciais esparsos (PANDIT; SOMAN; KHAPARDE, 2001, 2002);

- Técnicas de programação orientada a objetos (HAKAVIK; HOLEN, 1994; NOR; MOKHLIS; GANI, 2004) aplicadas a modelagem de sistemas de potência. 


\subsection{Contribuições}

As principais contribuições deste trabalho, analisadas no Capítulo 6, são brevemente relacionadas abaixo:

- Análise do impacto dos modelos de carga abordados recentemente em (NAVARRO, 2005) sobre as margens de estabilidade de tensão do sistema elétrico utilizando simulações dinâmicas (modelagem multimáquina);

- Comparação dos resultados obtidos a partir do modelo multimáquina citado com os oriundos do modelo baseado nas equações do fluxo de potência, tradicionalmente utilizado para avaliação em tempo-real do limites de estabilidade de tensão (SAVULESCU, 2005);

- Aplicação pioneira do solver DASSLC (SECCHI, 1992; F. VIEIRA R. C., 2003) para simulação dinâmica multimáquina de sistemas de potência.

\subsection{Organização da tese}

Este trabalho está organizado da seguinte forma.

- O capítulo 2 fornece uma introdução ao problema elétrico da estabilidade de tensão. O problema é descrito segundo uma perspectiva qualitativa, apresentando uma análise de suas causas principais. Uma simulação exemplo de um colapso de tensão é incluída com o intuito de ilustrar alguns mecanismos que são observados durante o processo de instabilidade de tensão. Ao final desse capítulo especifica-se detalhadamente o escopo desse trabalho.

- O capítulo 3 contém uma revisão geral da literatura que aborda o assunto estabilidade de tensão. Devido ao elevado número de trabalhos existentes nessa linha de pesquisa, as contribuições são apresentadas segundo os principais problemas elétricos existentes no contexto de Controle de Segurança.

- O capítulo 4 descreve o simulador dinâmico DSIM desenvolvido neste trabalho. Primeiramente apresenta-se a modelagem multi-máquina do sistema elétrico utilizada para abordar o problema da estabilidade de tensão e o método numérico empregado pelo solver DASSLC. A seguir, discutem-se aspectos relacionados à análise modal expandida (SILVA et al., 2002) utilizada como ferramenta auxiliar nesse trabalho para 
avaliar a estabilidade de tensão dos sistemas analisados. Ao final desse capítulo, apresenta-se a validação das ferramentas desenvolvidas, através da simulação de alguns cenários no sistema elétrico de 10 barras da BPA, cujos resultados são amplamente divulgados e conhecidos na literatura técnica (KUNDUR, 1994; TAYLOR, 1994; CIGRE, 1995; CUTSEM; VOURNAS, 1998).

- O capítulo 5 apresenta alguns aspectos relacionados ao comportamento dinâmico da carga sobre a estabilidade de tensão. Analisam-se suas respostas transitórias e em regime permanente através de sistemas exemplo. A seguir, avalia-se o impacto da interação entre os controles existentes e o comportamento dos modelos dinâmicos de carga sobre alguns dos principais índices adotados para avaliar a estabilidade de tensão utilizando o sistema de 14 barras do IEEE.

- O capítulo 6 apresenta as conclusões desse trabalho. 


\section{O Problema da Estabilidade de Tensão}

\subsection{Introdução}

Esse capítulo apresenta o problema da Estabilidade de Tensão. Inicialmente esse problema elétrico é descrito de uma forma qualitativa. Uma simulação de colapso de tensão é apresentada com o intuito de ilustrar as principais causas relacionadas a esse tipo de instabilidade.

\subsection{Descrição e causas do Colapso de Tensão}

Apesar da probabilidade de ocorrência de um colapso de tensão ser muito baixa, as conseqüências desse fenômeno são tão sérias que justificam os grandes esforços dispendidos na sua investigação. Exemplos práticos de colapsos de tensão foram observados na França (CHEIMANOFF; CURROYER, 1980; COUNAN et al., 1993), Japão (KURITA; SAKURAI, 1988), Estados Unidos (MILLER et al., 1993), Grécia (VOURNAS et al., 2000) e muitos outros países.

A instabilidade de tensão pode se manifestar de diversas maneiras, mas, geralmente, segue o seguinte mecanismo: primeiro observa-se um declínio lento na tensão de barras pertencentes a uma determinada área. Durante esse período, não existem indicativos físicos claros que possam ser utilizados pelos operadores sobre um processo iminente de colapso de tensão. Esse primeiro estágio pode se manter durante vários minutos e já se observou que alguns dispositivos utilizados no controle automático de tensão, como compensadores de reativos e transformadores com controle automático de tape (LTCs), podem piorar a situação. O segundo período é rápido (durando apenas alguns segundos) e se caracteriza pela propagação das péssimas condições locais (afundamento das tensões e abertura dos ângulos nas barras) por todo o resto do sistema (SCHMIDT, 1994). 
Existem diversas causas que podem levar um sistema a instabilidade de tensão. Como uma possível causa de "longo-prazo" pode-se mencionar situações em que a expansão do sistema elétrico não acompanha o crescimento da demanda das cargas devido a restrições econômicas e operacionais. Assim, vários sistemas interconectados encontram-se operando mais próximos que nunca de seus limites admissíveis máximos, muito freqüentemente em condições para as quais não foram projetados. Por outro lado, entre as possíveis causas de "curto-prazo" pode-se citar eventos como saídas de linhas e variações aleatórias da demanda nas cargas em sistemas atuando na proximidade de seu limite seguro.

A instabilidade de tensão também está associada a um suporte reativo inadequado. Se essa condição é verificada, pelo menos em uma determinada área, a potência reativa precisa ser fornecida por uma fonte localizada em outra área. Sabe-se que "fluxos elevados de potência reativa" provocam aumentos nas "perdas reativas" e afundamentos das tensões nas barras. Além disso, podem fazer os geradores atingirem seus limites de fornecimento de potência reativa. O colapso de tensão pode ocorrer quando esse desequilíbrio entre a geração e a carga não pode ser corrigido através de uma redução limitada da tensão.

Em alguns exemplos práticos de colapso de tensão observou-se que os ângulos das barras e a frequência do sistema mantiveram-se quase que inalterados durante o decaimento das tensões, e em outras situações observou-se que eles acompanharam esse decaimento. Em casos de colapsos de tensão induzidos por distúrbios, observou-se também situações em que o sistema alcançou um estado estável apresentando tensões significativamente reduzidas nas barras, a estabilidade somente foi perdida devido às ações de controles nas cargas e/ou atuações dos limitadores de potência reativa nos geradores.

Sabe-se que as cargas do sistema possuem um papel essencial no processo de instabilidade de tensão, especialmente aquelas conhecidas como "cargas rígidas" (stiff loads). Esse termo refere-se as cargas que possuem dispositivos de controle automático, cuja finalidade é manter a potência absorvida pela carga inalterada independentemente do nível de tensão a que essa é submetida. As ações desses tipos de dispositivo de controle podem ser bastante prejudiciais ao sistema, especialmente em situações nas quais faz-se necessário algum nível de alívio de carga para que o sistema atinja um novo ponto de operação estável. As cargas rígidas normalmente exibem um comportamento dinâmico caracterizado por constantes de tempo da ordem de minutos e, dessa forma, podem ser consideradas "dispositivos lentos". Motores de indução, apesar de possuírem uma resposta dinâmica muito mais rápida que as cargas rígidas, também contribuem significativamente para o processo de instabilidade de tensão devido ao seu comportamento em baixas tensões. Nessas situações, os motores de indução absorvem grandes quantidades de potência reativa e podem apresentar até 
travamento do rotor.

Além das cargas, também convém ressaltar o papel desempenhado pelos seguintes controles: controladores automáticos de tape (LTCs) nos transformadores, reguladores de tensão (AVRs) e limitadores de sobre-excitação (OXLs) nos geradores, além dos controles para desconexão automática de carga em tensões baixas. Sabe-se que os LTCs podem, em algumas situações, contribuir para o agravamento do processo de instabilidade de tensão e, em outras, podem melhorar a estabilidade do sistema (ZHU; TSO; LO, 2000; PEREIRA et al., 2004; VOURNAS; KARYSTIANOS, 2004). O comportamento dinâmico dos AVRs e OXLs pode manter a estabilidade de tensão do sistema ou agravar a situação de tal forma que uma situação de estabilidade aparente pode evoluir rapidamente para um estado de colapso, especialmente quando a sobrecarga de potência reativa nos geradores é elevada e persiste por um intervalo de tempo considerável (CUTSEM, 2000). Similarmente, a atuação dos controles para desconexão automática de carga pode fazer a diferença entre uma evolução rápida para um colapso de tensão e uma situação de estabilidade desde que a parcela "correta" da carga seja desconectada do sistema no instante de tempo adequado (CUTSEM; MOORS; LEFEBVRE, 2002; LEFEBVRE; MOORS; CUTSEM, 2003; LEFEBVRE; BERNARD; CUTSEM, 2004). O capítulo 3 apresenta algumas pesquisas recentes voltadas ao monitoramento e ajuste desses dispositivos com o objetivo de melhorar a estabilidade de tensão do sistema.

\subsection{Um exemplo de colapso de tensão}

Com o objetivo de ilustrar alguns aspectos físicos do processo de instabilidade de tensão, apresenta-se, a seguir, um exemplo de colapso de tensão para o sistema da figura 2.1. Os dados desse sistema encontram-se no anexo A e baseiam-se em parâmetros reais de dispositivos encontrados nas referências (KUNDUR, 1994; ANDERSON; FOUAD, 2002). Os resultados apresentados a seguir foram obtidos utilizando ferramentas estáticas e dinâmicas para análise de estabilidade de tensão desenvolvidas durante a confecção deste trabalho e são apresentadas no capítulo 4.

A figura 2.1 ilustra um sistema em que a carga, situada na barra 4, exige uma demanda excessiva de potências ativa e reativa (no caso $50 \mathrm{MW}$ e $41 \mathrm{MVAr}$ ) que não pode ser suprida unicamente pelo gerador hidráulico de 40 MVA localizado na barra 2. A fim de suprir a demanda imposta pela carga, a barra 3 foi interligada com um sistema próximo, aqui representado por uma barra "swing", através de duas ${ }^{1}$ linhas de $138 \mathrm{kV}$. Essa solução

\footnotetext{
${ }^{1} \mathrm{~A}$ rigor, mais de três linhas deveriam existir a fim de atender ao critério $\mathrm{N}-1$.
} 


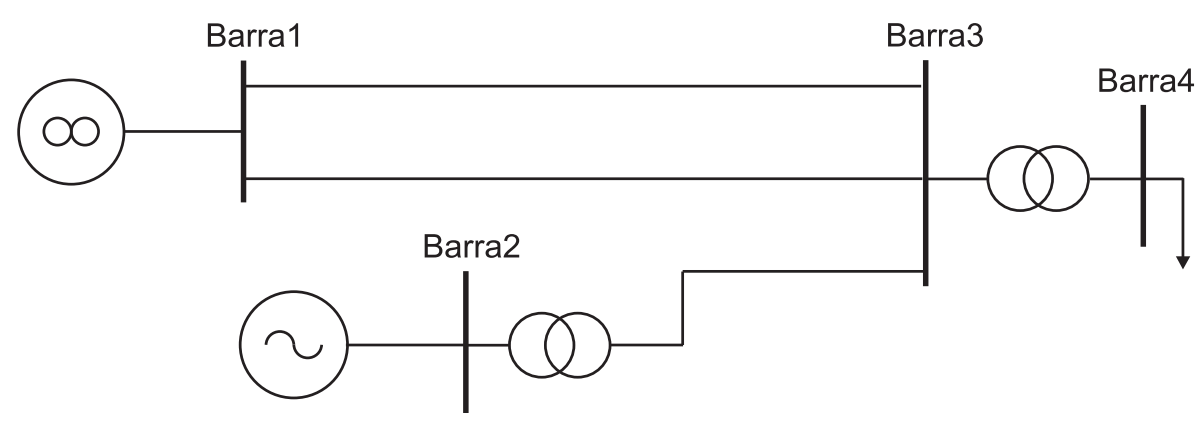

Figura 2.1: Sistema Exemplo para ilustrar um Colapso de Tensão.

viabiliza o atendimento da demanda exigida pela carga em que cerca de $79 \%$ da potência aparente é fornecida pelo sistema interligado através das linhas de $138 \mathrm{kV}$ e os outros $21 \%$ são supridos pelo gerador localizado na barra 2 (vide solução do fluxo no anexo A.1).

Claramente o cenário descrito exemplifica uma situação em que a restrição econômica impede uma expansão adequada do sistema. Essa afirmação pode ser facilmente verificada na figura 2.2 que mostra a evolução temporal das tensões nas barras 2, 3 e 4 após a simulação de uma contingência em t=36 s para uma das linhas de $138 \mathrm{kV}$.

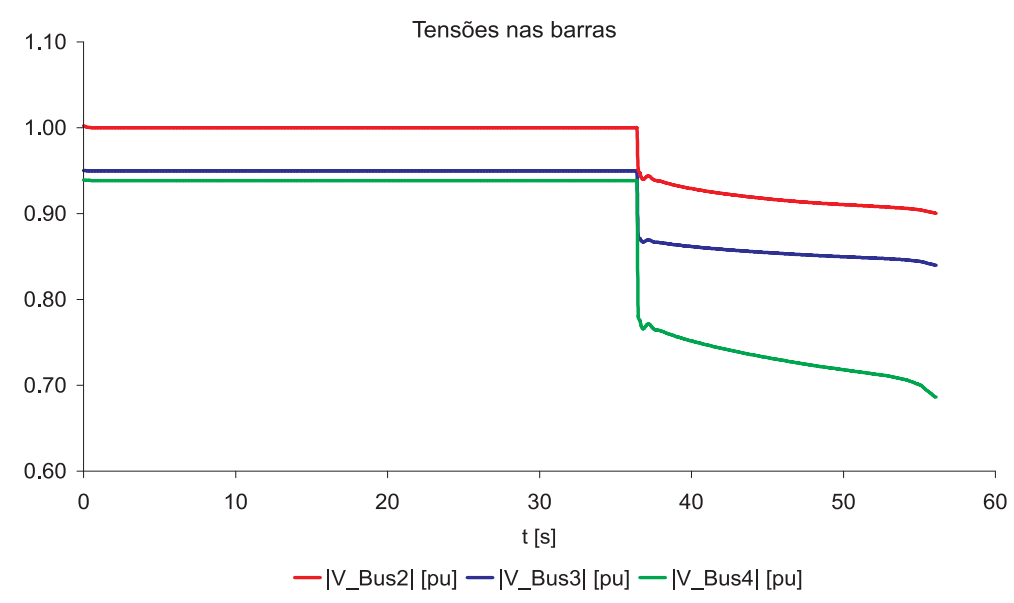

Figura 2.2: Tensão nas barras do sistema exemplo.

Observando a figura 2.2 percebe-se que, logo após a contingência, as tensões nas barras 2, 3 e 4 apresentam um afundamento para, respectivamente, $0.95 \mathrm{pu}, 0.87 \mathrm{pu}$ e $0.78 \mathrm{pu}$. A seguir, observa-se que, durante cerca de 20 s, essas três tensões apresentam uma tendência gradual de queda culminando, no instante $\mathrm{t}=56 \mathrm{~s}$, em uma situação de colapso com essas tensões atingindo, respectivamente, $0.90 \mathrm{pu}, 0.84 \mathrm{pu}$ e $0.69 \mathrm{pu}$.

A figura 2.3 apresenta a evolução temporal da tensão de campo para o gerador localizado na barra 2. Observa-se que, imediatamente após a retirada de uma das linhas de $138 \mathrm{kV}$ 
em $\mathrm{t}=36 \mathrm{~s}$, esse gerador passa a suprir gradualmente a demanda por reativos imposta pela carga. No instante $t=47 \mathrm{~s}$, o gerador atinge seu o limite máximo para fornecimento de potência reativa e, a partir desse instante, a carga passa a apresentar um declínio cada vez mais acentuado de sua tensão fruto da inexistência de um suporte reativo local. Esse declínio, por sua vez torna a situação mais grave, uma vez que ele provoca também a queda das tensões nas barras 2 e 3 comprometendo ainda mais o fluxo de reativos em direção a barra 4 .

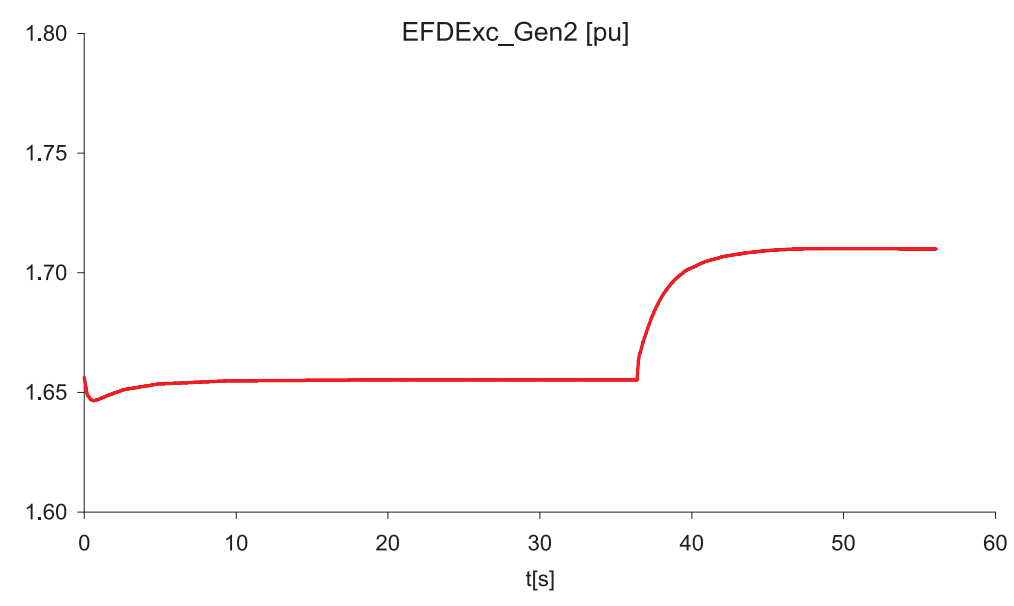

Figura 2.3: Tensão de Campo do Gerador utilizado no sistema exemplo.

Após a análise acima conclui-se que o sistema exemplo atingiu o colapso de tensão devido à conjugação de duas causas mencionadas anteriormente: uma causa de "longo prazo", que pode ser atribuída à adoção da interconexão através de uma linha adicional de $138 \mathrm{kV}$ sem prever um reforço do suporte reativo local, e uma causa de "curto prazo", que pode ser atribuída à saída de uma das linhas utilizadas na interconexão cujo o impacto não foi contemplado nos estudos de avaliação de curto prazo da operação desse sistema (ONS, 2002).

\subsection{Escopo do presente trabalho}

Qualquer estudo de instabilidade de tensão têm por objetivos principais: (i) avaliar o quão o estado de operação atual do sistema se encontra próximo de um colapso de tensão e (ii) identificar através de qual mecanismo esse estado poderia ser afastado de um colapso de tensão.

O primeiro objetivo é atingido através do estabelecimento de indicadores capazes de quantificar o quão próximo do colapso de tensão o estado atual do sistema se encontra. Um indicador ideal deve atender aos seguintes requisitos: 
- significado: a métrica utilizada no indicador está fisicamente relacionada a grandezas elétricas (tensão, injeções de potência reativa, etc.).

- confiabilidade: o indicador deve ser suficientemente confiável de forma a evitar erros na classificação do estado de operação do sistema.

- eficiência: o indicador deve ser avaliado com o menor esforço computacional possível (especialmente no âmbito de aplicações em tempo real).

Com relação ao segundo objetivo, faz-se necessário analisar os principais fatores responsáveis por levar o sistema a uma situação de colapso de modo a: entender fisicamente o fenômeno e disparar as ações corretivas necessárias, preferencialmente em tempo real.

Sabe-se que o problema da Estabilidade de Tensão possui uma natureza dinâmica, entretanto ele pode ser analisado através de modelos estáticos e/ou dinâmicos dependendo de qual dos dois objetivos anteriores se pretende alcançar e do nível de precisão requerido para se proceder à avaliação de segurança.

A utilização de modelos estáticos, em sua maioria baseados no modelo do fluxo de potência, permite estabelecer limites de segurança em relação ao estado de operação atual do sistema (SAUER; PAI, 2005) e quando utilizados juntamente com ferramentas para cálculo de sensibilidades (SOUZA; QUINTANA, 1994; GREENE; DOBSON; ALVARADO, 1997) e análise de autovalores (GAO; MORISON; KUNDUR, 1992; MORISON; GAO; KUNDUR, 1993) permitem obter informações importantes relacionadas: a sensibilidade do ponto de operação do sistema em relação a parâmetros do sistema (como a variação da demanda nas carga, o ajuste dos LTCs, etc) e a adoção de ações corretivas.

Os modelos dinâmicos por sua vez, além de possibilitarem uma avaliação mais precisa do estado de operação do sistema, permitem um melhor entendimento do mecanismo de instabilidade, uma vez que reproduzem, cronologicamente, a trajetória que leva o sistema ao colapso. Apesar dos avanços nas técnicas numéricas para solução de sistemas de equações algébrico-diferenciais (ASTIC; BIHAIN; JEROSOLIMSKI, 1994; ASCHER; PETZOLD, 1998) essas metodologias ainda são consideradas inadequadas para aplicação em tempo real (VOURNAS; CUTSEM, 2005).

Convém ressaltar que a idéia de se caracterizar a instabilidade de tensão como um mecanismo de "longo prazo" não pode ser considerada plenamente verdadeira, uma vez que alguns estudos já apresentaram situações em que esse fenômeno se manifesta através de uma instabilidade de "curto prazo" (DEUSE; STUBBE, 1993; KURITA et al., 1993; CUTSEM; VOURNAS, 1996; CUTSEM; MAILHOT, 1997). 
O presente trabalho faz uma análise comparativa entre os principais índices adotados para aferir as margens de estabilidade de tensão nos sistemas elétricos, a citar: limites de carregamento pré-contingência (vide item 3.5) e limites de carregamento pós-contingência (vide item 3.5) obtidos partir das modelagens estática e dinâmica. Na abordagem estática utilizam-se os modelos de carga Exponencial e ZIP (PERFORMANCE, 1993, 1995) e na abordagem dinâmica acrescentam-se os modelos de carga propostos em (HILL, 1993) e (IHARA; TANI; TOMIYAMA, 1994), recentemente validados através de medições de campo em (NAVARRO, 2005), além de um modelo de $3^{a}$ ordem para motores de indução (ONG, 1997). Nesse ponto convém ressaltar que, até o presente momento, não existem trabalhos na literatura que contenham resultados provenientes do modelo (IHARA; TANI; TOMIYAMA, 1994) para os índices anteriormente citados, por isso esse tópico está relacionado no item 1.2 deste trabalho. 


\section{Revisão Bibliográfica}

\subsection{Introdução}

Esse capítulo apresenta uma visão geral sobre assunto Análise de Estabilidade de Tensão. Pelo fato desse assunto ser muito vasto, optou-se por apresentar as principais contribuições segundo um critério orientado aos principais problemas abordados no Controle de Segurança (CUTSEM; VOURNAS, 1998; CANIZARES, 2002).

\subsection{Controle de Segurança}

Conforme visto anteriormente, as restrições ambientais e econômicas juntamente com a crescente demanda por energia impõem requisitos mais severos e exigem metodologias de análise mais complexas para viabilizar o funcionamento dos sistemas elétricos de potência segundo padrões de qualidade e segurança adequados. Nesse contexto, o controle de segurança possui um papel muito importante nos processos de planejamento, operação e controle uma vez que esse tem por objetivo manter o sistema funcionando em estado normal (CUTSEM; VOURNAS, 1998). Para isso, esse controle é subdividido em quatro processos de avaliação, cada um com seu foco específico, apresentados na figura 3.1.

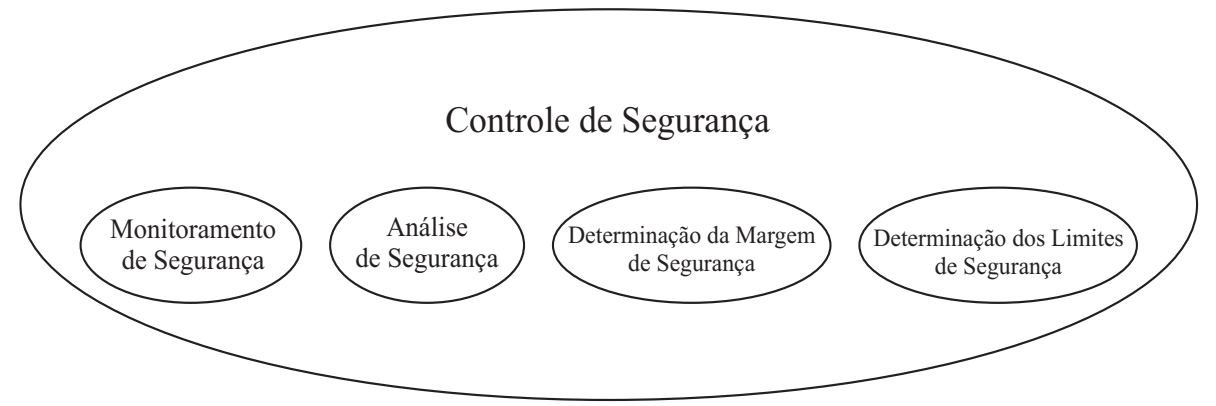

Figura 3.1: Subdivisões do Controle de Segurança.

A seguir define-se o escopo de cada um desses processos de avaliação e, para cada um 
deles, apresentam-se os principais trabalhos com foco no problema da estabilidade de tensão.

\subsection{Monitoramento de Segurança}

Consiste basicamente em monitorar as variáveis associadas ao comportamento do sistema de potência com o objetivo de verificar se os limites máximos e mínimos dessas variáveis foram violados e, em caso de alguma violação, disparar as ações necessárias para afastá-lo de um possível colapso de tensão.

Em (TARANTO et al., 2000) os autores analisam o impacto da aplicação de um Controle Secundário de Tensão na área do Rio de Janeiro frente a cenários de contingência simples e de aumento da carga no sub-sistema da Light. Para isso, utilizam uma ferramenta de simulação rápida no tempo, vide item 3.4.5, que permite avaliar o desempenho do controle proposto frente aos cenários citados. Além disso, os autores apresentam uma análise de sensibilidade desse controle em função da seleção da barra piloto e das fontes de reativos que o integram. As simulações apresentadas ilustram as melhorias alcançadas no controle dos perfis de tensões e no aumento da margem de estabilidade dessa região caso esse controle seja implantado.

Em (VOURNAS; KARYSTIANOS, 2004) os autores propõem uma estratégia denominada "reversão do tape" para os controladores automáticos de tape localizados nos transformadores das subestações de distribuição. Resumidamente, a lógica de "reversão do tape" consiste em inverter a barra de tensão controlada, originalmente situada do lado da média tensão (carga), para o lado da alta tensão (transmissão) quando a tensão do lado da alta fica abaixo de um limiar $\boldsymbol{V}_{\boldsymbol{L}}$. A barra de tensão controlada retorna ao lado da baixa tensão assim que a tensão do lado da alta ultrapassa um limiar $\boldsymbol{V}_{\boldsymbol{H}}$. Os autores identificam quais controladores automáticos de tape devem ter sua lógica revertida através de uma técnica de otimização cujo objetivo é maximizar a margem de carregamento através de alterações nos ajustes dos LTCs. Essa formulação baseia-se na determinação das sensibilidades dos LTCs em função da margem de carregamento do sistema (DOBSON; LU, 1992; GREENE; DOBSON; ALVARADO, 1997). Ao final os autores concluem que a técnica de "reversão do tape" é vantajosa em relação à técnicas tradicionais (TAYLOR, 1994) como "bloqueio do tape" e "redução do ajuste do LTC".

Em (HISKENS; GONG, 2005) os autores propõem uma estratégia de controle "não-disruptiva" para as cargas. Essa estratégia baseia-se em um controle preditivo que, através de um mo- 
delo simplificado da carga, prevê seu comportamento em um instante de tempo próximo. Com base nessa previsão, o controle indica qual seria a quantidade necessária de carga a ser cortada a fim de manter a tensão na barra dentro de limites aceitáveis para evitar a ocorrência de um colapso de tensão. Os autores ressaltam que essa estratégia requer a implantação de uma estrutura hierárquica descentralizada para o controle das cargas.

Em (OLIVEIRA, 2005) os autores apresentam uma metodologia para melhorar a margem de estabilidade de tensão do sistema, via redespacho da potência ativa nos geradores, quando este é submetido a uma contingência. Com esse objetivo, faz-se uma uma análise comparativa do uso de diferentes "tipos" de fatores de participação dos geradores no fluxo de potência ótimo, a citar:

- Fatores de participação unitários.

- Fatores de participação calculados a partir da Matriz Jacobiana do Fluxo de Potência.

- Fatores de participação calculados a partir da Matriz de Sensibilidades $P \theta$.

- Fatores de participação calculados a partir da Matriz de Estados do Sistema.

Após essa análise os autores concluem que não existe um único "tipo" de fator de participação que, se incluído na formulação do fluxo de potência ótimo, resulta na obtenção do melhor despacho da potência ativa dos geradores para aumentar a margem de estabilidade do sistema. Apenas observou-se que a aplicação dos fatores de participação baseados na Matriz P $\theta$, proposta em (SILVA et al., 2002), sempre resultou em margens de estabilidade maiores quando comparadas ao cenário em que a metodologia não foi aplicada.

\subsection{Análise de Segurança}

Consiste em verificar a capacidade do sistema de potência em superar distúrbios. Um sistema é considerado seguro se ele é capaz de superar cada um dos distúrbios especificados sem entrar em estado de emergência, ou seja, se nenhuma das variáveis associadas ao seu comportamento viola os seus limites máximo e mínimo.

A definição anterior pressupõe que a resposta do sistema seja verificada contra todos os distúrbios possíveis, porém esse critério é considerado bastante severo para ser aplicado em sistemas reais. Assim, na prática, a segurança do sistema é verificada com relação a um conjunto de distúrbios que possuem uma maior probabilidade de ocorrência. Na 
literatura esses distúrbios são denominados contingências e o processo de se analisar a segurança do sistema é conhecido por avaliação de contingências.

\subsubsection{Avaliação de Contingências}

O critério N-1 é bastante utilizado para aferir a segurança de um sistema frente a um conjunto de contingências: "O sistema deve ser capaz de suportar a saída de uma linha de transmissão ou gerador sem entrar em um estado de emergência". Adicionalmente, quando se pretende aferir a segurança sob uma ótica de estabilidade de tensão, pode-se acrescentar que, após a contingência, nenhum dos geradores em serviço opere sob limitação de fornecimento de potência reativa.

Em algumas situações pode-se acrescentar a avaliação de contingências múltiplas ao critério de segurança, desde que essas possam ser relacionadas a uma causa comum que possui uma probabilidade significativa de ocorrência. Um exemplo típico dessa situação seria avaliar a segurança do sistema frente a um cenário em que um atraso na eliminação de um curto-circuito em uma barra dispara a atuação de sua proteção diferencial que, por sua vez, retira de operação as várias linhas de transmissão conectadas a essa barra.

Um outro aspecto importante na avaliação de segurança refere-se à influência dos controles de pós-contingência. Sabe-se que os dispositivos de proteção podem contribuir para estabilizar o sistema na sua configuração pós-contingência e, desse modo, sua influência deve ser incluída na análise de segurança. Uma prática comum é avaliar a capacidade de o sistema superar as contingências com somente a ajuda dos controles pós-contingência que não exercem nenhum impacto direto ou indireto sobre os consumidores. Assim, podem-se classificar os dispositivos de proteção, relevantes ao problema de estabilidade de tensão, em dois grupos:

- Aqueles que não impactam os consumidores, como: chaveamento de reatores e/ou capacitores de derivação, aumento no ajuste dos reguladores de tensão dos geradores e o controle de tensão secundário.

- Aqueles que impactam os consumidores, como: bloqueio e/ou redução no ajuste do LTCs e a desconexão de parte e/ou totalidade da carga.

Dessa forma, pode-se primeiramente proceder à avaliação de contingência incluindo somente a influência dos controles que não impactam os consumidores e, de forma complementar, verificar a adequação dos demais controles em relação a distúrbios mais severos, 
como curtos-circuitos e contingências múltiplas que usualmente não são incluídos nessa avaliação.

Para análise da estabilidade de tensão de "longo-prazo" as contingências relevantes consistem na simulação de saídas de linhas de transmissão e geradores. Já para análise de "curto-prazo" a resposta do sistema a curtos-circuitos também precisa ser investigada. A seguir apresentam-se as principais vertentes para a análise de contingências segundo o foco da estabilidade de tensão.

\subsubsection{Metodologias baseadas no fluxo de potência pós-contingência}

Consistem em utilizar as equações do fluxo de potência com o objetivo de verificar se o sistema analisado na situação de pós-contingência apresenta um ponto de equilíbrio. Caso esse ponto de equilíbrio não exista o fluxo de potência divergirá. Apesar de se tratar de uma metodologia bastante simples e com excelente desempenho computacional, possui as seguintes desvantagens:

- Não há como ter certeza se a divergência apresentada por essa metodologia pode ser atribuída à existência de um problema real de instabilidade de tensão ou a problemas de natureza numérica.

- Mesmo em uma situação real de instabilidade de tensão, a metodologia não fornece informações relacionadas à natureza do problema e sua localização.

- A inclusão dos efeitos produzidos pela atuação de dispositivos discretos não é simples, uma vez que sua atuação é extremamente dependente da evolução temporal do sistema.

- Essa metodologia é incapaz de detectar instabilidades cuja natureza está relacionada com a falta de atração do ponto de operação pós-contingência em relação ao ponto de equilíbrio existente (instabilidade tipo LT-2) (CUTSEM; VOURNAS, 1996).

Em (GAO; MORISON; KUNDUR, 1992) os autores propõem uma metodologia para avaliação da estabilidade de tensão aplicada a sistemas de grande porte baseada nos programas VSTAB (EPRI's Voltage Stability Program) e ETMSP (EPRI's Extended Transient/Midterm stability Program). Além disso, uma comparação entre resultados obtidos utilizando a técnica estática baseada nos fluxos de potência pós-contingência (VSTAB) e a técnica dinâmica (ETMSP) é apresentada. 
Também baseado nesse princípio (VAAHEDI et al., 1999) propõe um índice denominado Reactive Support Index (RSI) para a avaliação on-line de contingências. Nesse mesmo trabalho os autores propõem uma metodologia denominada Iterative Filtering (IF) para selecionar de forma mais precisa as $N$ contingências mais severas dentre uma lista de contingências a serem analisadas. O funcionamento desta metodologia é ilustrado na figura 3.2. Basicamente, o Iterative Filtering consiste em aplicar níveis de stress decrescentes (deslocando o ponto $\mathrm{C}$ para a esquerda na figura 3.2), a partir do limite de carregamento pré-contingência (ponto A na figura 3.2) e resolver os fluxos de potência para todas as situações de pós-contingências pendentes para análise. A cada passo, descartamse somente as contingências para as quais o fluxo de potência convergiu (vide curvas pontilhadas na figura 3.2). O processo para quando restarem apenas as $N$ contingências mais severas.

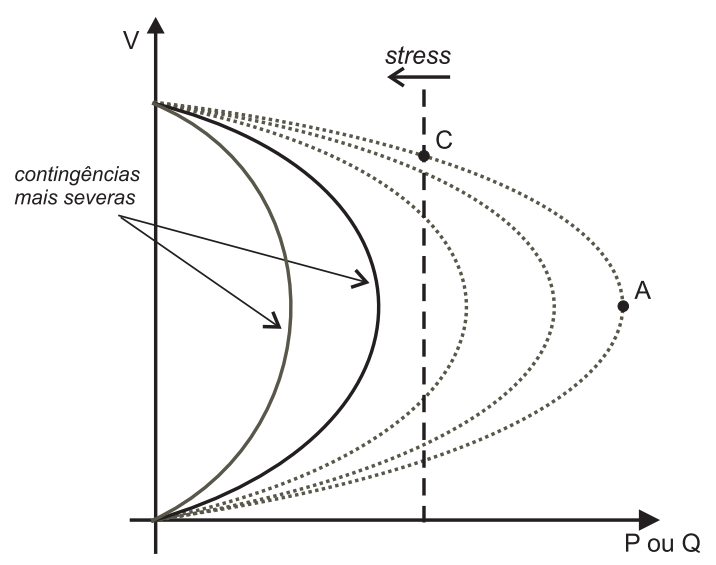

Figura 3.2: Princípio do Iterative Filtering.

Em (CUTSEM; MOISSE; MAILHOT, 1999) os autores propõem uma metodologia para análise de contingências mais rigorosa que o trabalho supracitado pois permite a inclusão da influência dos controles e operadores nas situações de pré e pós-contingência. Esse trabalho é discutido mais detalhadamente na Sec. 3.6.

\subsubsection{Metodologias baseadas no Fluxo de Potência para casos não-resolvíveis}

Vários autores (IWAMOTO; TAMURA, 1981; OVERBYE, 1994, 1995) propuseram alterações no método de Newton-Raphson com o intuito de lidar com situações de difícil convergência ou ausência de solução. Em particular a solução proposta em (IWAMOTO; TAMURA, 1981) permite identificar quando a solução efetivamente não existe devido a uma instabilidade de tensão e, além disso, fornece uma indicação de como restaurar o sistema. Os traba- 
lhos (OVERBYE, 1994) e (OVERBYE, 1995) baseiam-se em (IWAMOTO; TAMURA, 1981) e propõem uma metodologia para determinar a mínima desconexão de carga a fim de restaurar a estabilidade de tensão.

\subsubsection{Metodologia baseada em Curvas VQ}

Utilizadas em (MANSOUR et al., 1994) e (CHOWDHURY; TAYLOR, 2000) consiste em alocar um gerador fictício com potência ativa nula (condensador síncrono) em uma barra do sistema de forma a garantir a convergência do fluxo de potência. A seguir, simula-se o fluxo de potência para uma série de valores impostos à tensão do condensador síncrono e determina-se a curva VQ a partir dos valores obtidos para potência reativa injetada. Supondo que a barra analisada não possua compensação reativa, o ponto de operação atual encontra-se na ordenada com potência reativa nula (correspondente à remoção do gerador fictício), vide figura 3.3, e a margem de potência reativa $\Delta Q$ na barra é estimada a partir da distância do ponto de operação ao mínimo da curva VQ, vide figura 3.3.

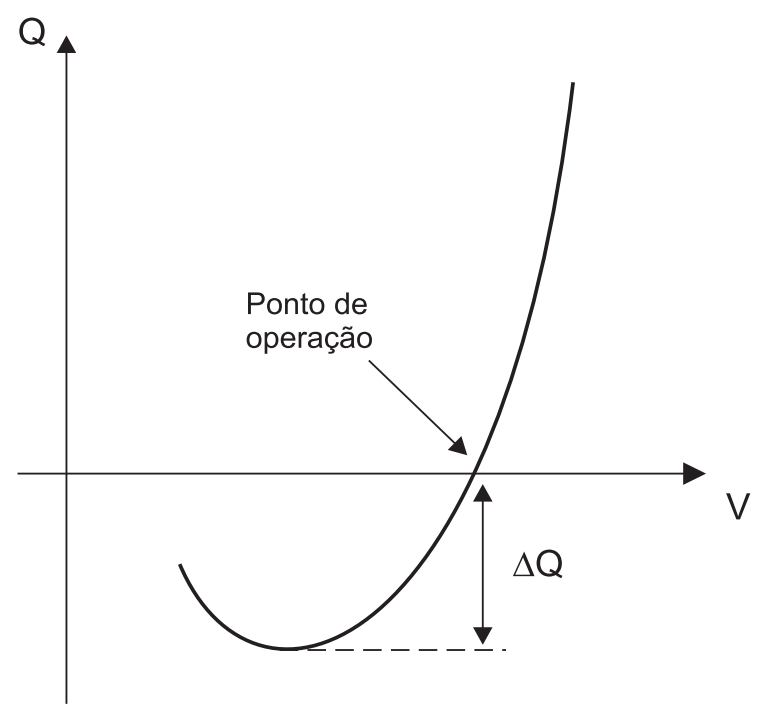

Figura 3.3: Curva VQ

Além de viabilizar a solução do fluxo de potência em situações de difícil convergência essa metodologia permite obter uma margem de potência reativa para garantir a estabilidade de tensão. Apesar dessas vantagens, essa metodologia:

- Requer um conhecimento prévio do sistema uma vez que o gerador fictício precisa ser alocado nas barras "mais susceptíveis" a um eventual colapso de tensão.

- Fornece uma margem de potência reativa que não corresponde a um padrão de 
carregamento real, uma vez que essa é obtida concentrando a injeção de potência reativa em uma única barra do sistema.

\subsubsection{Metodologias baseadas na simulação temporal}

Baseiam-se na modelagem detalhada do sistema de potência através de um sistema de equações algébrico-diferenciais contínuas e discretas. A evolução temporal do sistema pode ser obtida através da integração numérica do sistema "acoplado" (KUNDUR, 1994) ou através do princípio da simulação quase estática (QSS), em que as equações diferenciais correspondentes à dinâmica rápida são substituídas por equações algébricas (CUTSEM; VOURNAS, 1996; KURITA et al., 1993). Essas metodologias apresentam as seguintes vantagens:

- Permitem avaliar outros "mecanismos de instabilidade" (CUTSEM; VOURNAS, 1996) além da perda de equilíbrio contemplada nas metodologias anteriormente citadas.

- Os resultados obtidos são considerados mais confiáveis (CHOWDHURY; TAYLOR, 2000; MORISON; GAO; KUNDUR, 1993) uma vez que a modelagem dos equipamentos e controle é mais precisa.

- Produzem resultados detalhados que permitem: analisar a seqüência de eventos que levou o sistema à instabilidade e/ou ao colapso e obter informações que viabilizem a adoção de ações corretivas.

Apesar dos avanços alcançados nos métodos de integração numérica, através de algoritmos para o controle automático do passo de integração (DEUSE; STUBBE, 1993), alguns autores argumentam que o desempenho alcançado ainda é insuficiente para aplicações em tempo real (CUTSEM, 2000).

A modelagem através da simulação quase-estática (QSS) aumenta consideravelmente o desempenho desses métodos viabilizando sua aplicação em tempo real (CUTSEM; MAILHOT, 1997) porém não permite analisar todos os "mecanismos de instabilidade" possíveis em cenários de instabilidade de tensão (CUTSEM; VOURNAS, 1998). 


\subsection{Metodologias para Determinação da Margem de Segurança}

Consiste em verificar o quão distante o sistema elétrico de potência pode se afastar do ponto de operação atual, e ainda permanecer no estado seguro. Esse desvio do ponto de operação é originado por alterações significativas e lentas nos parâmetros de stress do sistema (aqueles que os operadores podem observar e/ou controlar), como por exemplo, a demanda da carga e o despacho dos geradores. O parâmetro de stress também é caracterizado por uma direção no espaço de parâmetros, como por exemplo, a participação das barras no aumento da carga ou no novo despacho dos geradores. Definir as margens de segurança é particularmente necessário em um ambiente irrestrito de comercialização de energia que está prevalecendo em um número crescente de países. Nesse, o operador precisa saber qual seria o aumento aceitável de carga ou de transferência de potência a fim de manter o sistema seguro. As principais margens de segurança utilizadas na literatura são as seguintes:

- Limite de carregamento pré-contingência: consiste em submeter o sistema a níveis crescentes de stress até torná-lo inseguro (ou instável). Tem por objetivo verificar a capacidade do sistema em suportar, por exemplo, um aumento de carga previsto ou um novo cenário de despacho nos geradores.

- Limite de carregamento pós-contingência: consiste em aplicar uma contingência ao sistema e, em seguida, submetê-lo a níveis crescentes de stress até torná-lo inseguro (ou instável). Tem por objetivo avaliar a margem de carregamento que deve permanecer após uma contingência: trata-se de uma medida de robustez do sistema.

Os limites anteriores podem ser visualizados no espaço de parâmetros $\mathbf{p}$ na figura 3.4 onde $\boldsymbol{\Sigma}$ é a superfície de bifurcação ${ }^{1}$. Partindo de um ponto de operação $\mathbf{O}$ e incrementando o parâmetro de stress $\boldsymbol{\mu}$ ao longo da direção $\mathbf{d}$, o limite de carregamento ou de operação é atingido no ponto $\mathbf{L}$.

Quando as cargas se comportam como potência constante, um espaço de parâmetros conveniente é o espaço de potências. Quando as cargas possuem uma dependência com a tensão, a superfície de bifurcação não coincide com a superfície de máxima transferência de potência, ou seja, o Jacobiano do sistema não se anula quando esse é submetido à potência

\footnotetext{
${ }^{1} \mathrm{O}$ conceito de bifurcação está associado a mudanças na estrutura qualitativa (número de pontos de equilíbrio, estabilidade) de um sistema de equações algébrico-diferenciais devido a pequenas variações de seus parâmetros.
} 


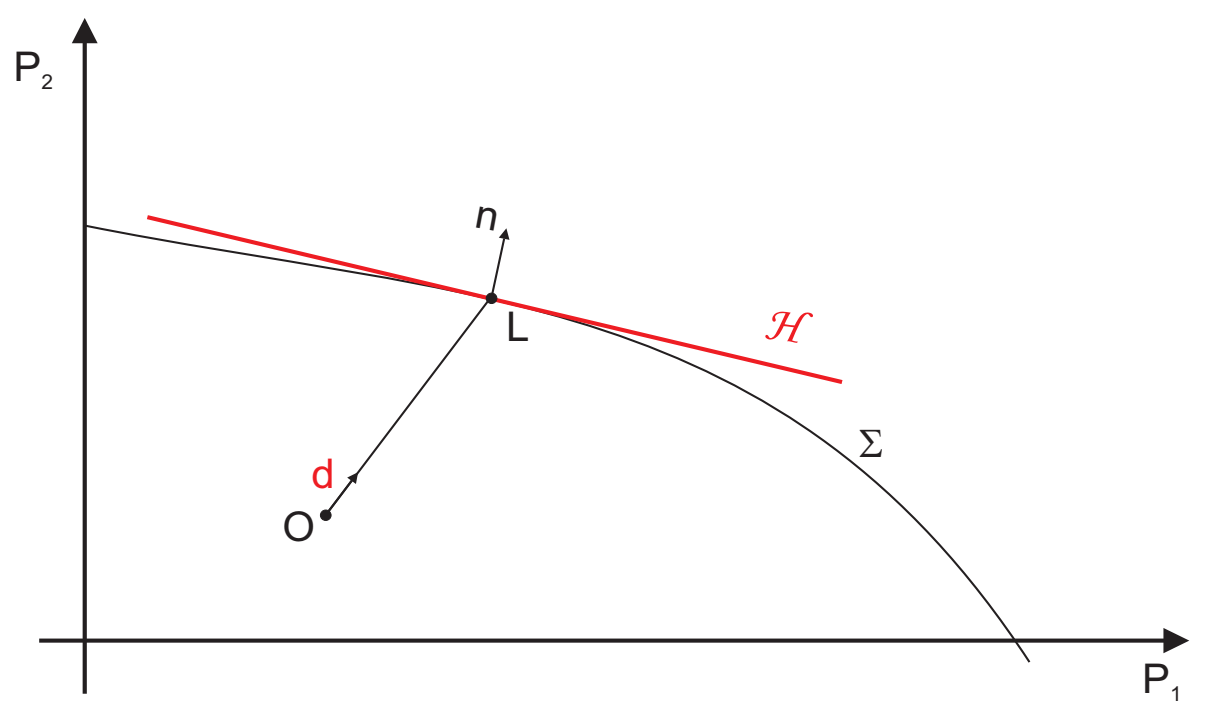

Figura 3.4: Conceito de Limite de Carregamento.

máxima "transportável" pela rede (CUTSEM; VOURNAS, 1998; CANIZARES, 2002). Nessa situação as curvas VP, VQ ou VS não são consideradas diagramas de bifurcação (o "nariz da curva" não corresponde a uma bifurcação do sistema dinâmico). A seguir apresentamse as principais metodologias focadas na determinação da margem de segurança.

\subsubsection{Métodos de Continuação}

Também conhecidos como Fluxos de Potência Continuados, consistem em calcular automaticamente o trajeto das soluções do sistema de potência a partir de um caso base até o seu limite de carregamento. Esse trajeto é obtido a partir de um método preditor-corretor incrementando um parâmetro de continuação, usualmente a potência ativa ou reativa, a partir de seu valor no caso base. Próximo ao ponto crítico (ou limite de carregamento) o método apresenta dificuldades de convergência contornadas através de uma lógica que detecta esse problema e muda o parâmetro de continuação (AJJARAPU; CHRISTY, 1992). Alguns trabalhos propõem melhorias para o desempenho do método como em (CHIANG et al., 1995; CANIZARES; ALVARADO, 1993). Apesar de permitir a inclusão de controles, como reguladores de tensão e limites de corrente de campo nos geradores, a modelagem desses dispositivos não é precisa uma vez sua atuação não se baseia na evolução temporal do sistema. 


\subsubsection{Métodos de Otimização}

São conhecidos também como métodos diretos uma vez que o limite de carregamento é calculado diretamente sem a necessidade de se determinar soluções intermediárias a partir do caso base. Vários trabalhos que utilizam métodos de otimização baseiam-se em uma formulação do problema de máximo carregamento similar à descrita na equação (3.1):

$$
\left\{\begin{array}{l}
\max \mu \\
\text { sujeito a } \varphi(\mathbf{u}, \mathbf{p})=0
\end{array}\right.
$$

E a relação entre $\mathbf{p}$ e $\mu$ é dada por:

$$
\mathbf{p}=\mathrm{p}^{0}+\mu \cdot \mathbf{d}=0
$$

onde: $\mu$ é o parâmetro de stress escolhido

$\varphi(\mathbf{u}, \mathbf{p})$ é o jacobiano do sistema

$\mathbf{p}$ é o vetor de stress

u é o vetor de variáveis do problema;

d é a direção de stress.

A referência (CUTSEM; VOURNAS, 1998) analisa a formulação anterior, que despreza os limites dos geradores, e demonstra que o resultado desse problema de otimização é dado pelo Lagrangiano.

$$
\iota=\zeta(\mathbf{p})+\mathbf{w}^{T} \cdot \varphi(\mathbf{u}, \mathbf{p})
$$

onde: $\iota$ é o lagrangiano;

$\zeta(\mathbf{p})$ é uma função escalar do vetor de stress $\mathbf{p}$.

Em que os multiplicadores de Lagrange (w), obtidos na solução do problema descrito, correspondem aos componentes do autovetor esquerdo associado ao autovalor nulo (no limite de carregamento). Assim, o vetor $\mathbf{w}$ pode ser utilizado para determinar estratégias para os controles preventivos e corretivos (CUTSEM, 1991).

Em (OBADINA; BERG, 1988; CUTSEM, 1991) acrescenta-se a ação dos limites dos impostos pelos reguladores de tensão e limitadores de corrente de campo nos geradores (limites de potência reativa). Em (CUTSEM; VOURNAS, 1998) os autores analisam uma formulação 
genérica para essa situação, apresentada a seguir:

$$
\left\{\begin{array}{l}
\max \mu \\
\text { sujeito a } \varphi(\mathbf{u}, \mathbf{p})=0 \\
\psi(\mathbf{u}, \mathbf{p}) \geq 0
\end{array}\right.
$$

E a relação entre $\mathbf{p}$ e $\mu$ é dada por:

$$
\mathbf{p}=\mathrm{p}^{0}+\mu \cdot \mathbf{d}=0
$$

onde: $\mu \quad$ é o parâmetro de stress escolhido

$\varphi(\mathbf{u}, \mathbf{p})$ é o jacobiano do sistema

$\psi(\mathbf{u}, \mathbf{p})$ representa as restrições dos reguladores de tensão ou limitadores de corrente de campo

p é o vetor de stress

d é a direção de stress.

E o resultado desse problema de otimização é dado pelo Lagrangiano:

$$
\iota=\zeta(\mathbf{p})+\mathbf{w}_{\varphi}^{T} \cdot \varphi(\mathbf{u}, \mathbf{p})+\mathbf{w}_{\psi}^{T} \cdot \psi(\mathbf{u}, \mathbf{p})
$$

Em que os multiplicadores de Lagrange $\mathbf{w}_{\varphi}$ e $\mathbf{w}_{\psi}$ obtidos correspondem, respectivamente, às restrições de igualdade e desigualdade. Analisando essa formulação (CUTSEM; VOURNAS, 1998) concluem que a resposta obtida pode corresponder a uma situação em que o limite de carregamento não corresponde a uma bifurcação Saddle-node e sim a um breaking-point (ponto em que a resposta do gerador deixa de ser controlada pelo regulador de tensão e passa a ser regida pelo limitador de corrente de campo). A figura 3.5 a seguir ilustra essas duas situações para um gerador.

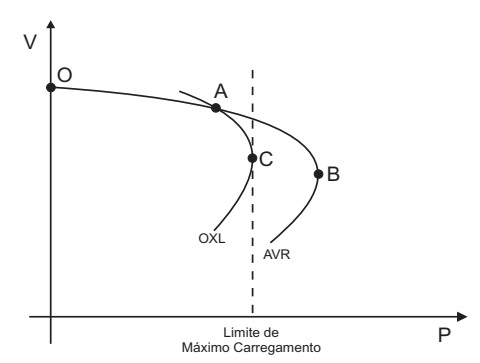

(a)

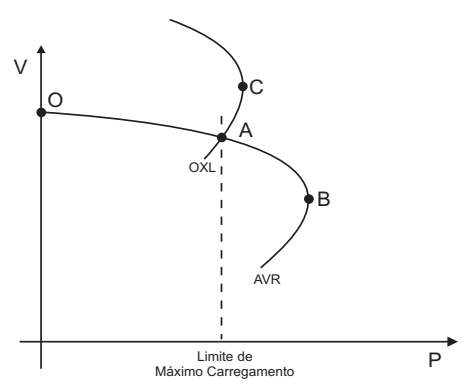

(b)

Figura 3.5: Cenários possíveis para um gerador e seus controles. 
Tendo em vista a formulação (3.4), observa-se na figura 3.5(a) que o método converge primeiramente para o ponto A (devido à restrição imposta pelo regulador de tensão) e, a partir desse ponto, a restrição do limitador de corrente de campo faz com que a solução convirja corretamente para o ponto C. Já na figura 3.5(b) o método converge inicialmente para o ponto A (idem ao ocorrido no cenário anterior), porém a restrição correspondente ao limitador de corrente de campo faz com que a solução se desloque para o ponto C de forma incorreta, pois o limite de carregamento corresponde ao breaking-point A. Para evitar isso, (CUTSEM, 1991) propõe verificar se o valor da tensão começa a aumentar com o incremento do parâmetro de stress $\mu$, caso isso ocorra conclui-se que o limite de carregamento já foi atingido e corresponde ao ponto A.

Os autores em (CUTSEM; VOURNAS, 1998) ressaltam que um ponto chave para a formulação anterior é a identificação correta de quais geradores estão sob controle dos reguladores de tensão e quais estão sob limitação da corrente de campo. Em (CUTSEM, 1991) esse problema é resolvido aplicando-se primeiramente a formulação que despreza os controles nos geradores e, baseado nas potências reativas fornecidas pelos mesmos decide-se quais dos geradores têm sua corrente de campo limitada e quais permanecem somente sob influência do regulador de tensão.

Em (IRISARRI et al., 1997; PARKER; MORRISON; SUTANTO, 1996) os autores utilizam uma formulação baseada no método dos pontos interiores para resolver esse problema de otimização. Esse método permite lidar de maneira "mais natural" com os controles dos geradores, porém exige a solução de um sistema linear com dimensão muito maior à formulação anterior, assim faz-se necessário o uso de técnicas de esparsidade a fim de manter o desempenho computacional superior aos métodos de continuação.

Em (GRANVILLE; MELLO; MELO, 1996) os autores utilizam o método dos pontos interiores para formular o problema de máximo carregamento de forma "reversa", ou seja, o objetivo é minimizar a quantidade de ações de controle, no caso somente considerou-se a desconexão de carga, a fim de restaurar a estabilidade do sistema.

Além do bom desempenho computacional, os métodos de otimização permitem a inclusão de aspectos "mais tradicionais" na sua função objetivo assim, por exemplo, poder-seia obter a máxima transferência de potência como parte de um problema de despacho econômico incluindo os custos associados aos geradores existentes na rede ou minimizando o total de compensação reativa. 


\subsubsection{Métodos baseados nas múltiplas soluções do fluxo de potência}

Ao contrário das metodologias discutidas até agora, os métodos apresentados em (TAMURA; SAKAMOTO; TAYAMA, 1988; DEMARCO; OVERBYE, 1990; IBA et al., 1990; YORINO; HARADA; CHENG, 1997; OVERBYE; KLUMP, 1996) não se baseiam na distância ao limite de carregamento, mas sim na distância que separa o ponto de equilíbrio atual (estável) ao ponto de equilíbrio instável mais próximo. Na figura 3.6 a seguir percebe-se que quanto mais próximo o ponto de operação do sistema chega do limite de carregamento, mais os pontos E (estável) e I (instável) se aproximam. Assim, a medida da distância entre esses pontos fornece uma métrica relacionada à proximidade da instabilidade.

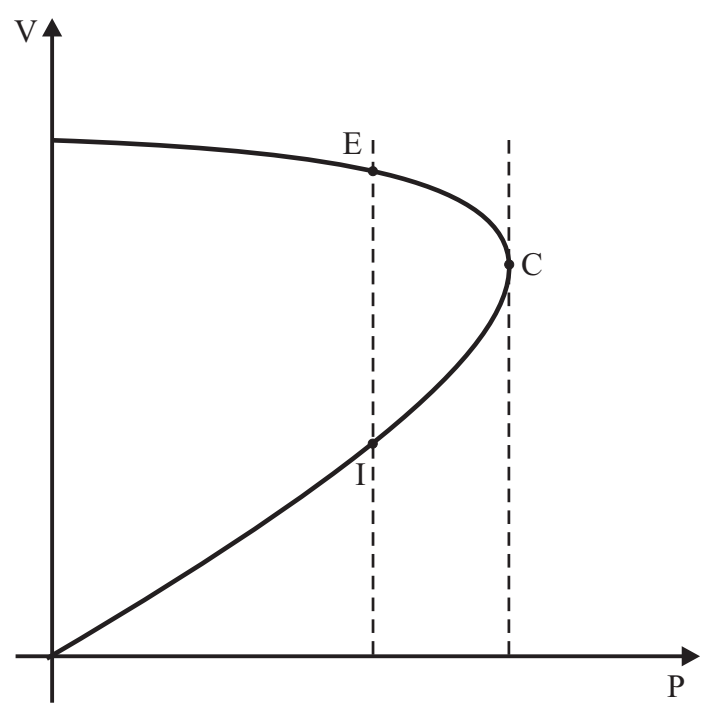

Figura 3.6: Distância entre os pontos de equilíbrio Estável e Instável.

A grande dificuldade em se aplicar esses métodos é a determinação do ponto de equilíbrio instável mais próximo, particularmente em sistemas grandes. Além disso, deve-se considerar que existe a possibilidade do ponto de equilíbrio instável mais próximo ao ponto de operação ser diferente daquele que coalesce com esse na bifurcação Saddle-node (OVERBYE; KLUMP, 1996).

\subsubsection{Métodos baseados na análise de bifurcações}

São métodos capazes de determinar, a partir de valores iniciais de parâmetros para os quais o sistema apresenta um equilíbrio estável, os valores desses mesmos parâmetros para os quais o equilíbrio muda de característica, deixando de ser estável. Nessas metodologias, os parâmetros não precisam ser necessariamente as cargas do sistema (LERM; MORAES, 2003), podem também ser usados o despacho seguro dos geradores (LERM, 2001) ou mesmo 
o intervalo de ajuste seguro para controles como os reguladores de tensão (LERM; CANIZARES; SILVA, 2003) e os estabilizadores de sistemas de potência (LERM; SILVA, 2004) presentes nos geradores.

De forma geral, uma bifurcação ocorre quando a estrutura qualitativa do sistema (número de pontos de equilíbrio, estabilidade, etc) muda devido a pequenas variações de seus parâmetros (AJJARAPU; LEE, 1992). Em sistemas de potência descritos por sistemas de equações algébrico-diferenciais há três tipos principais de bifurcações (PAI; SAUER; LESIEUTRE, 1995), a citar: Saddle-node, Hopf e Singularity-induced. Fenômenos de instabilidade de tensão em que o ponto de equilíbrio do sistema desaparece após o distúrbio estão diretamente relacionados a bifurcações Saddle-node (CUTSEM, 2000). Provou-se também que em uma bifurcação Saddle-node a matriz Jacobiana é singular (SAUER; PAI, 1990). Em vários trabalhos essa condição é monitorada através do: cálculo do determinante, menor valor singular ou autovalor mais próximo à origem (CANIZARES et al., 1992).

Outros trabalhos, baseados na propriedade anterior, demonstram que, para o modelo adotado no fluxo de potência, o jacobiano reduzido $\boldsymbol{J}_{\boldsymbol{R} Q \boldsymbol{V}}$ (correspondente as injeções de potências reativas com relação às tensões nas barras) também se torna singular em uma bifurcação Saddle-node. Essa propriedade é a base de uma metodologia denominada Análise Modal (GAO; MORISON; KUNDUR, 1992; MORISON; GAO; KUNDUR, 1993) que fornece uma interpretação algébrica para os autovetores relativos ao autovalor mais próximo de zero e aos outros autovalores dominantes.

Outros trabalhos como (GAO; MORISON; KUNDUR, 1992; TAMURA; MORY; IWAMOTO, 1983; BERIZZI et al., 1996) propõem o uso de sensibilidades para detectar bifurcações Saddle-node, uma vez que elas tendem a infinito à medida que o ponto de equilíbrio do sistema se aproxima desse tipo de bifurcação.

\subsubsection{Simulação temporal acoplada com análise de sensibilidade}

Em (CUTSEM et al., 1995) os autores propõem uma metodologia que utiliza a simulação temporal juntamente com a análise de sensibilidade para calcular o limite de carregamento do sistema. Sucintamente, trata-se de se obter as respostas temporais do sistema, de forma automatizada, a aumentos progressivos do parâmetro de stress. As respostas temporais obtidas devem são submetidas a um diagnóstico de instabilidade. A figura 3.7 ilustra esse fato supondo uma situação em que as cargas do sistema se encontram em um processo de restauração a potência constante. 


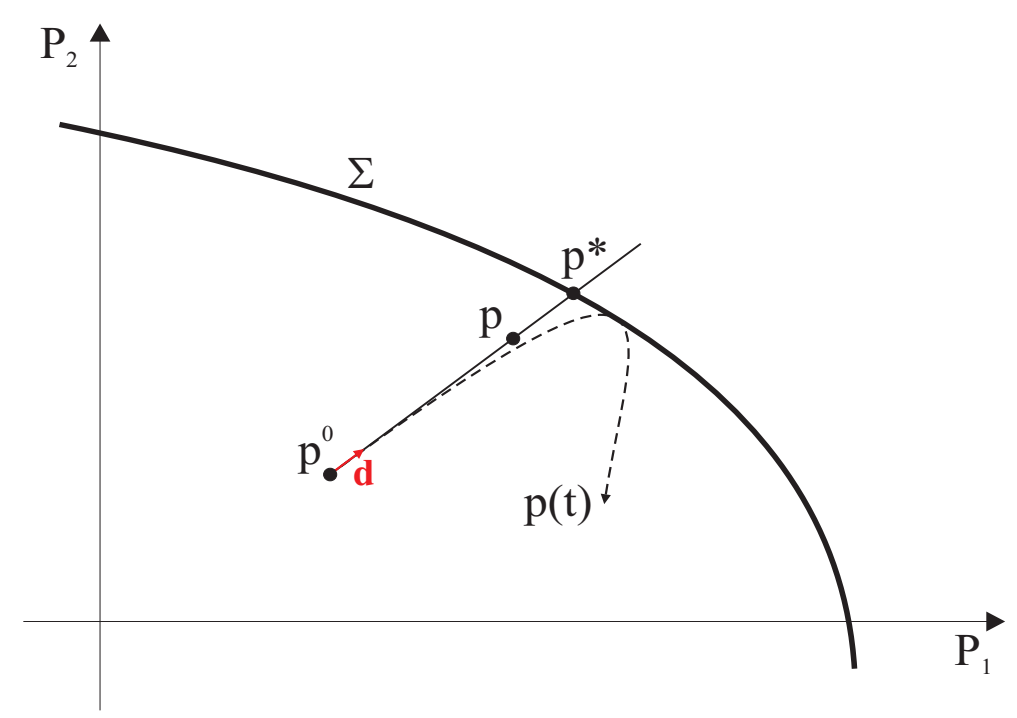

Figura 3.7: Restauração de cargas com potência constante.

Na figura acima o ponto $\mathbf{p}$ se move ao longo da direção $\mathbf{d}$, a partir de $\mathbf{p}^{\mathbf{0}}$. A linha tracejada $\mathbf{p}(\mathbf{t})$ representa a evolução das potências nas cargas ao longo do tempo. Percebese que enquanto $\mathbf{p}$ move-se lentamente entre os pontos $\mathbf{p}^{\mathbf{0}}$ e $\mathbf{p}^{*}$, a reta (definida pelo vetor $\mathbf{d}$ ) e os pontos definidos por $\mathbf{p}(\mathbf{t})$ estão muito próximos. Por outro lado, quando o parâmetro de stress $\mathbf{p}$ ultrapassa o ponto $\mathbf{p}^{*}$, deixando para trás a região limitada pela superfície de bifurcação $\Sigma, \mathbf{p}(\mathbf{t})$ se separa de $\mathbf{p}$ e retorna ao interior de $\Sigma$. Assim, durante a simulação temporal faz-se necessário estabelecer um critério capaz de identificar o ponto crítico, em que $\mathbf{p}(\mathbf{t})$ intercepta a superfície $\Sigma$. Para isso, os autores sugerem o uso das sensibilidades da geração total da potência reativa em relação às várias demandas das cargas, propostas em (CARPENTIER; GIRARD; SCANO, 1984), uma vez que essas mudam de sinal ao interceptar a superfície de bifurcação (CUTSEM; VOURNAS, 1998). O esforço computacional despendido no cálculo das sensibilidades é moderado desde que esse procedimento seja feito em intervalos pré-determinados, e não a cada ponto da evolução temporal do sistema. Como vantagens, essa metodologia reúne os benefícios próprios dos métodos baseados na simulação temporal (vide Sec. 3.4.5) com o recurso de diagnosticar a instabilidade ao longo do tempo. Além disso, os autores propõem uma metodologia para analisar essa instabilidade, baseada na análise do autovetor esquerdo correspondente ao ponto imediatamente após o instante em que a instabilidade é detectada, e sugerir ações corretivas (no caso contemplou-se a menor desconexão de carga) para evitá-la. 


\subsection{Determinação dos Limites de Segurança}

Essa metodologia combina as avaliações de stress, vistas na Sec. 3.5, com a análise de contingências para determinar os limites seguros para operação do sistema. Conceitualmente, um limite seguro de operação corresponde ao máximo stress que o sistema é capaz de suportar considerando as contingências. Assim, para obtê-lo deve-se expor o sistema a níveis crescentes de stress, segundo uma determinada direção no espaço de parâmetros, na situação de pré-contingência, e em seguida, submetê-lo a uma contingência. O sistema é considerado seguro caso seja capaz de suportá-la.

A referência (CUTSEM; MOISSE; MAILHOT, 1999) utiliza o conceito anterior para propor uma metodologia, denominada binary search, com o intuito de identificar o limite de operação seguro levando em conta: as ações dos operadores/controles nas situações de pré-contingência e as ações dos controles corretivos nas situações de pós-contingência. O exemplo a seguir ilustra a influência dessas ações sobre o limite de operação seguro do sistema.

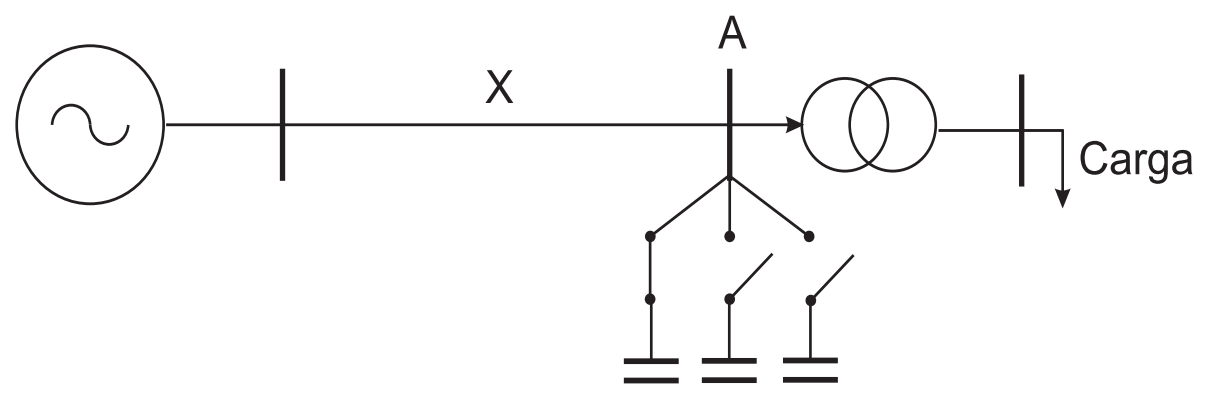

Figura 3.8: Sistema exemplo para ilustrar o conceito de limite de operação seguro.

Considere o sistema da figura 3.8 em que uma carga é restaurada por um LTC e a barra A possui capacitores de derivação que podem ser usados da seguinte forma:

- Em condições normais, o operador do sistema ajusta a compensação da barra A, a fim de manter sua tensão dentro de certos limites.

- Após um incidente qualquer o controle corretivo acrescenta capacitores em derivação a fim de complementar a reserva de reativos do sistema.

A figura 3.9 ilustra o efeito dessas duas ações sobre o limite de operação seguro do sistema.

Considerando que o sistema opera inicialmente no ponto $\mathbf{B}$ (pré-contingência). Imediatamente após uma contingência a curva PV, vista a partir da barra A, se transforma na 


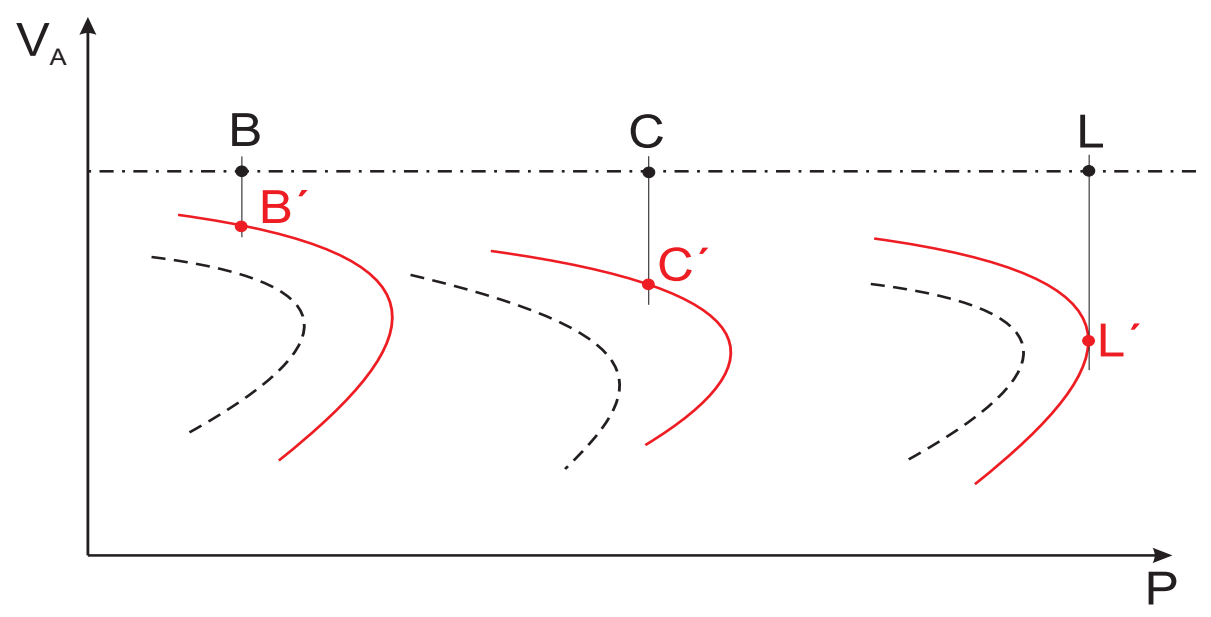

Figura 3.9: Efeito das ações de pré e pós contingência.

curva pontilhada. Após o chaveamento dos capacitores de derivação, a curva pontilhada se transforma na curva sólida (pós-contingência) e o sistema passa a operar no ponto B'. Obviamente que o sistema pode falhar em alcançar o ponto de operação B', caso o tempo de chaveamento dos capacitores exceda o tempo crítico (por simplicidade essa situação não é considerada nessa análise).

Como o sistema foi capaz de suportar a contingência acima, desloca-se o seu ponto de operação (pré-contingência) na direção do limite de segurança incrementando a carga até, por exemplo, o ponto C. Novamente verifica-se que o sistema também se estabiliza após a contingência agora no ponto C'. Observando a figura 3.9, conclui-se que, devido às ações tomadas durante as situações de pré e de pós-contingência, não existe uma única curva PV de pós-contingência correspondente a um determinado ponto de operação, mas sim uma família delas. Na situação ilustrada na figura 3.9, o limite de segurança corresponde ao ponto $\mathbf{L}$.

Do exposto acima, pode-se relacionar o limite de carregamento pós-contingência, utilizado em vários trabalhos (GAO; MORISON; KUNDUR, 1996; VAAHEDI et al., 1999) como métrica para avaliação estática de contingências, e o limite de operação seguro definido em (CUTSEM; MOISSE; MAILHOT, 1999). Supondo que nas situações de pré-contingência não existem ações de operadores ou controles preventivos e nas situações de pós-contingência não existem ações de controles corretivos ambos os limites são coincidentes, conforme ilustra a figura 3.10.

Da observação acima, conclui-se que para calcular o limite de operação seguro, faz-se necessário utilizar uma simulação temporal do sistema, em que a ação dos operadores e controles pode ser modelada adequadamente. 


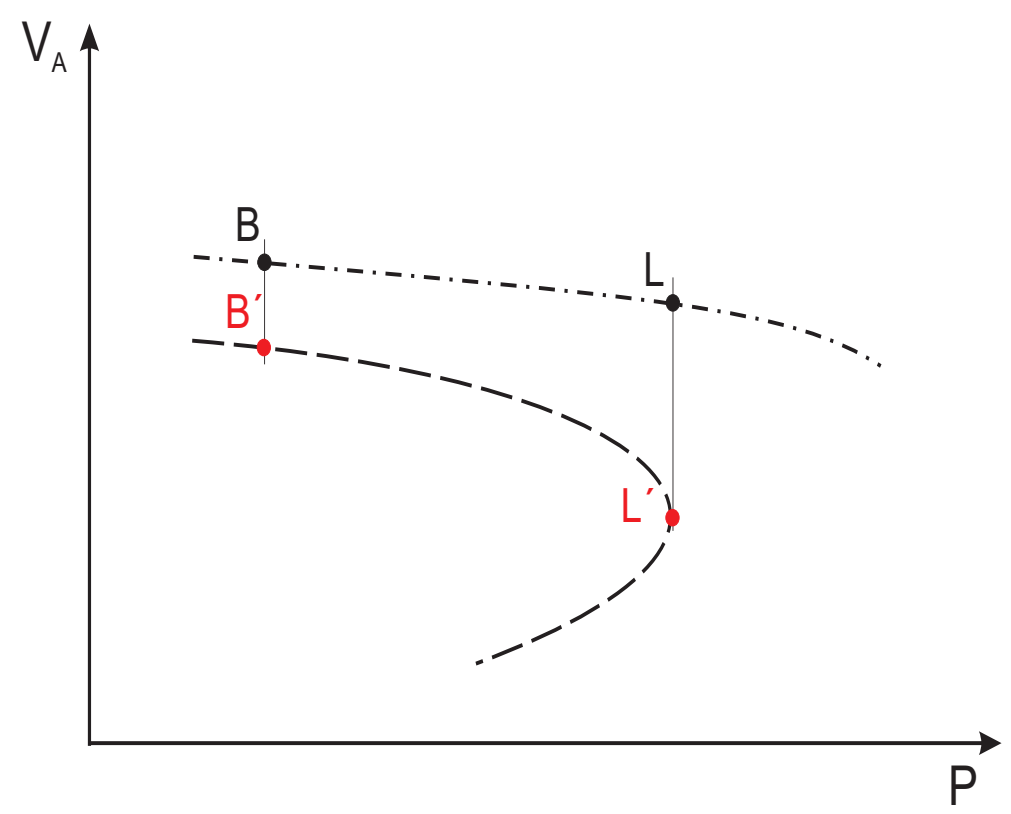

Figura 3.10: Relação entre o limite de carregamento (pós-contingência) e o limite de operação seguro.

Em (CUTSEM; MOISSE; MAILHOT, 1999) os autores propõem uma simulação quase-estática (QSS) aliada ao método binary search, para determinar o limite de operação seguro mais severo. O binary search consiste em construir progressivamente um intervalo de stress $\left[\mathbf{S}_{\mathbf{E}} \mathbf{S}_{\mathbf{I}}\right]$, até que a diferença $\left[\mathbf{S}_{\mathbf{E}} \mathbf{S}_{\mathbf{I}}\right]$ seja inferior a uma tolerância pré-estabelecida $\left(\mathbf{S}_{\mathbf{E}}\right.$ e $\mathbf{S}_{\mathbf{I}}$ correspondem, respectivamente, aos valores de stress em que o sistema opera de forma estável e instável).

A figura 3.11 ilustra o funcionamento do binary search. Iniciando $\mathbf{S}_{\mathbf{E}}=\mathbf{0}$ e $\mathbf{S}_{\mathbf{I}}=\mathbf{S}_{\mathbf{m a x}}$ o intervalo é dividido em duas partes iguais a cada passo: se o ponto central é estável (ponto branco) ele passa a ser o novo limite inferior do intervalo $\left(\mathbf{S}_{\mathbf{E}}\right)$, em caso contrário (ponto preto) ele passa a ser o novo limite superior do intervalo $\left(\mathbf{S}_{\mathbf{I}}\right)$. $\mathbf{S}_{\max }$ é o nível de stress máximo estipulado.

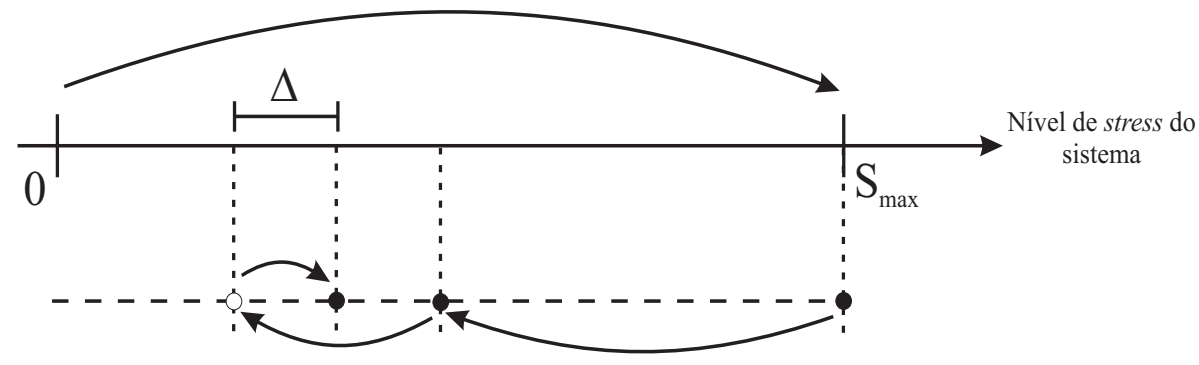

Figura 3.11: Funcionamento do Binary Search.

Se aplicado a várias contingências, esse método exige uma demanda computacional alta, 
pois deve ser executado individualmente para cada uma delas a fim de determinar seus limites seguros e, somente após isso, atribui-se o menor valor de stress encontrado ao limite global de operação seguro. Para contornar esse problema os autores propõem uma alteração nessa metodologia, denominada simultaneous binary search, que consiste em simular "simultaneamente" as várias contingências para cada passo. Após isso, descartamse somente as contingências para as quais o sistema pode ser considerado estável (uma vez que seu limite de operação seguro é superior ao nível de stress imposto no passo atual). As restantes (que levam o sistema à instabilidade) passam a compor um novo conjunto de contingências, cada vez menor, que deve ser analisado no próximo passo. A figura 3.12, a seguir ilustra esse processo.

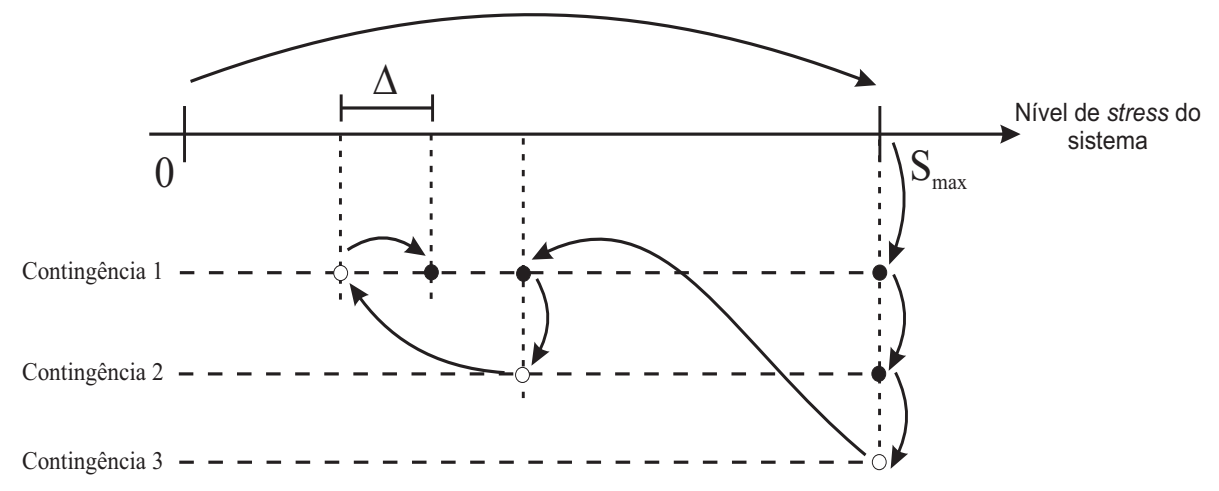

Figura 3.12: Funcionamento do Simultaneous Binary Search.

Percebe-se que a economia de recurso computacional depende de como os limites seguros individuais estão distribuídos dentro do intervalo $\left[\mathbf{0}_{\mathbf{m a x}}\right]$. Além disso, o nível de stress para o qual cada contingência é descartada fornece uma estimativa conservativa para os limites de segurança individuais.

Com a finalidade de contemplar também a filtragem de contingências em tempo real, os autores propõem uma alteração desse método que consiste em utilizar o simultaneous binary search juntamente com um índice de severidade para ordenar as contingências. O índice proposto corresponde à "carga não restaurada" no primeiro ponto de equilíbrio alcançado pelo sistema imediatamente após o distúrbio (ponto JAD - Just After Disturbance). Na abordagem de simulação temporal quase estática (QSS) esse ponto corresponde ao primeiro ponto calculado imediatamente após o distúrbio. As principais vantagens dessa metodologia em relação a outras utilizadas para avaliação e filtragem de contingências são:

- A métrica utilizada para avaliar as contingências, limite de operação seguro, é expressa em termos de grandezas na situação de pré-contingência e, portanto, os opera- 
dores do sistema podem observá-la ou controlá-la em tempo hábil de tomar decisões.

- O uso de um método de simulação temporal, no caso a abordagem quase estática (QSS), permite uma modelagem mais precisa dos controles.

- A possibilidade de se incluir as estratégias utilizadas para o controle e a operação do sistema nos períodos de pré e pós-contingência. 


\section{Modelagem dinâmica do sistema elétrico voltada para o problema da estabilidade de tensão.}

\subsection{Objetivos}

Esse capítulo tem por objetivo apresentar a modelagem dinâmica do sistema elétrico utilizada para abordar o problema da estabilidade de tensão. O modelo utilizado baseia-se no "Modelo Genérico para Representação de Sistemas Elétricos" (CUTSEM; VOURNAS, 1996, 1998) e contempla modelos dinâmicos de geradores, transformadores com controle automático de tape, reguladores de tensão, limitadores de sobreexcitação, motores de indução de $3^{a}$ ordem (ONG, 1997), além dos modelos dinâmicos de cargas abordados em (NAVARRO, 2005). Adicionalmente descreve-se o método numérico empregado pelo solver DASSLC (SECCHI, 1992; F. VIEIRA R. C., 2003) utilizado na confecção do simulador dinâmico multi-máquina DSIM desenvolvido no presente trabalho e valida-se a sua aplicação para a simulação dinâmica de sistemas elétricos através de uma análise comparativa dos resultados obtidos para o sistema BPA de 10 barras (KUNDUR, 1994; TAYLOR, 1994; CIGRE, 1995; CUTSEM; VOURNAS, 1998), bastante utilizado em trabalhos voltados para a análise dinâmica da estabilidade de tensão.

\subsection{Modelagem dinâmica do sistema elétrico}

Nesse item discute-se a modelagem dinâmica do sistema. Primeiramente apresenta-se cada um dos modelos considerados nesse trabalho e posteriormente discutem-se aspectos relacionados à modelagem multi-máquina do sistema como um todo. 


\subsubsection{Unidade Geradora}

A figura 4.1, a seguir apresenta uma descrição esquemática do sistema de controle de excitação utilizado em unidades geradoras. Genericamente esse sistema é composto por: (a) Excitatriz, (b) Regulador de tensão, (c) Transdutor de tensão terminal, (d) Limitador de sobreexcitação (OXL) e (e) PSS (Power System Stabilizer). Para uma descrição detalhada de cada um desses componentes, recomenda-se a consulta a (KUNDUR, 1994; CUTSEM; VOURNAS, 1998).

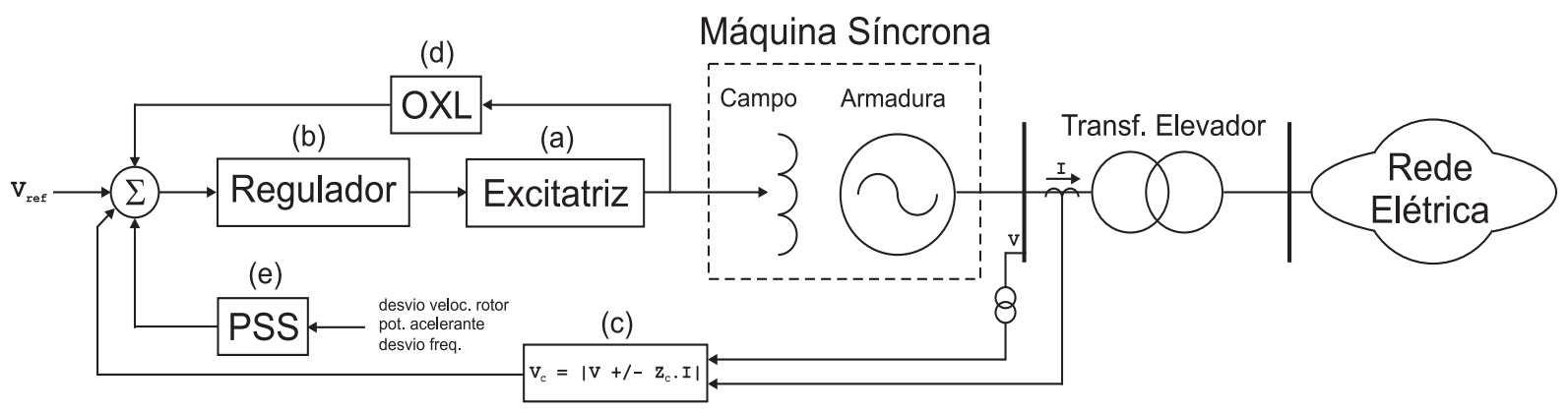

Figura 4.1: Sistema de controle de excitação.

Nesse trabalho, utiliza-se um modelo simplificado do controle de excitação, porém suficiente, para representar os principais aspectos qualitativos e quantitativos inerentes aos processos de instabilidade de colapso de tensão (CUTSEM; VOURNAS, 1998; CUTSEM, 2000). Assim, o modelo utilizado não contempla: o sistema de controle de freqüência nos geradores (turbinas), componentes utilizados nos sistemas de controles de excitação mais novos como: excitatrizes estáticas (que possuem ganhos elevados) e Power System Stabilizers. Naturalmente a adição de tais componentes ao modelo detalhado a seguir constitui-se em uma extensão natural do presente trabalho.

\subsubsection{Máquina Síncrona}

Os modelos matemáticos para representação de máquinas síncronas em estudos de estabilidade encontram-se muito bem consolidados (KUNDUR, 1994; ONG, 1997; ANDERSON; FOUAD, 2002). Esses modelos baseiam-se na Teoria Geral das Máquinas Elétricas (ADKINS, 1967) em que se assume um referencial girante na mesma velocidade do rotor da máquina. Os eixos $\mathbf{d}$ e $\mathbf{q}$ desse referencial encontram-se defasados de $90^{\circ}$ nas direções, respectivamente, dos fluxos de eixo direto e quadratura da máquina. Assim, as grandezas apresentadas nas equações desses modelos encontram-se nesse referencial girante e deve-se proceder a uma mudança de coordenadas quando se pretende simular a interação desse 
dispositivo com a rede elétrica (KUNDUR, 1994; ONG, 1997). Neste trabalho, considera-se apenas o modelo 1.1, que não contempla o efeito dos enrolamentos amortecedores, recomendado por (DANDENO et al., 1991) para estudos de estabilidade incluindo-se o efeito da saturação no eixo de quadratura da máquina. Através dele é possível representar dinamicamente máquinas de pólos salientes em que são considerados os efeitos transitórios do enrolamento de campo e desconsiderados os efeitos sub-transitórios devido aos enrolamentos amortecedores. As equações para esse modelo são enumeradas a seguir:

\section{Equações do rotor}

$$
\begin{gathered}
\frac{d E_{q}^{\prime}}{d t}-\frac{1}{T_{d 0}^{\prime}} \cdot\left[E_{f d}-\operatorname{Sat}\left(E_{q}^{\prime}\right)-\left(x_{d}-x_{d}^{\prime}\right) \cdot i_{d}\right]=0 \\
\frac{d E_{d}^{\prime}}{d t}-\frac{1}{T_{q 0}^{\prime}} \cdot\left[-E_{d}^{\prime}+\left(x_{q}-x_{q}^{\prime}\right) \cdot i_{q}\right]=0
\end{gathered}
$$

\section{Equações do estator}

$$
\begin{aligned}
& V_{q}-E_{q}^{\prime}+r_{a} \cdot i_{q}+x_{d}^{\prime} \cdot i_{d}=0 \\
& V_{d}-E_{d}^{\prime}+r_{a} \cdot i_{d}-x_{q}^{\prime} \cdot i_{q}=0
\end{aligned}
$$

\section{Equações mecânicas}

$$
\begin{gathered}
\frac{d w}{d t}-\left(\frac{w_{0}}{2 \cdot H}\right) \cdot\left(T_{m e c}+T_{e m}-T_{a m}\right)=0 \\
\frac{d \delta}{d t}-w=0 \\
T_{e m}=\left[E_{q}^{\prime} \cdot i_{q}+E_{d}^{\prime} \cdot i_{d}+\left(x_{q}^{\prime}-x_{d}^{\prime}\right) \cdot i_{q} \cdot i_{d}\right] \\
T_{a m}=D \cdot\left(\frac{w_{0}}{w}\right)
\end{gathered}
$$

onde: $E_{d}^{\prime}$ e $E_{q}^{\prime} \quad$ são as fem (proporcionais ao fluxo concatenado transitório) de eixo direto e quadratura em pu;

$V_{d}$ e $V_{q} \quad$ são as componentes de eixo direto e quadratura da tensão terminal em pu;

$E_{f d} \quad$ é a tensão do enrolamento de campo em pu;

$T_{d 0}^{\prime}$ e $T_{q 0}^{\prime} \quad$ são as constantes de tempo transitórias de circuito aberto nos eixos direto e quadratura em $\mathbf{s}$;

$i_{d}$ e $i_{q} \quad$ são as correntes de eixo direto e quadratura em $\mathbf{p u}$;

$r_{a} \quad$ é a resistência de armadura em pu;

$x_{d}$ e $x_{q} \quad$ são as reatâncias síncronas de eixo direto e quadratura em pu;

$x_{d}^{\prime}$ e $x_{q}^{\prime} \quad$ são as reatâncias transitórias de eixo direto e quadratura em $\mathbf{p u}$;

$T_{m e c}$ e $T_{e m}$ são os torques mecânico e eletromagnético em pu; 


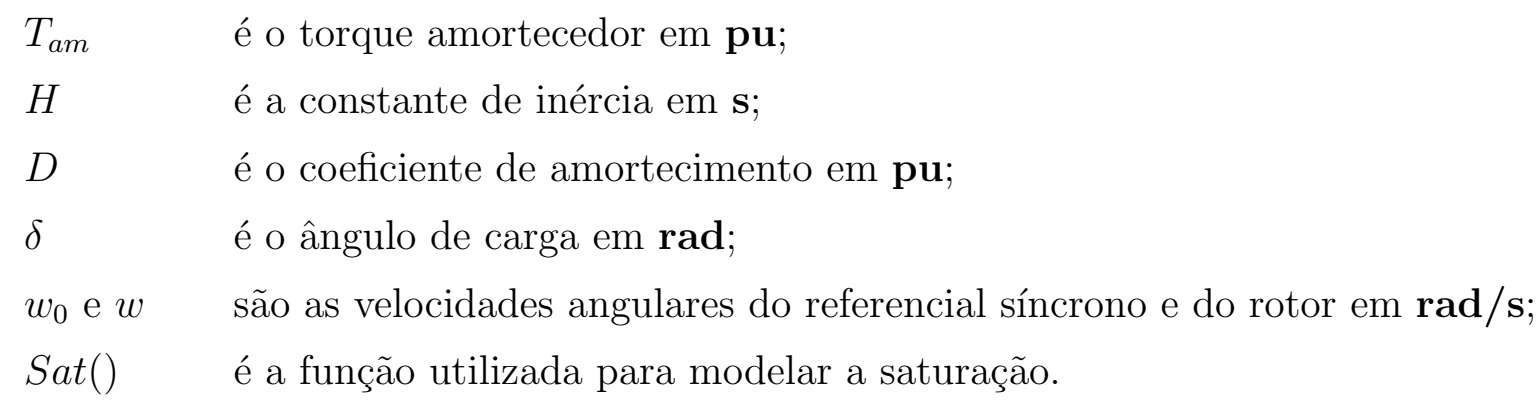

E as relações (4.9) e (4.10) permitem, respectivamente, a mudança das grandezas expressas no referencial síncrono para o referencial girante da máquina síncrona e vice-versa.

$$
\begin{aligned}
& {\left[\begin{array}{l}
i_{q} \\
i_{d}
\end{array}\right]=\left[\begin{array}{cc}
\cos \left(\delta-w_{0} \cdot t\right) & -\operatorname{sen}\left(\delta-w_{0} \cdot t\right) \\
\operatorname{sen}\left(\delta-w_{0} \cdot t\right) & \cos \left(\delta-w_{0} \cdot t\right)
\end{array}\right] \cdot\left[\begin{array}{c}
i_{Q} \\
i_{D}
\end{array}\right]} \\
& {\left[\begin{array}{c}
i_{Q} \\
i_{D}
\end{array}\right]=\left[\begin{array}{cc}
\cos \left(\delta-w_{0} \cdot t\right) & \operatorname{sen}\left(\delta-w_{0} \cdot t\right) \\
-\operatorname{sen}\left(\delta-w_{0} \cdot t\right) & \cos \left(\delta-w_{0} \cdot t\right)
\end{array}\right] \cdot\left[\begin{array}{c}
i_{q} \\
i_{d}
\end{array}\right]}
\end{aligned}
$$

onde: $i_{d}$ e $i_{q} \quad$ são as correntes de eixo direto e quadratura em pu no referencial girante da máquina;

$i_{D}$ e $i_{Q} \quad$ são as correntes de eixo direto e quadratura em pu no referencial síncrono do sistema multimáquina.

Convém ressaltar que as equações (4.9) e (4.10) são também aplicáveis às tensões.

\subsubsection{Controle de Excitação (Regulador de Tensão)}

Na literatura (LEE et al., 1992) encontram-se diversos modelos matemáticos que permitem representar a maioria dos reguladores de tensão em uso atualmente. Nesse trabalho, utilizou-se um controlador tipo proporcional-integral, ilustrado na figura 4.2.

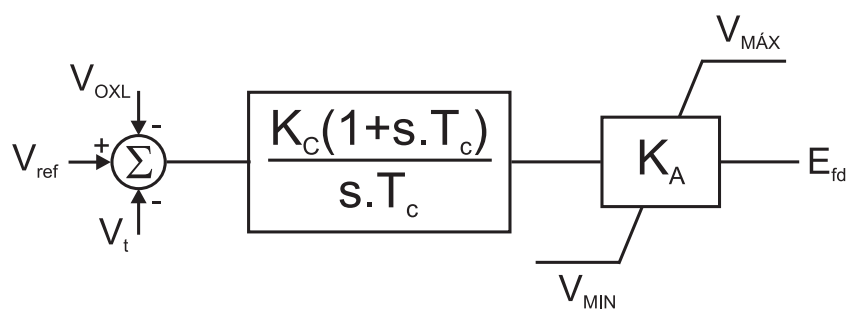

Figura 4.2: Modelo de $1^{a}$ ordem do Regulador de Tensão.

onde: $V_{\text {ref }}$

é a tensão de referência ajustável em pu; 


$\begin{array}{ll}V_{O X L} & \text { é o sinal auxiliar proveniente do } \mathbf{O X L} ; \\ V_{t} & \text { é a tensão terminal do gerador em } \mathbf{p u} ; \\ E_{f d} & \text { é a tensão aplicada no enrolamento de campo do gerador em pu; } \\ V_{M I N} \text { e } V_{M A X} & \text { são os limites mínimo e máximo de } E_{f d} \text { em } \mathbf{p u} ; \\ K_{C} \text { e } K_{A} & \text { são os ganhos do regulador e da excitatriz em } \mathbf{p u} ; \\ T_{C} & \text { é a constante de tempo do regulador em } \mathbf{s} .\end{array}$

\subsubsection{Limitador de Sobre-Excitação}

Ao contrário dos reguladores de tensão, ainda não existem modelos padronizados para limitadores de sobre-excitação. Assim, nesse trabalho utiliza-se o modelo sugerido em (TAYLOR, 1994) ilustrado na figura 4.3.

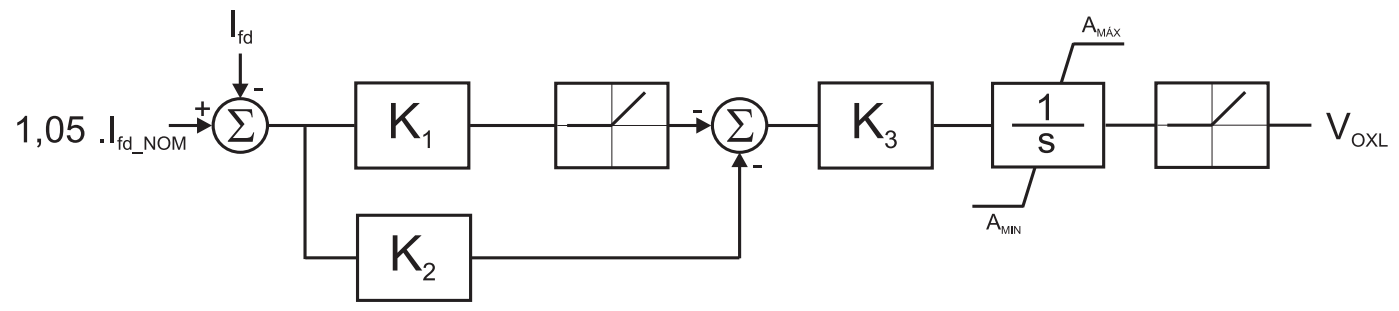

Figura 4.3: Modelo do Limitador de Sobre-Excitação.

onde: $I_{f d}$ e $I_{f d_{N O M}} \quad$ são as correntes medida e nominal do enrolamento de campo em pu;

$K_{1}, K_{2}$ e $K_{3}$ são os ajustes para a curva de tempo inverso do OXL;

$V_{O X L} \quad$ é o sinal enviado ao AVR para redução da corrente de campo;

$A_{M I N}$ e $A_{M A X}$ são os limites mínimo e máximo do sinal $V_{O X L}$.

E a corrente de campo é calculada através da equação (4.11), conforme recomendado em (POTAMIANAKIS E.G.; VOURNAS, 2006).

$$
I_{f d}=\left[E_{q}^{\prime}+\left(x_{d}-x_{d}^{\prime}\right) \cdot i_{d}\right]
$$

Esse dispositivo apresenta uma característica de tempo inverso e seus parâmetros são ajustados de forma a atender a seletividade com as capacidades do gerador e excitatriz (TAYLOR, 1994). 


\subsubsection{Transformadores com Controle Automático de Tape}

Nesse trabalho adota-se o modelo contínuo apresentado em (CUTSEM; VOURNAS, 1998), descrito pela equação (4.12).

$$
\begin{gathered}
\frac{d r}{d t}-\frac{V-V_{\text {ref }}}{T_{C}}=0 \\
\mathrm{com:} r_{\min } \leq r \leq r_{\max } \text { e } T_{C}=\frac{T_{d} \cdot \frac{D B}{2}}{\Delta r}
\end{gathered}
$$

onde: $V$ e $V_{\text {ref }}$

são as tensões controlada pelo LTC e de referência em pu;

$r \quad$ é o valor do tape em $\mathbf{p u} / \mathbf{p u}$

$\Delta r \quad$ é a variação discreta do tape em $\mathbf{p u} / \mathbf{p u}$;

$T_{C} \quad$ é a constante de tempo para o modelo contínuo em $\mathbf{s}$;

$T_{d} \quad$ é o tempo para mudança de tape em $\mathbf{s}$;

$D B \quad$ é a "zona morta" do LTC em pu/pu;

$r_{M I N}$ e $r_{M A X}$ são os limites inferior e superior do tape em $\mathbf{p u} / \mathbf{p u}$.

Convém ressaltar que o modelo discreto do LTC não é utilizado nas simulações, uma vez que, após vários testes realizados, observou-se que esse introduz instabilidade no solver DASSLC utilizado para solução do sistema de equações algébrico-diferenciais.

\subsubsection{Modelos de cargas}

Nesse trabalho utilizam-se modelos estáticos e dinâmicos de cargas capazes de representar a dependência das potências ativas e reativas consumidas com a tensão. A dependência das cargas com relação a frequência não é contemplada nos modelos descritos a seguir uma vez que essa característica não é comum em fenômenos de instabilidade e colapso de tensão (CUTSEM; VOURNAS, 1998; CANIZARES, 2002).

\subsubsection{Modelos estáticos das cargas}

Nesse trabalho utilizam-se os modelos estáticos de carga Exponencial e ZIP.

Modelo de carga Exponencial (PERFORMANCE, 1993)

$$
\begin{aligned}
& P=P_{0} \cdot\left(\frac{V}{V_{0}}\right)^{\alpha} \\
& Q=Q_{0} \cdot\left(\frac{V}{V_{0}}\right)^{\beta}
\end{aligned}
$$


onde: $V$ e $V_{0}$ são as tensões atual e antes do distúrbio em pu;

$P$ e $P_{0}$ são as potências ativa total e antes do distúrbio em pu;

$Q$ e $Q_{0}$ são as potências reativa total e antes do distúrbio em pu;

$\alpha$ e $\beta$ são as sensibilidades potência ativa-tensão e reativa-tensão.

Modelo de carga ZIP (PERFORMANCE, 1993)

$$
\begin{aligned}
& P=P_{0} \cdot\left[\alpha_{P} \cdot\left(\frac{V}{V_{0}}\right)^{2}+\beta_{P} \cdot\left(\frac{V}{V_{0}}\right)+\delta_{P}\right] \\
& Q=Q_{0} \cdot\left[\alpha_{Q} \cdot\left(\frac{V}{V_{0}}\right)^{2}+\beta_{Q} \cdot\left(\frac{V}{V_{0}}\right)+\delta_{Q}\right]
\end{aligned}
$$

onde: $V$ e $V_{0}$ são as tensões da atual e antes do distúrbio em pu;

$P$ e $P_{0}$ são as potências ativa total e antes do distúrbio em pu;

$Q$ e $Q_{0}$ são as potências reativa total e antes do distúrbio em pu;

$\alpha_{P}$ e $\alpha_{Q}$ são as porcentagens de impedância constante correspondentes, respectivamente, as parcelas ativa e reativa da carga;

$\beta_{P}$ e $\beta_{Q}$ são as porcentagens de corrente constante correspondentes, respectivamente, as parcelas ativa e reativa da carga;

$\delta_{P}$ e $\delta_{Q}$ são as porcentagens de potência constante correspondentes, respectivamente, as parcelas ativa e reativa da carga.

\subsubsection{Modelos dinâmicos das cargas}

Nesse trabalho utilizam-se os modelos de cargas propostos por (HILL, 1993) e (IHARA; TANI; TOMIYAMA, 1994).

Modelo proposto por (HILL, 1993)

$$
\begin{gathered}
T_{p} \cdot \frac{d P_{r}}{d t}+P_{r}-P_{0} \cdot\left(\frac{V}{V_{0}}\right)^{\alpha_{S}}+P_{0} \cdot\left(\frac{V}{V_{0}}\right)^{\alpha_{T}}=0 \\
P=P_{r}+P_{0} \cdot\left(\frac{V}{V_{0}}\right)^{\alpha_{T}} \\
T_{q} \cdot \frac{d Q_{r}}{d t}+Q_{r}-Q_{0} \cdot\left(\frac{V}{V_{0}}\right)^{\beta_{S}}+Q_{0} \cdot\left(\frac{V}{V_{0}}\right)^{\beta_{T}}=0 \\
Q=Q_{r}+Q_{0} \cdot\left(\frac{V}{V_{0}}\right)^{\beta_{T}}
\end{gathered}
$$

onde: $V$ e $V_{0}$ são as tensões atual e antes do distúrbio em pu; 
$P$ e $P_{0}$ são as potências ativa total e antes do distúrbio em pu;

$P_{r} \quad$ é a potência ativa recuperável após o distúrbio em pu;

$Q$ e $Q_{0}$ são as potências reativa total e antes do distúrbio em pu;

$Q_{r} \quad$ é a potência reativa recuperável após o distúrbio em $\mathbf{p u}$;

$T_{p}$ e $T_{q}$ são as constante de tempo para recuperação da potência ativa e reativa em $\mathbf{s}$;

$\alpha_{S}$ e $\alpha_{T}$ são as sensibilidades potência ativa-tensão em regime e transitória;

$\beta_{S}$ e $\beta_{T}$ são as sensibilidades potência reativa-tensão em regime e transitória.

Modelo proposto por (IHARA; TANI; TOMIYAMA, 1994)

$$
\begin{gathered}
P=\left[1+K_{p} \cdot\left(\frac{V}{V_{0}}-1\right)\right] \cdot\left(1-P_{d r o p}\right)+P_{d y n} \cdot\left[G \cdot\left(\frac{V}{V_{0}}\right)^{2}-1\right] \\
\frac{d G}{d t}+\frac{1}{T_{p}} \cdot\left[G \cdot\left(\frac{V}{V_{0}}\right)^{2}-1\right]=0 \\
Q=\left[1+K_{q} \cdot\left(\frac{V}{V_{0}}-1\right)\right] \cdot\left(1-Q_{d r o p}\right)+Q_{d y n} \cdot\left[B \cdot\left(\frac{V}{V_{0}}\right)^{2}-1\right] \\
\frac{d B}{d t}+\frac{1}{T_{q}} \cdot\left[B \cdot\left(\frac{V}{V_{0}}\right)^{2}-1\right]=0
\end{gathered}
$$

onde: $V$ e $V_{0}$

$G$

$B$

$K_{p}$ e $K_{q}$

$T_{p}$ e $T_{q}$

$P_{d r o p}$ e $Q_{d r o p}$

$P_{d y n}$ e $Q_{d y n}$ são as tensões atual e antes do distúrbio em pu;

é a condutância agregada da carga em pu;

é a susceptância agregada da carga em pu;

são as sensibilidades potência ativa-tensão e reativa-tensão;

são as constantes de tempo para restauração da potência ativa e reativa em $\mathbf{s}$;

são as porcentagens da potência ativa e reativa desconectadas pela proteção subtensão;

são as porcentagens da potência ativa e reativa consumidas por cargas dinâmicas.

A aderência desses dois modelos é analisada em (NAVARRO, 2005) utilizando dados de medições. Uma das principais conclusões desse trabalho é a recomendação do modelo 
de (IHARA; TANI; TOMIYAMA, 1994) para situações em que há distúrbios de curto-prazo acompanhados de grandes variações de tensão e do modelo de (HILL, 1993) para as demais situações.

\subsubsection{Motor de Indução}

Nesse trabalho utiliza-se o modelo de $3^{a}$ ordem, recomendado em (TAYLOR, 1994; ONG, 1997), para representação de cargas compostas por motores agregados. Nesse modelo desprezam-se os transitórios do estator resultando no circuito equivalente da fig. 4.4 que consiste em uma "tensão atrás da impedância transitória".

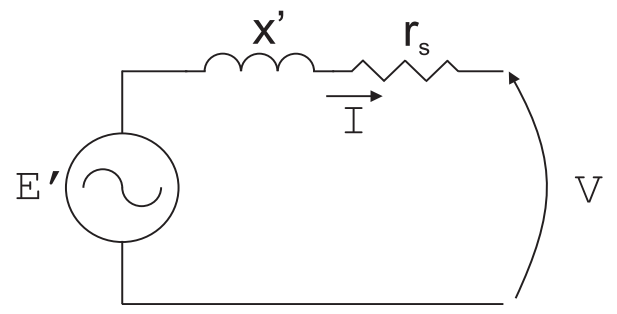

Figura 4.4: Circuito equivalente para o modelo transitório do motor.

E, a seguir, apresentam-se as equações para esse modelo.

$$
\begin{aligned}
& \frac{d E_{Q s}^{\prime}}{d t}+\left(\frac{1}{T_{0}^{\prime}}\right) \cdot\left[E_{Q s}^{\prime}+\left(x-x^{\prime}\right) \cdot i_{D s}\right]-\left(w_{0}-w\right) \cdot E_{D s}^{\prime}=0 \\
& \frac{d E_{D s}^{\prime}}{d t}+\left(\frac{1}{T_{0}^{\prime}}\right) \cdot\left[E_{D s}^{\prime}-\left(x-x^{\prime}\right) \cdot i_{Q s}\right]+\left(w_{0}-w\right) \cdot E_{Q s}^{\prime}=0 \\
& E_{Q s}^{\prime}-V_{Q}+r_{s} \cdot i_{Q s}-x^{\prime} \cdot i_{D s}=0 \\
& E_{D s}^{\prime}-V_{D}+r_{s} \cdot i_{D s}+x^{\prime} \cdot i_{Q s}=0 \\
& \frac{d w}{d t}-\left(\frac{1}{2 . H}\right) \cdot\left(T_{e m}-T_{m e c}\right)=0 \\
& T_{e m}=\left(E_{Q s}^{\prime} \cdot i_{Q s}+E_{D s}^{\prime} \cdot i_{D s}\right) \\
& T_{m e c}=T_{0} \cdot\left[A \cdot\left(\frac{w}{w_{0}}\right)^{2}+B \cdot\left(\frac{w}{w_{0}}\right)+C\right] \\
& x^{\prime}=x_{s}+\left(\frac{x_{m} \cdot x_{r}}{x_{m}+x_{r}}\right) \\
& x=x_{s}+x_{m} \\
& T_{0}^{\prime}=\left(\frac{x_{m}+x_{r}}{w_{0} \cdot r_{r}}\right)
\end{aligned}
$$


onde: $E_{D s}^{\prime}$ e $E_{Q s}^{\prime}$ são as fems proporcionais aos fluxos concatenados nos eixos D e Q em pu;

$V_{D}$ e $V_{Q} \quad$ são as componentes de eixo direto e quadratura da tensão terminal em pu;

$i_{D s}$ e $i_{Q s} \quad$ são as corrente de eixo direto e quadratura em $\mathbf{p u}$;

$T_{e m}$ e $T_{m e c}$ são os torques eletromagnético e mecânico do motor em pu;

$A, B$ e $C$ são as porcentagens que definem, respectivamente, uma característica quadrática, linear e constante do torque imposto ao eixo do motor pela carga mecânica;

$w_{0}$ e $w \quad$ são as velocidades angular do referencial síncrono e do rotor em $\mathbf{p u}$;

$H \quad$ é a constante de inércia do motor em $\mathbf{s}$;

$x_{s}$ e $x_{m} \quad$ são as reatâncias de dispersão e magnetização do estator em pu;

$r_{s}$ e $r_{r} \quad$ são as resistências ôhmica do estator e do rotor em $\mathbf{p u}$;

$x_{r} \quad$ é a reatância de dispersão do rotor em $\mathbf{p u}$;

$x$ e $x^{\prime} \quad$ são as reatâncias de circuito aberto e de curto-circuito do rotor em pu; $T_{0}^{\prime} \quad$ é a constante de tempo transitória de circuito aberto em $\mathbf{s}$.

\subsubsection{Demais elementos da rede elétrica}

Os elementos que compõem a rede elétrica são representados através de quadripolos estáticos (modelo $\pi$ para a maioria dos dispositivos) e, desta forma, podem ser descritos pelas equações (4.35) segundo os eixos $\mathbf{D}$ e $\mathbf{Q}$ do referencial síncrono.

$$
\left[\begin{array}{c}
i_{Q} \\
i_{D}
\end{array}\right]-\left[\begin{array}{cc}
G_{Q Q} & B_{Q D} \\
B_{D Q} & G_{D D}
\end{array}\right] \cdot\left[\begin{array}{c}
V_{Q} \\
V_{D}
\end{array}\right]=\left[\begin{array}{l}
0 \\
0
\end{array}\right]
$$

onde: $G_{Q Q}, B_{Q D}, B_{D Q}$ e $G_{D D}$ são os parâmetros do quadripolo;

$V_{D}$ e $V_{Q}$ são as tensões nas barras em $\mathbf{P U}$, respectivamente, nos eixos

$\mathrm{D}$ e Q do referencial síncrono;

$i_{D}$ e $i_{Q}$ são as correntes injetadas nas barras em $\mathbf{P U}$, respectivamente, nos eixos D e Q do referencial síncrono.

\subsubsection{O equacionamento multi-máquina}

A tabela 4.1 apresenta as equações e incógnitas para cada um dos componentes abordados. 
Tabela 4.1: Equacionamento multi-máquina do sistema elétrico.

\begin{tabular}{|c|c|c|c|}
\hline Componente & Equações & Incógnitas (Saídas) & Entradas \\
\hline Máquina Síncrona & $(4.1),(4.2),(4.3)$ & $E_{q}^{\prime}, E_{d}^{\prime}, V_{q}$, & $i_{q}, i_{d}$ e $E_{f d}$ \\
& $(4.4),(4.5) \mathrm{e}(4.6)$ & $V_{d}, w$ e $\delta$ & \\
\hline AVR & fig. 4.2 & $E_{f d}$ & $V_{r e f}, V_{O X L}, V_{q}$ e $V_{d}$ \\
\hline OXL & fig. 4.3 & $V_{O X L}$ & $I_{f d}{ }^{1}$ \\
\hline $\begin{array}{c}\text { Outros elementos } \\
\text { da rede Elétrica }\end{array}$ & $(4.35)(\mathrm{x} 2)$ & $i_{Q}$ e $i_{D}$ & $V_{Q}$ e $V_{D}$ \\
\hline $\begin{array}{c}\text { Cargas e } \\
\text { Motores }\end{array}$ & $\begin{array}{c}i_{Q}=f\left(V_{Q}, V_{D}\right)^{2} \\
i_{D}=g\left(V_{Q}, V_{D}\right)\end{array}$ & $i_{Q}$ e $i_{D}$ & $V_{Q}$ e $V_{D}$ \\
\hline Bloco DQ $\rightarrow \mathrm{dq}$ & $(4.9)(\mathrm{x} 2)$ & $i_{q}$ e $i_{d}$ & $i_{Q}$ e $i_{D}$ \\
\hline Bloco dq $\rightarrow \mathrm{DQ}$ & $(4.10)(\mathrm{x} 2)$ & $V_{Q}$ e $V_{D}$ & $v_{q}$ e $v_{q}$ \\
\hline
\end{tabular}

${ }^{1}$ Obtida a partir de (4.11).

${ }^{2}$ Determinadas a partir da tensão nodal e potência aparente injetada na barra.

Observando-se a tabela 4.1 percebe-se que a quantidade de incógnitas corresponde à quantidade de variáveis para cada um dos componentes. Assim, adicionando-se mais duas equações para cada uma das barras (correspondentes à aplicação da $1^{a}$ Lei de Kirchoff nos eixos D e Q) e mais duas variáveis por barra (correspondentes as correntes injetadas $I_{Q}$ e $I_{D}$ ) obtem-se um sistema de equações algébrico-diferenciais que representa o comportamento transitório da rede elétrica e pode ser resolvido numericamente.

\subsection{A Representação Genérica do Sistema Elétrico}

O conjunto de modelos mencionados no item 4.2 podem ser agrupados no seguinte conjunto de equações algébrico-diferenciais não-lineares:

$$
\begin{array}{r}
\dot{x}=f\left(x, y, z_{c}, z_{d}\right) \\
0=g\left(x, y, z_{c}, z_{d}\right) \\
\dot{z}_{c}=h_{c}\left(x, y, z_{c}, z_{d}\right) \\
z_{d}(k+1)=h_{d}\left(x, y, z_{c}, z_{d}(k)\right)
\end{array}
$$

As equações (4.36) representam os modelos de equipamentos que possuem "atuação rápida", como: geradores, reguladores de tensão e de velocidade, turbinas, PSSs, SVCs, HVDCs e motores de indução. As equações (4.37) representam a rede, cujos dispositivos são modelados segundo a hípótese de "atuação instantânea" em estudos de estabilidade. As equações (4.38) e (4.39) representam, respectivamente, os modelos contínuos e discretos de equipamentos que possuem "atuação lenta", como: LTCs, OXLs, bancos de capacitores 
ou reatores chaveados, cargas dinâmicas, controles secundários de tensão e frequência. De fato, as constantes de tempo associadas aos componentes existentes no sistema elétrico podem variar de microssegundos para a rede elétrica a minutos para controles automáticos de geração, vide figura 4.5, extraída de (TAYLOR, 1994).

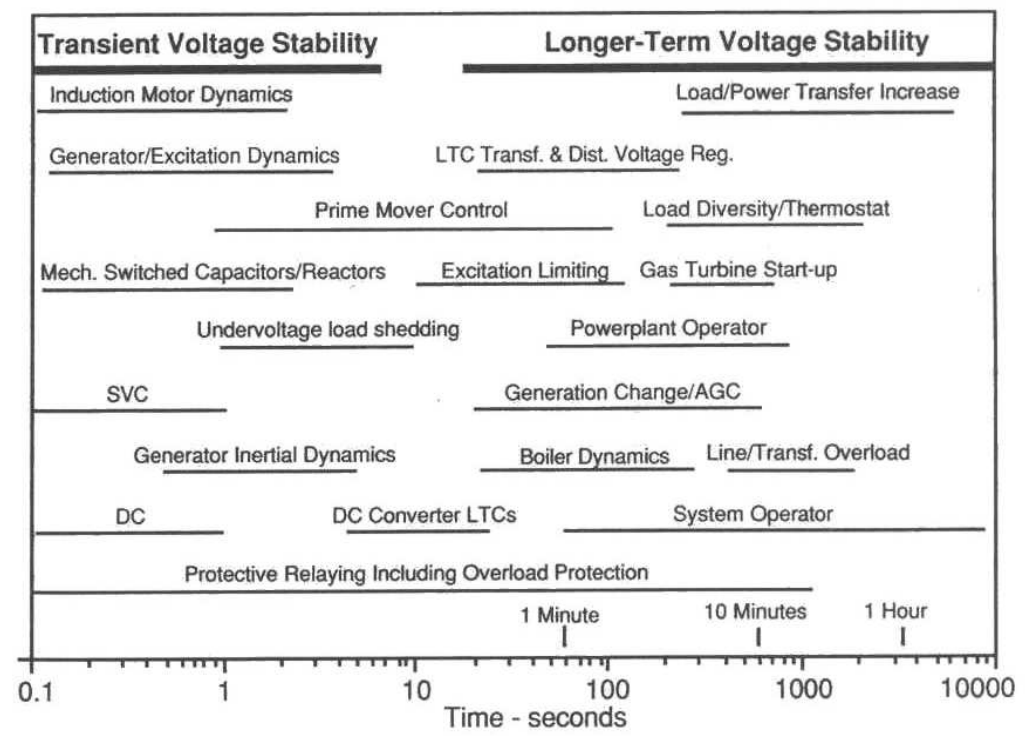

Figura 4.5: Escalas de tempo dos componentes do sistema elétrico.

A existência dessas diferentes escalas de tempo confere uma característica rígida (stiff) ao modelo matemático descrito pelo sistema de equações (4.36), (4.37), (4.38) e (4.39) (CUTSEM; VOURNAS, 1998) que, juntamente com a dimensionalidade do problema (diretamente ligada a quantidade de componentes modelados) e a não linearidade das equações requerem o uso de algoritmos de integração numérica sofisticados para sua solução. Nos itens a seguir abordam-se alguns conceitos relacionados a esse assunto.

\subsection{O integrador algébrico-diferencial DASSLC}

\subsubsection{Uma visão geral sobre métodos de integração numérica}

O sistema formado pelas equações (4.36), (4.37), (4.38) e (4.39) juntamente com as condições iniciais obtidas a partir da solução do fluxo potência definem um problema matemático conhecido como "Problema do Valor Inicial" que pode ser resolvido através de diversas técnicas numéricas. Definindo o problema simples de se integrar uma equação 
diferencial ordinária (EDO) do tipo:

$$
\dot{y}=f(y)
$$

Um método de integração numérica consiste basicamente em discretizar a equação (4.40) com o intuito de obter uma fórmula algébrica recursiva que pode ser implementada em um computador.

Na literatura (ASCHER; PETZOLD, 1998) existem numerosos métodos propostos para resolver esse problema, muitos deles podem ser expressos através da seguinte forma:

$$
y_{j+1}=\sum_{i=1}^{k} \alpha_{i} \cdot y_{j+1-i}+h \cdot \sum_{i=0}^{l} \beta_{i} \cdot \dot{y}_{j+1-i}
$$

onde: $j$ é o passo de tempo

$h$ é o tamanho do passo de integração.

Quando $k=l=1$, diz-se que o método de integração é do tipo "passo simples" uma vez que cada novo ponto $y_{j+1}$ é calculado somente a partir do ponto anterior $y_{j}$. Por sua vez, um método de integração numérica é considerado "multi-passo" quando $k>1$ ou $l>1$. Uma outra classificação importante categoriza os métodos de integração existentes em "implícitos" e "explícitos". Diz-se que um método de integração é "implícito" quando $\beta_{0} \neq 0$, ou seja, quando o ponto $y_{j+1}$ somente pode ser obtido a partir do conhecimento da derivada $\dot{y}_{j+1}$. Por sua vez, um método de integração numérica é considerado "explícito" quando $\beta_{0}=0$. Esse último critério de classificação é muito importante, uma vez que é possível provar matematicamente que os métodos numéricos "ímplicitos" apresentam uma estabilidade numérica superior se comparados aos métodos "explícitos" (ASCHER; PETZOLD, 1998; CUTSEM; VOURNAS, 1998).

\subsubsection{Uma análise breve da estabilidade dos métodos de inte- gração}

A estabilidade dos métodos de integração numérica está relacionada à evolução do erro global ${ }^{3}$ durante o processo de integração numérica. Sabe-se que o erro global é composto por duas parcelas: o erro de truncamento local ${ }^{4}$, inerente ao método numérico escolhido para o processo de integração (ASCHER; PETZOLD, 1998), e o fator de amplificação ${ }^{5}$

\footnotetext{
${ }^{3}$ Definido com a diferença entre a solução exata $f(t)$ e a solução calculada pelo método numérico em um determinado ponto (ASCHER; PETZOLD, 1998).

${ }^{4}$ Também conhecido como erro teórico.

${ }^{5}$ Também conhecido como erro prático.
} 
através do qual o erro global do passo anterior é multiplicado no passo atual causando o fenômeno conhecido como instabilidade numérica. Assim, deve-se garantir que o fator de amplificação seja sempre inferior a unidade, caso contrário o erro global crescerá com o passar do tempo (independentemente do método numérico utilizado) e o processo de integração será considerado instável.

A fim de garantir o requisito citado, faz-se uma análise de estabilidade baseada na equação teste de Dahlquist, vide equação (4.42), cuja solução encontra-se em (4.43).

$$
\begin{gathered}
\dot{y}=\lambda . y \\
y=e^{\lambda \cdot\left(t-t_{0}\right)}
\end{gathered}
$$

Resumidamente, essa análise consiste em determinar uma região de estabilidade numérica no plano $h \lambda^{6}$ aplicando a equação (4.42) na expressão corretora do método multi-passo (ASCHER; PETZOLD, 1998). Feito isso, pode-se afirmar que o método numérico é "A-Estável" se essa região está completamente contida no lado esquerdo do plano $h \lambda$. Uma vez atendida essa restrição, pode-se garantir que a resposta numérica do método será estável para qualquer valor de passo $\Delta t$ utilizado (CUTSEM; VOURNAS, 1998).

\subsubsection{Sobre sistemas de equações rígidas (stiff)}

Sabe-se que a "rigidez" de um sistema de equações algébrico-diferenciais está relacionada com as grandes diferenças existentes nas constantes de tempo de suas variáveis de estado, porém não existe ainda uma definição plenamente aceita sobre o conceito de rigidez. Um sistema não-linear é considerado rígido quando os autovalores de sua matriz jacobiana além de apresentarem parte real negativa, possuem magnitudes muito distintas (Em sistema lineares define-se rigidez como a razão entre o maior e o menor autovalores (CUTSEM; VOURNAS, 1998)). A seguinte definição possui uma conotação mais prática: "Um sistema de equações algébrico-diferenciais é considerado rígido se um método numérico é obrigado a usar um passo de integração muito pequeno em relação à suavidade da solução exata do problema em um determinado intervalo" (JARDIM, 1997).

\footnotetext{
${ }^{6}$ Define-se $h=\lambda \cdot \Delta t$.
} 


\subsubsection{O método de Diferenciação Regressiva}

Os métodos de diferenciação regressiva (BDF) são muito utilizados para resolver sistemas de EADs rígidas. Essencialmente são métodos lineares multi-passo implícitos cujas fórmulas interpoladoras baseiam-se em uma combinação linear dos polinômios de Lagrange (ASCHER; PETZOLD, 1998). A equação (4.44) ilustra a fórmula geral utilizada nos métodos BDF.

$$
\sum_{i=0}^{k} \alpha_{i} \cdot y_{n-i}=h \cdot \beta_{0} \cdot f\left(y_{n}, x_{n}\right)
$$

A tabela 4.2 ilustra os seis primeiros membros da família de fórmulas BDF de $k$-passos, em que $k=p$ e $p$ é a ordem do método. Convém ressaltar que o primeiro, correspondente ao método BDF de passo simples, é idêntico ao método de Euler backward.

Tabela 4.2: coeficientes das fórmulas BDF até ordem 6

\begin{tabular}{c|c|c|ccccccc}
$\mathrm{p}$ & $\mathrm{k}$ & $\beta_{0}$ & $\alpha_{0}$ & $\alpha_{1}$ & $\alpha_{2}$ & $\alpha_{3}$ & $\alpha_{4}$ & $\alpha_{5}$ & $\alpha_{6}$ \\
\hline 1 & 1 & 1 & 1 & -1 & & & & & \\
2 & 2 & $\frac{2}{3}$ & 1 & $-\frac{4}{3}$ & $\frac{1}{3}$ & & & & \\
3 & 3 & $\frac{6}{11}$ & 1 & $-\frac{18}{11}$ & $\frac{9}{11}$ & $-\frac{2}{11}$ & & & \\
4 & 4 & $\frac{12}{25}$ & 1 & $-\frac{48}{25}$ & $\frac{36}{25}$ & $-\frac{16}{25}$ & $-\frac{3}{25}$ & & \\
5 & 5 & $\frac{60}{137}$ & 1 & $-\frac{300}{137}$ & $\frac{300}{137}$ & $-\frac{200}{137}$ & $\frac{75}{137}$ & $-\frac{12}{137}$ & \\
6 & 6 & $\frac{60}{147}$ & 1 & $-\frac{360}{147}$ & $\frac{450}{147}$ & $-\frac{400}{147}$ & $\frac{225}{147}$ & $-\frac{72}{147}$ & $\frac{10}{147}$ \\
\hline
\end{tabular}

A equação (4.44) é apropriada para resolver problemas de valor inicial na forma implícita descrita pela equação (4.45).

$$
F(t, y, \dot{y})=\left\{\begin{array}{l}
\dot{y}=f(y, x) \\
0=g(y, x)
\end{array}\right.
$$

O método BDF apresenta dois estágios, o estágio previsor utiliza uma fórmula explícita e o estágio corretor utiliza as fórmulas implícitas BDF, ilustradas em (4.44), para formar um sistema de equações não lineares.

$\mathrm{Na}$ etapa de previsão utiliza-se um polinômio de diferenças divididas que interpola os pontos de solução $y_{j+1-k}$ dos últimos $k$ intervalos de tempo. Esse polinômio é responsável pela primeira aproximação de $y_{j+1}$ através da equação (4.46).

$$
y_{j+1}(t)=y_{j}+\left(t-t_{j}\right) \cdot\left[y_{j}, y_{j-1}\right]+\cdots+\left(t-t_{j}\right) \cdot\left(t-t_{j-1}\right) \cdot\left(t-t_{j-k+1}\right) \cdot\left[y_{j}, \cdots, y_{j-k}\right]
$$


em que as diferenças divididas são definidas pelas equações (4.47) e (4.48).

$$
\left[y_{j}, \cdots, y_{j-k}\right]=\frac{\left[y_{j}, y_{j-1}, \cdots, y_{j-k+1}\right]-\left[y_{j-1}, y_{j-2}, \cdots, y_{j-k}\right]}{t_{j}-t_{j-k}}
$$

Na etapa de correção, a derivada $\dot{y}$ da equação (4.45) é aproximada usando uma fórmula da família BDF, vide equação (4.44), de ordem de convergência $p=k$, vide tabela 4.2, obtendo o sistema de equações algébricas não-lineares das equações (4.49) que é solucionado através do método de Newton modificado (ASCHER; PETZOLD, 1998), ilustrado nas equações (4.50) e (4.51).

$$
\begin{gathered}
F\left(t_{n+1}, y_{n+1}, \dot{y}_{n+1}\right)=\left\{\begin{array}{l}
y_{n+1}+\sum_{i=0}^{k} \alpha_{i} \cdot y_{n-i}-h \cdot \beta_{0} \cdot f\left(y_{n+1}, x_{n+1}\right)=0 \\
g\left(y_{n+1}, x_{n+1}\right)=0
\end{array}\right. \\
\dot{y}=y-c \cdot[G]^{-1} \cdot F(t, y, \dot{y}) \\
G=\alpha \cdot \frac{\partial F}{\partial \dot{y}}+\frac{\partial F}{\partial y}
\end{gathered}
$$

onde: $c$ é uma constante escalar selecionada para acelerar a taxa de convergência do estágio corretor;

G é a matriz de iteração calculada a partir da equação (4.51).

Em cada intervalo de integração a ordem $k$ e o comprimento do $j$-ésimo passo de integração $h$ são escolhidos com base no comportamento do erro de truncamento local. Ao final de cada passo de integração $h$ verifica-se se a estimativa desse erro está dentro de uma tolerância permitida. Em caso positivo, aceita-se o passo e determina-se, com base nesse mesmo erro, se há margem para aumento do passo. Em caso negativo, rejeita-se o passo e determina-se que passo será necessário para que o erro se mantenha dentro da tolerância (ASCHER; PETZOLD, 1998).

\subsection{Ferramentas desenvolvidas neste trabalho}

Esse item apresenta uma descrição das ferramentas computacionais FLOW e DSIM desenvolvidas para avaliar a estabilidade de tensão a partir do modelo genérico do sistema elétrico apresentado nos itens anteriores. Essa ferramentas foram desenvolvidas segundo o paradigma de orientação a objetos e, para sua implementação, utilizou-se o compilador Microsoft Visual C++ 7.0, contido no pacote Microsoft Visual Studio .NET 2003. 
Nesse ponto convém mencionar que utilizou-se o programa de fluxo continuado UWPFLOW (CANIZARES C. A.; ALVARADO, 1991) para obter as curvas PV e QV ESTÁTICAS dos sistemas analisados no capítulo 5 .

O programa FLOW calcula o fluxo de potência e a análise modal de uma rede elétrica definida pelo usuário. Os dados da rede são fornecidos através de um arquivo texto com extensão .dat e, após sua execução, dois outros arquivos são criados: um arquivo com extensão .flo que contém as condições iniciais necessárias para realizar a simulação dinâmica do sistema e um arquivo com extensão .out que contém todos os resultados das análises mencionadas anteriormente.

O programa DSIM calcula a simulação dinâmica de uma rede elétrica definida pelo usuário. Para isso, faz-se necessário fornecer dois arquivos: um arquivo com extensão .flo, gerado pelo programa FLOW, e um arquivo texto com extensão .dyn que contém os dados necessários à simulação dinâmica da rede elétrica. A partir dessas informações, esse programa cria um arquivo com extensão .csv que contém a resposta da simulação dinâmica. A fim de traçar os gráficos das variáveis de interesse, utiliza-se o programa Microsoft Excel.

A seguir apresentam-se descrições mais detalhadas desses programas.

\subsubsection{O programa de fluxo de potência FLOW}

\subsubsection{Solução do fluxo de potência}

O programa de fluxo de potência FLOW suporta os tipos de barra relacionados na tabela 4.3 .

Tabela 4.3: Tipos de barra considerados no programa FLOW.

\begin{tabular}{|c|c|c|c|}
\hline Tipo de barra & Componentes & Variáveis fornecidas & Variáveis calculadas \\
\hline$P Q$ & cargas & $P, Q$ & $V, \theta$ \\
\hline$P V$ & geradores & $P, V, Q_{\min }, Q_{\max }$ & $Q, \theta$ \\
\hline$P Q V$ & barras controladas & & \\
\hline Swing & Barra Swing (uma barra) & $V, Q, V$ & $\theta$, tape do LTC \\
\hline
\end{tabular}

\footnotetext{
${ }^{7}$ Somente barras de carga.
}

Assumindo que um sistema de potência possui $l$ barras do tipo $P Q, m$ barras do tipo $P V$ e $n$ barras do tipo $P Q V$ têm-se um sistema com $l+m+n$ equações do tipo (4.52) e $l$ $+n$ equações do tipo (4.53). 


$$
\begin{aligned}
P_{i} & =V_{i} \cdot \sum V_{j} \cdot\left(G_{i j} \cdot \cos \left(\theta_{i j}\right)+B_{i j} \cdot \operatorname{sen}\left(\theta_{i j}\right)\right) \\
Q_{i} & =V_{i} \cdot \sum V_{j} \cdot\left(G_{i j} \cdot \operatorname{sen}\left(\theta_{i j}\right)-B_{i j} \cdot \cos \left(\theta_{i j}\right)\right)
\end{aligned}
$$

onde: $P_{i}, Q_{i}$ são as potências ativas e reativas injetadas na barra $i$;

$V_{i}, \theta_{i}$ são, respectivamente, a tensão em [pu] e o ângulo em [rad] na barra $i$;

$\theta_{i j}=\theta_{i}-\theta_{j}$;

$G_{i j}+j \cdot B_{i j}$ é o elemento $(i, j)$ da matriz de admitâncias nodais do sistema.

Desta forma, o problema do fluxo de potência consiste em determinar os valores de $V_{i}$ (para as barras tipo $P Q$ ) e $\theta_{i}$ (para as barras tipo $P Q, P V$ e $P Q V$ ) de forma que as potências calculadas a partir das equações (4.52) e (4.53) sejam iguais, respectivamente, aos valores de potências ativa $P_{i}$ (para as barras tipo $P Q, P V$ e $P Q V$ ) e reativa $Q_{i}$ (para as barras tipo $P Q$ e $P Q V$ ) especificados. No programa FLOW, esse sistema de equações é resolvido através do método de Newton-Raphson utilizando a matriz Jacobiana completa calculada a cada iteração (MONTICELLI, 1983; POWELL, 2005). Uma vez que o processo iterativo converge, dentro de uma tolerância pré-definida, obtêm-se os valores das "Variáveis calculadas" apresentados na tabela 4.3.

O programa FLOW contempla os modelos estáticos de cargas ZIP e Exponencial, descritos no item 4.2.3.1 desse trabalho. Além disso, o programa permite calcular automaticamente os ajustes dos tapes nos LTCs e simular a ação dos AVRs nos geradores (barras $P V$ ) quando os limites mínimo e máximo de potência reativa são fornecidos pelo usuário.

O ajuste automático dos tapes nos LTCs é calculado através da metodologia proposta por (PETTERSON; MEYER, 1971). Resumidamente, esta consiste em reescrever as equações (4.52) e (4.53) para o LTC expressando-as em função de seu tape. Para isso, introduz-se o conceito de barra controlada $P Q V$ (a fim de manter o número de equações igual ao de incógnitas) e incluem-se na matriz Jacobiana do sistema as derivadas das injeções de potências ativa e reativa do LTC com relação ao seu tape. Assim, os valores dos tapes podem ser calculados a cada iteração pelo método de Newton-Raphson, enquanto mantêm-se constantes os valores de tensão nas barras tipo $P Q V$.

A ação dos AVRs nos geradores é simulada através das conversões da barra $P V$ em $P Q$ (a barra $P V$ torna-se não controlada) e de $P Q$ em $P V$ (a barra $P V$ volta a ser controlada). Esse procedimento equivale a aproximar a curva de capacidade do gerador pela área retangular ilustrada na figura 4.6. 


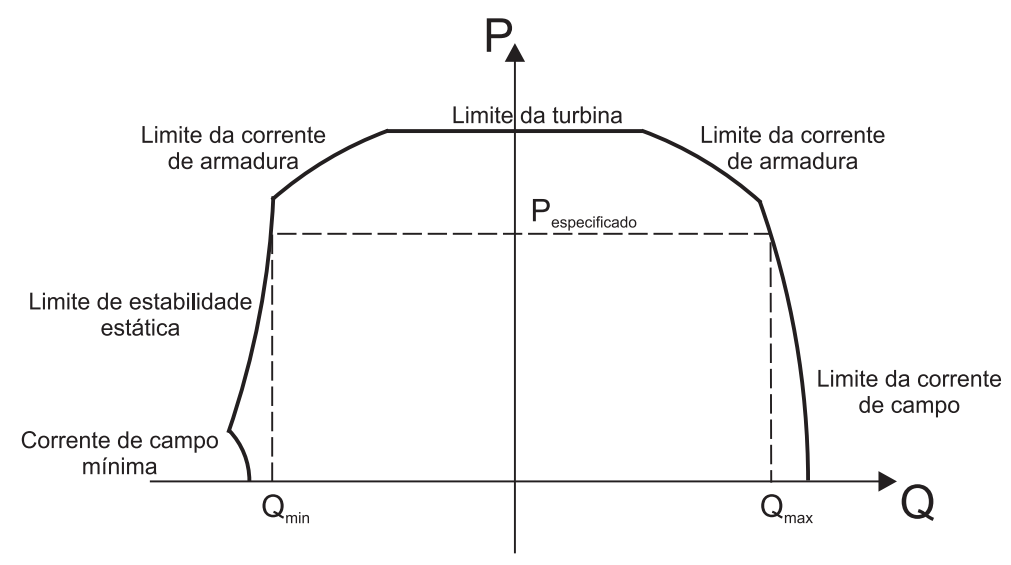

Figura 4.6: Curva de capacidade do gerador.

A conversão no sentido $P V$ para $P Q$ ocorre quando um dos limites de potência reativa $\left(Q_{\min }\right.$ ou $\left.Q_{\max }\right)$ da barra $P V$ é violado. Nessa situação, fixa-se a potência reativa no patamar violado e deixa-se a tensão "livre" para ser calculada pelo método de Newton Raphson.

A conversão no sentido $P Q$ para $P V$ ocorre em duas situações: quando a tensão calculada na barra se torna igual ou superior à tensão controlada e sua potência reativa está fixada em $Q_{\max }$ (há possibilidade da barra voltar a ser $P V$, uma vez que uma redução de tensão na barra acarreta uma redução da potência reativa injetada), ou quando a tensão calculada na barra se torna inferior à tensão controlada e sua potência reativa está fixada em $Q_{\text {min }}$ (há possibilidade da barra voltar a ser $P V$, uma vez que um aumento de tensão na barra acarreta em um aumento da potência reativa injetada).

Observou-se que o procedimento anteriormente descrito torna-se ineficaz em sistemas que possuem uma grande quantidade de barras $P V$, uma vez que a ocorrência simultânea de muitas conversões torna o algoritmo de Newton - Raphson instável, impedindo que a convergência do fluxo seja atingida. Esse trabalho soluciona esse problema através de uma heurística que consiste em restringir tais conversões somente às barras $P V$ cujos erros calculados ( $\Delta V$ no caso de barras $P V$ não controladas e $\Delta Q$ no caso de barras $P V$ controladas) tornam-se inferiores a um limiar pré-definido.

Finalmente, deve-se ressaltar que a matriz Jacobiana, proveniente da linearização do sistema de equações (4.52) e (4.53), é esparsa devido à natureza topológica dos sistemas elétricos. O programa FLOW explora essa característica utilizando uma implementação de grafo orientado ponderado, denominada adjacent-lists (SEDGEWICK, 2002), para armazenar essa matriz. Além disso, convém ressaltar que alcançaram-se boas características de desempenho computacional e precisão numérica combinando-se essa estrutura de ar- 
mazenagem com uma técnica para solução de sistemas lineares esparsos denominada $M i$ nimum Degree Algorithm (MDA), recentemente publicada em (PANDIT; SOMAN; KHAPARDE, 2001).

\subsubsection{Análise modal}

Adicionalmente, o programa FLOW é capaz de calcular a análise modal expandida (SILVA et al., 2002) sobre o ponto de operação da rede elétrica obtido após a solução do fluxo de potência. Para isso, obtêm-se as matrizes jacobianas reduzidas $\boldsymbol{J}_{\boldsymbol{R} \boldsymbol{Q} \boldsymbol{V}}$ e $\boldsymbol{J}_{\boldsymbol{R P \boldsymbol { \theta }}}$ a partir da linearização do modelo estático do fluxo ilustrada em (4.54).

$$
\left[\begin{array}{c}
\Delta P \\
\Delta Q
\end{array}\right]=\left[\begin{array}{ll}
J_{P \theta} & J_{P V} \\
J_{Q \theta} & J_{Q V}
\end{array}\right] \cdot\left[\begin{array}{c}
\Delta \theta \\
\Delta V
\end{array}\right]
$$

onde: $\Delta \mathrm{P}$ é a variação incremental da potência ativa

$\Delta \mathrm{Q}$ é a variação incremental da potência reativa

$\Delta \theta$ é a variação incremental do ângulo da tensão nodal

$\Delta \mathrm{V}$ é a variação incremental da magnitude da tensão nodal.

Os elementos da matriz Jacobiana representam as sensibilidades entre as variações das injeções de potências e as variações das tensões e ângulos nas barras do sistema. A partir de (4.54) obtêm-se, respectivamente, as variações de potência ativa (4.55) e reativa (4.56) injetadas nas barras em função das variações das magnitudes e ângulos das tensões.

$$
\begin{aligned}
& \Delta P=J_{P \theta} \cdot \Delta \theta+J_{P V} \cdot \Delta V \\
& \Delta Q=J_{Q \theta} \cdot \Delta \theta+J_{Q V} \cdot \Delta V
\end{aligned}
$$

Na análise modal convencional (GAO; MORISON; KUNDUR, 1992; MORISON; GAO; KUNDUR, 1993) supõem-se as variações de potência ativa nulas $(\Delta P=0)$ para o ponto de operação. Assim, a matriz reduzida $\boldsymbol{J}_{\boldsymbol{R} \boldsymbol{V} \boldsymbol{V}}$, vide equação (4.57), é obtida a partir das equações (4.55) e (4.56) e, através dela, pode-se avaliar o impacto das potências reativas injetadas nas barras sobre a estabilidade de tensão do sistema, conforme ilustrado na equação (4.58).

$$
J_{R Q V}=\left[J_{Q V}-J_{Q \theta} \cdot\left(J_{P \theta}\right)^{-1} \cdot J_{P V}\right]
$$




$$
\Delta V=\left(J_{R Q V}\right)^{-1} \cdot \Delta Q
$$

A análise modal expandida (SILVA et al., 2002) amplia o conceito anteriormente descrito com o intuito de avaliar o impacto das potências ativas injetadas sobre a estabilidade de tensão, vide equação (4.60). Para isso, supõem-se as variações de potência reativa nulas $(\Delta Q=0)$ para o ponto de operação e a matriz reduzida $\boldsymbol{J}_{\boldsymbol{R P} \boldsymbol{\theta}}$, vide equação (4.59), é obtida a partir das equações (4.55) e (4.56).

$$
\begin{gathered}
J_{R P \theta}=\left[J_{P \theta}-J_{P V} \cdot\left(J_{Q V}\right)^{-1} \cdot J_{Q \theta}\right] \\
\Delta \theta=\left(J_{R P \theta}\right)^{-1} \cdot \Delta P
\end{gathered}
$$

Assim, através da análise de autovalores, decompõem-se as matrizes reduzidas $J_{R Q V}$ e/ou $J_{R P \theta}$ em seus autovalores e autovetores direitos e esquerdos, conforme (4.61).

$$
J_{R}=[\xi] \cdot[\lambda] \cdot[\eta]
$$

onde: $J_{R}$ é a matriz reduzida $J_{R Q V}$ ou $J_{R P \theta}$

$[\lambda]$ é a matriz diagonal dos autovalores de $J_{R}$

$[\xi]$ é a matriz dos autovetores direitos de $J_{R}$

$[\eta]$ é a matriz dos autovetores esquerdos de $J_{R}$.

Assim, as equações (4.58) e (4.60) tornam-se, respectivamente, (4.62) e (4.63).

$$
\begin{gathered}
\Delta V=\left[\xi_{Q V}\right] \cdot\left(\left[\lambda_{Q V}\right]\right)^{-1} \cdot\left[\eta_{Q V}\right] \cdot \Delta Q \\
\Delta \theta=\left[\xi_{P \theta}\right] \cdot\left(\left[\lambda_{P \theta}\right]\right)^{-1} \cdot\left[\eta_{P \theta}\right] \cdot \Delta P
\end{gathered}
$$

onde: $\left[\lambda_{Q V}\right]$ e $\left[\lambda_{P \theta}\right]$ são, respectivamente, as matrizes diagonais dos autovalores de $J_{R Q V}$ e $J_{R P \theta}$;

$\left[\xi_{Q V}\right]$ e $\left[\xi_{P \theta}\right]$ são, respectivamente, as matrizes dos autovetores direitos de $J_{R Q V}$ e $J_{R P \theta}$;

$\left[\eta_{Q V}\right]$ e $\left[\eta_{P \theta}\right]$ são, respectivamente, as matrizes dos autovetores esquerdos de $J_{R Q V}$ e $J_{R P \theta}$. 
E admitindo-se que as matrizes reduzidas $J_{R Q V}$ e $J_{R P \theta}$ são simétricas em valor $\left(\xi^{-1}=\eta\right)$ obtêm-se as equações (4.64) e (4.65) para as variações modais de tensão e ângulo em função das variações modais das potências ativa e reativa.

$$
\begin{gathered}
\Delta v_{m}=\left(\left[\lambda_{Q V}\right]\right)^{-1} \cdot \Delta q_{m} \\
\Delta \theta_{m}=\left(\left[\lambda_{P \theta}\right]\right)^{-1} \cdot \Delta p_{m}
\end{gathered}
$$

onde: $\Delta v_{m}$ e $\Delta \theta_{m}$ são, respectivamente, as variações modais das tensões e ângulos;

$\Delta q_{m}$ e $\Delta p_{m} \quad$ são, respectivamente, as variações modais das potências ativas e reativas.

Sabe-se que cada variação modal de tensão $\Delta v_{m}$, ângulo $\Delta \theta_{m}$, potência ativa $\Delta p_{m}$ e potência reativa $\Delta q_{m}$ são, respectivamente, combinações lineares ${ }^{8}$ das variações de tensão $\Delta V$, ângulo $\Delta \theta$, potência ativa $\Delta P$ e potência reativa $\Delta Q$ em cada uma das barras do sistema. Assim, as equações (4.64) e (4.65) mostram que a estabilidade de tensão do sistema pode ser avaliada através da inspeção dos autovalores $\lambda_{Q V}$ e $\lambda_{P \theta}$, uma vez que:

Se $\lambda_{Q V}=0$ (ou $\lambda_{P \theta}=0$ ), qualquer variação da potência reativa modal $\Delta q_{m}$ (ou da potência ativa modal $\Delta p_{m}$ ) causa variações muito grandes nas tensões modais $\Delta v_{m}$ (ou ângulos modais $\Delta \theta_{m}$ ) indicando uma situação de colapso do sistema;

Se $\lambda_{Q V}>0$ (ou $\left.\lambda_{P \theta}>0\right)$, as variações $\Delta q_{m}\left(\Delta p_{m}\right)$ e $\Delta v_{m}\left(\Delta \theta_{m}\right)$ ocorrem no mesmo sentido, indicando que o sistema é estável;

Se $\lambda_{Q V}<0$ (ou $\left.\lambda_{P \theta}<0\right)$, as variações $\Delta q_{m}\left(\Delta p_{m}\right)$ e $\Delta v_{m}\left(\Delta \theta_{m}\right)$ ocorrem em sentidos opostos, indicando que o sistema é instável.

E a contribuição da j-ésima barra para o $i$-ésimo modo crítico $\left(\lambda_{Q V(i)} \approx 0\right.$ ou $\left.\lambda_{P \theta(i)} \approx 0\right)$ é obtida a partir do fator de participação $\left(F P_{i j}\right)$, expresso pela equação $(4.66)$.

$$
F P_{i j}=\frac{\left\|\xi_{i j}\right\| \cdot\left\|\eta_{i j}\right\|}{\left\|\xi_{i}\right\| \cdot\left\|\eta_{i}\right\|}
$$

Assim, quanto maior o fator de participação de uma determinada barra (associada a um modo crítico), mais impacto ela exerce sobre a margem de estabilidade de tensão do sistema quando ocorrem variações nas suas potências ativa ou reativa injetadas. Esse

\footnotetext{
${ }^{8}$ Uma vez que $\Delta v_{m}=\eta . \Delta V, \Delta \theta_{m}=\eta \cdot \Delta \theta, \Delta p_{m}=\eta \cdot \Delta P$ e $\Delta q_{m}=\eta . \Delta Q$
} 
fato torna a análise modal uma ferramenta poderosa para identificar as áreas e/ou barras críticas com o intuito de investigar possíveis ações preventivas e/ou corretivas.

O programa FLOW realiza a análise de autovalores, vide (4.61), das matrizes reduzidas $J_{R Q V}$ e $J_{R P \theta}$ utilizando uma versão implementada em C++ da rotina ZGEEV, pertencente à biblioteca LAPACK (Linear Algebra PACKage), capaz de lidar com matrizes complexas não-simétricas (ANDERSON et al., 1999).

\subsubsection{O programa DSIM}

Sabe-se que o programa DSIM contempla todos os modelos descritos no item 4.2 e resolve numericamente o sistema de equações algébrico-diferenciais resultante dessa modelagem (vide equacionamento no item 4.2.5) utilizando o solver DASSLC que implementa o método BDF, descrito no item 4.4.4. Assim, os próximos itens fornecem informações relacionadas aos recursos de simulação disponíveis até o momento e detalham o tratamento conferido às não linearidades existentes nos LTCs, AVRs e OXLs.

\subsubsection{Recursos disponíveis}

Para executar uma simulação dinâmica, faz-se necessário fornecer o tempo final da simulação em segundos, o intervalo de tempo $\Delta t$ para impressão dos resultados e os valores para os erros relativo RTOL ${ }^{9}$ e absoluto ATOL ${ }^{10}$ para o cálculo da matriz de iteração $G$, definida na equação (4.51). A seguir, devem-se fornecer os parâmetros dos modelos dinâmicos para todos os dispositivos escolhidos e agendar os eventos a serem executados durante a simulação. A tabela 4.4 apresenta os eventos disponíveis no programa DSIM juntamente com os parâmetros necessários a sua execução.

A tabela 4.4 também ilustra as limitações existentes no programa DSIM até o presente momento. Sabe-se, por exemplo, que ainda não é possível simular: desconexões de uma única extremidade de linhas (ou transformadores), retirada de geradores e alterações no ajuste dos OXLs e tapes do LTCs durante a simulação dinâmica.

\footnotetext{
${ }^{9}$ Em (E. CAMPBELL S. L., 1996), recomenda-se adotar $R T O L=10^{-m+1}$, onde $m$ igual ao número de dígitos necessários para calcular $y$.

${ }^{10} \mathrm{Em}$ (E. CAMPBELL S. L., 1996), recomenda-se adotar ATOL igual ao valor em que y é considerado insignificante.
} 
Tabela 4.4: Eventos contemplados no programa DSIM.

\begin{tabular}{|c|c|c|c|c|c|}
\hline $\begin{array}{c}\text { Tipo } \\
\text { de evento }\end{array}$ & Contingência & $\begin{array}{c}\text { Desconexão } \\
\text { de carga }\end{array}$ & $\begin{array}{c}\text { Variação } \\
\text { de demanda }\end{array}$ & $\begin{array}{c}\text { Chavear } \\
\text { dispositivos }\end{array}$ & $\begin{array}{c}\text { Alterar } \\
\text { ajuste }\end{array}$ \\
\hline Dispositivos & $\begin{array}{l}\text { linhas } \\
\text { trafos }\end{array}$ & cargas & $\begin{array}{l}\text { cargas } \\
\text { motores }\end{array}$ & $\begin{array}{c}\text { capacitores } \\
\text { indutores }\end{array}$ & geradores \\
\hline Barra1 & $\operatorname{sim}$ & $\operatorname{sim}$ & $\operatorname{sim}$ & $\operatorname{sim}$ & $\operatorname{sim}$ \\
\hline Barra2 & $\operatorname{sim}$ & não & não & não & não \\
\hline $\begin{array}{l}\text { Varíáveis } \\
\text { de controle }\end{array}$ & - & - & - & - & $\begin{array}{c}\text { torque } \\
\text { vref }\end{array}$ \\
\hline Ações & $\begin{array}{l}\text { colocar } \\
\text { retirar }\end{array}$ & $\begin{array}{l}\text { colocar } \\
\text { retirar }\end{array}$ & $\begin{array}{l}\text { aumentar } \\
\text { diminuir }\end{array}$ & $\begin{array}{l}\text { colocar } \\
\text { retirar }\end{array}$ & $\begin{array}{l}\text { aumentar } \\
\text { diminuir }\end{array}$ \\
\hline Valor1 & - & - & $\operatorname{taxa}[\mathrm{pu} / \mathrm{s}]$ & condutância [pu] & $\operatorname{taxa}[\mathrm{pu}]$ \\
\hline Valor2 & - & - & - & susceptância [pu] & - \\
\hline$t_{0}$ & $\operatorname{sim}$ & $\operatorname{sim}$ & $\operatorname{sim}$ & $\operatorname{sim}$ & $\operatorname{sim}$ \\
\hline$t_{f}$ & não & não & $\operatorname{sim}$ & não & não \\
\hline $\boldsymbol{k} \boldsymbol{p}^{11}$ & não & não & $\operatorname{taxa}[\mathrm{pu}]$ & não & não \\
\hline $\boldsymbol{k} \boldsymbol{q}^{12}$ & não & não & $\operatorname{taxa}[\mathrm{pu}]$ & não & não \\
\hline
\end{tabular}

${ }^{11}$ Define que porcentagem da demanda ativa, não é aplicável no caso de motores.

${ }^{12}$ Define que porcentagem da demanda reativa, não é aplicável no caso de motores.

\subsubsection{Tratamento dos limites nos controles}

Sabe-se que a instabilidade de tensão possui uma forte relação com a atuação dos controles existentes no sistema elétrico, principalmente quando esses atingem os seus limites de operação (vide exemplo no item 2.3). Assim, representar corretamente esses limites é um aspecto fundamental para avaliar dinâmicamente a estabilidade de tensão. A figura 4.7 apresenta a definição para os limites "anti-windup" encontrados em alguns tipos de controles.

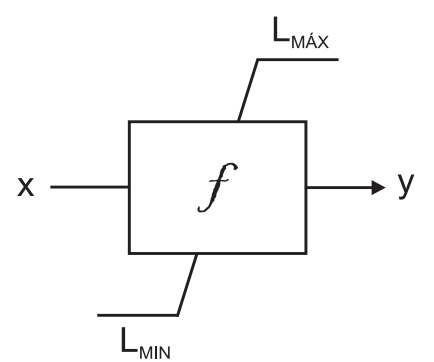

$$
\begin{aligned}
& \text { Se } L_{\text {MIN }}<y<L_{\text {MAX }} \text { então } \frac{d y}{d t}=f \\
& \text { Se } y \geq L_{\text {MAX }} \text { e } f>0 \text { então } \frac{d y}{d t}=0, y=L_{\text {MAX }} \\
& \text { Se } y \leq L_{\text {MIN }} \text { e } f<0 \text { então } \frac{d y}{d t}=0, y=L_{\text {MN }}
\end{aligned}
$$

Figura 4.7: Controlador com limites.

Observa-se que os limites "anti-windup" interrompem o processo de integração $(d y / d t=$ 0) quando a variável y atinge $L_{M I N}$ ou $L_{M A X}$ e ainda há acúmulo do termo integral ( $\boldsymbol{f}$ diferente de zero). 
Nesse trabalho verificou-se que o procedimento mencionado não é adequado para implementar os limites "anti-windup", quando se utiliza o pacote DASSLC, uma vez que a execução abrupta da condição $d y / d t=0$ gera instabilidade numérica. A fim de contornar esse problema, aplicaram-se as técnicas Tracking e FeedBack-Reset, explicadas a seguir.

A técnica denominada Tracking (ou Bloqueio do termo integral) consiste em reduzir a integração suavemente através da realimentação do valor absoluto do erro entre os de valores de $\mathbf{y}$ antes $\left(y_{1}\right)$ e depois do limitador $\left(y_{2}\right)$, conforme ilustrado na figura 4.8.

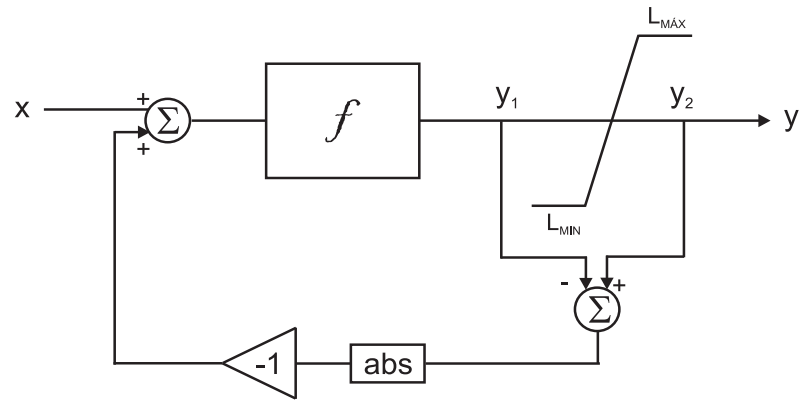

Figura 4.8: Anti-windup: técnica Tracking.

A técnica denominada FeedBack-Reset é diretamente aplicável a controladores tipo proporcionalintegral (vide figura 4.9(a)) e consiste em realizar a transformação de blocos ilustrada na figura 4.9(b). Em (FERNANDES, 2001) demonstra-se que para realizar essa transformação deve-se impor a constante de tempo $T_{I}=K_{P} / K_{I}$.

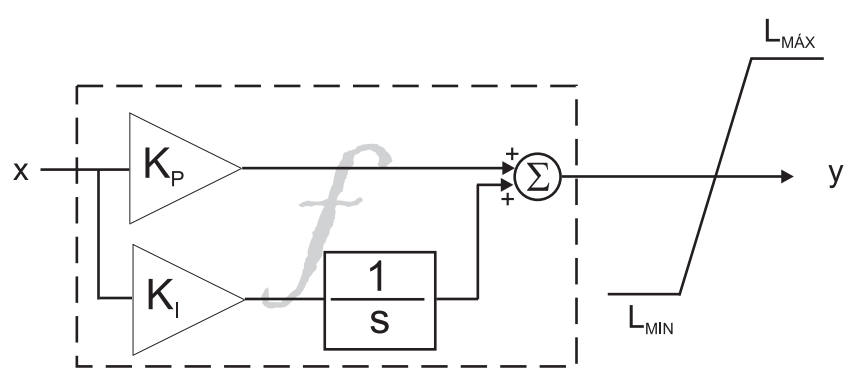

(a)

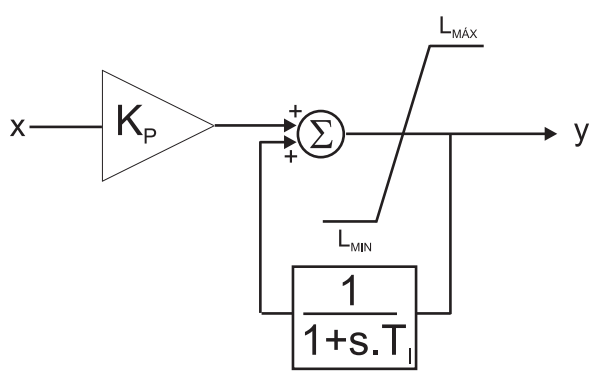

(b)

Figura 4.9: Anti-windup: técnica FeedBack-Reset.

No programa DSIM aplicam-se as duas técnicas mencionadas: os limites dos AVRs são implementados através da técnica FeedBack-Reset e os limites nos LTCs e OXLs são implementados através da técnica Tracking. 


\subsection{Resultados para o sistema de 10 barras da BPA}

Com o objetivo de validar as ferramentas descritas nos itens anteriores, apresentam-se resultados provenientes da simulação dinâmica do sistema de 10 barras da BPA, cujos resultados são amplamente divulgados e conhecidos na literatura técnica (KUNDUR, 1994; TAYLOR, 1994; CIGRE, 1995; CUTSEM; VOURNAS, 1998).

A fig. 4.10 mostra o diagrama unifilar do sistema de 10 barras da BPA. Esse sistema representa uma situação em que a maior parte do consumo total nas barras 8 e 11 (6855 MW, 1045.7 MVAr) é suprido por cinco linhas de transmissão de 500kV. O gerador localizado na barra 3 fornece apenas $1155 \mathrm{MW}$, e a potência restante é suprida pelos dois geradores, eletricamente distantes, localizados nas barras 1 e 2 .

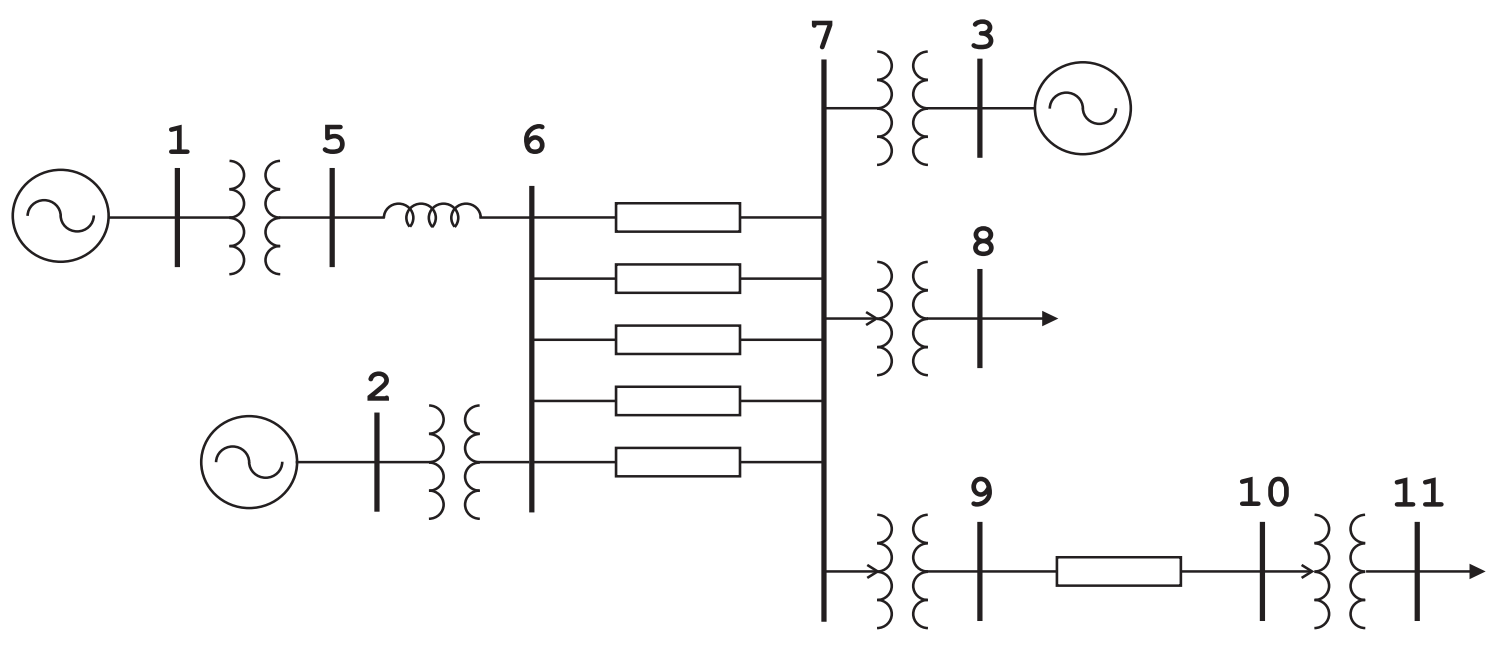

Figura 4.10: Sistema de 10 barras da BPA.

As duas cargas nas barras 8 e 11 são, respectivamente, de naturezas industrial e um misto de comercial e residencial. A área de carga possui uma grande quantidade de reserva reativa suprida por vários capacitores em derivação e, além disso, existe um gerador local de 1600 MVA na barra 3. Sabe-se que esse sistema desenvolve um cenário típico de instabilidade de tensão que evolui rapidamente para uma situação de colapso quando uma das cinco linhas de $500 \mathrm{kV}$, entre as barras 6 e 7 , é aberta sem a necessidade da ocorrência de uma falta.

Os resultados apresentados a seguir correspondem aos Casos A, B, C e D de (CIGRE, 1995) em que a representação das cargas e demais componentes desse sistema é apresentada na tabela 4.5. Os dados utilizados nas simulações encontram-se no item A.2. 
Tabela 4.5: Hipóteses adotadas na simulação do sistema BPA de 10 barras.

\begin{tabular}{|l|l|l|l|l|l|}
\hline & & Caso A & Caso B & Caso C & Caso D \\
\hline \multirow{2}{*}{ Cargas } & Barra 8 & $100 \%$ Z cte & $100 \%$ S cte & $100 \%$ S cte & $50 \%$ S cte, $50 \%$ motor \\
& Barra 11 & $100 \%$ Z cte & $100 \%$ Z cte & $100 \%$ Z cte & $100 \%$ Z cte \\
\hline \multirow{3}{*}{ Limites $I_{f d}$} & Gerador 1 & barra swing & barra swing & barra swing & barra swing \\
& Gerador 2 & limitado & limitado & limitado & limitado \\
& Gerador 3 & limitado & limitado & limitado & limitado \\
\hline \multirow{2}{*}{ LTC } & barras 10-11 & inativo & inativo & ativo & ativo \\
& demais & inativos & inativos & inativos & inativos \\
\hline
\end{tabular}

A figura 4.11(a) mostra a evolução temporal da tensão na barra 11 para os casos A e B da tabela 4.5. Nessas duas situações a estabilidade do sistema é mantida após a ocorrência da contingência. Convém ressaltar que esses resultados são próximos aos publicados em (CIGRE, 1995) cujo resultado do programa EUROSTAG encontra-se reproduzido na figura $4.11(\mathrm{~b})$.

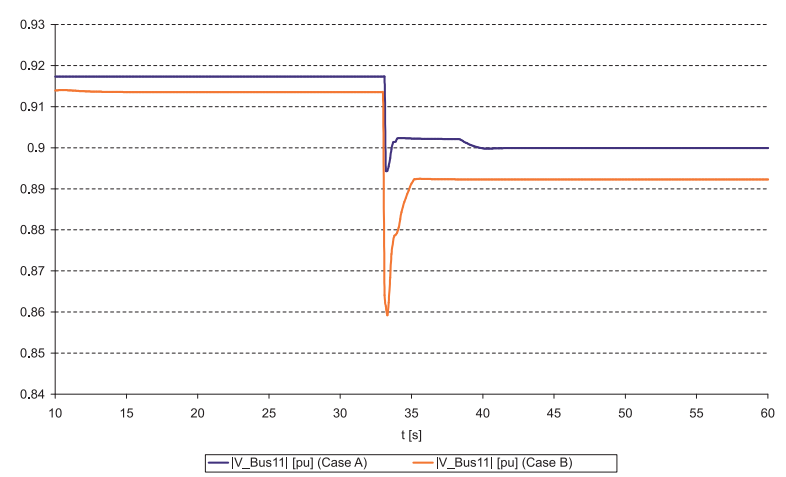

(a)

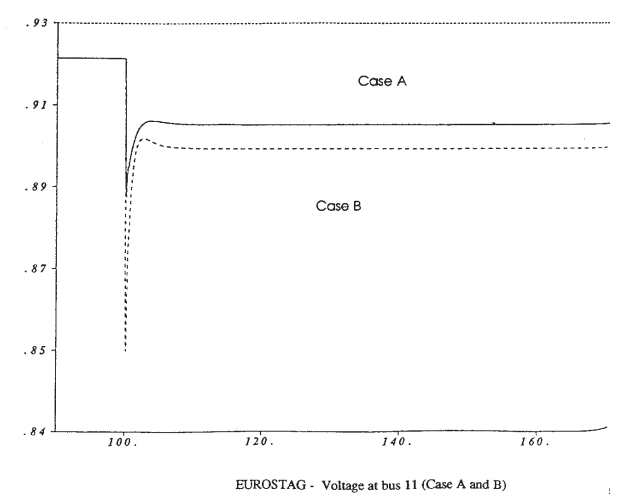

(b)

Figura 4.11: Tensão barra 11 - Casos A e B.

Convém comentar que a principal diferença existente entre as figuras 4.11(a) e (b) deve-se à condição inicial assumida para a tensão da barra 11. Na figura 4.11(a) admitiu-se que a composição da barra 11 deveria ser utilizada para o cálculo do fluxo de potência enquanto na 4.11(b) observa-se que essa hipótese não foi adotada na simulação.

A fig. 4.12 mostra a evolução temporal das tensões no primário(barra 10) e secundário(barra 11) do LTC que alimenta a carga situada na barra 11 para o caso $\mathrm{C}$ da tabela 4.5. Pode-se observar claramente que o LTC, na tentativa de sustentar a tensão na barra 11 próxima a seu valor de regime, prejudica a sua tensão primária (barra10) contribuindo para agravar a instabilidade de tensão que culmina em colapso. 


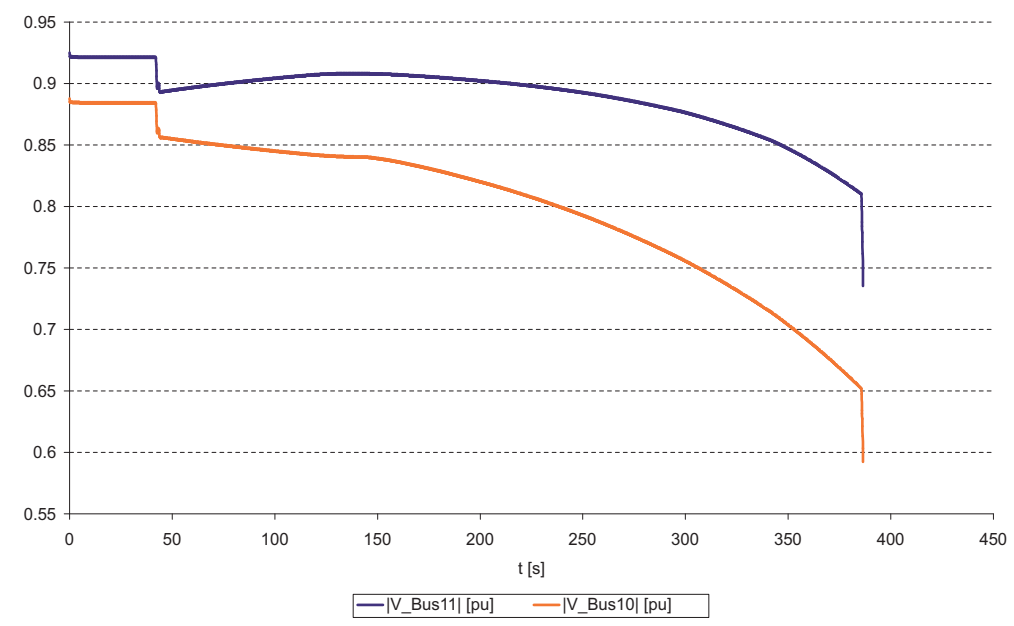

Figura 4.12: Tensões nas barra 10 e 11 - caso C.

As figuras 4.13 e 4.14 explicam a sequência de eventos que leva o sistema de uma situação de instabilidade de tensão ao colapso. A fig. 4.13 mostra que imediatamente após a contingência (em 30s) o LTC entra em operação mantendo a tensão na barra 11 próxima ao seu valor de regime até o instante $\mathrm{t}=140 \mathrm{~s}$.

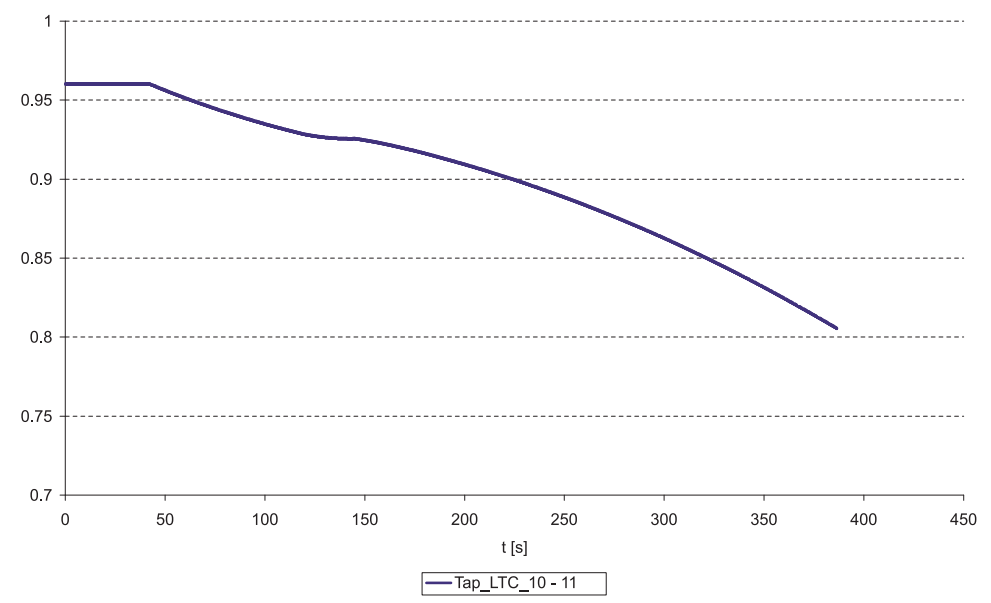

Figura 4.13: Tape do LTC 1011 - caso C.

Paralelamente, observa-se na fig. 4.14 que a contingência exige um aumento no despacho de reativos do gerador local (barra 3). Esse supre essa demanda adicional até o instante $\mathrm{t}=140 \mathrm{~s}$, quando o seu OXL limita em definitivo a sua capacidade de suprir reativos para as cargas. A partir desse instante $(\mathrm{t}=140 \mathrm{~s})$, a potência reativa adicional exigida pelas cargas não pode mais ser suprida somente pelo gerador local e o gerador remoto (barra 2) assume o fornecimento de parte desses reativos. Como o gerador remoto está eletricamente distante das cargas, o envio de reativos torna-se ineficiente e observa-se uma queda progressiva das tensões nas barras de carga até a situação de colapso. O processo 
é agravado pelo LTC que torna a atuar a partir de $\mathrm{t}=143 \mathrm{~s}$ acelerando o declínio de sua tensão primária (barra 10) e tornando o suporte reativo dos capacitores de derivação localizados nas barras 7, 8 e 9 ineficazes (vide dados do sistema no item A.2).

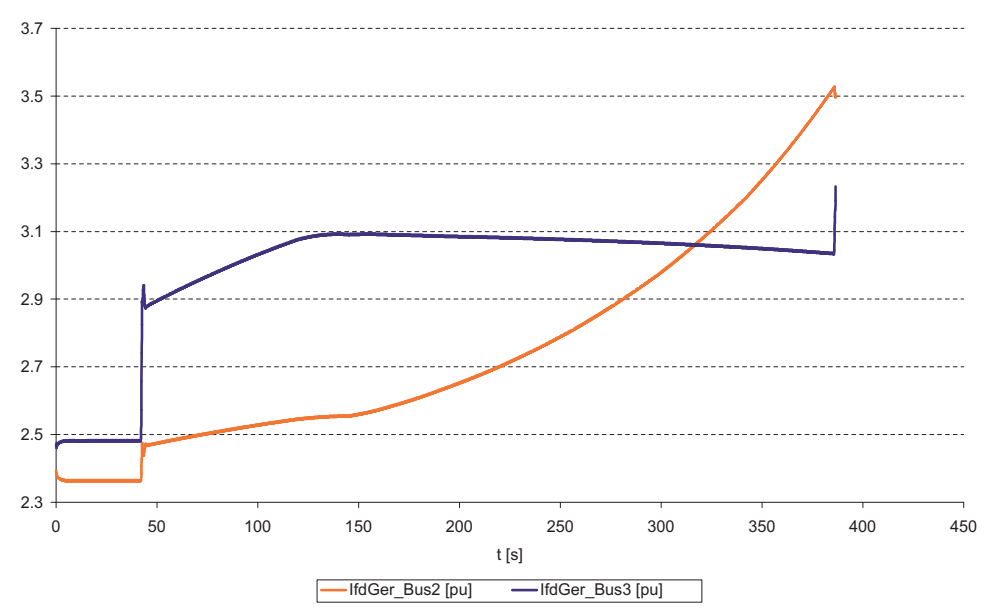

Figura 4.14: Correntes de campo geradores 2 e 3 - caso C.

Ao mudar a composição da carga na barra 8 de $100 \%$ potência constante (Caso C) para $50 \%$ potência e $50 \%$ motor (Caso D) verifica-se que o sistema tende ao colapso de tensão segundo uma seqüência de eventos bastante similar à descrita anteriormente, porém observa-se que o colapso de tensão é atingido mais rapidamente devido à alta porcentagem de motores na barra 8, vide fig. 4.15 .

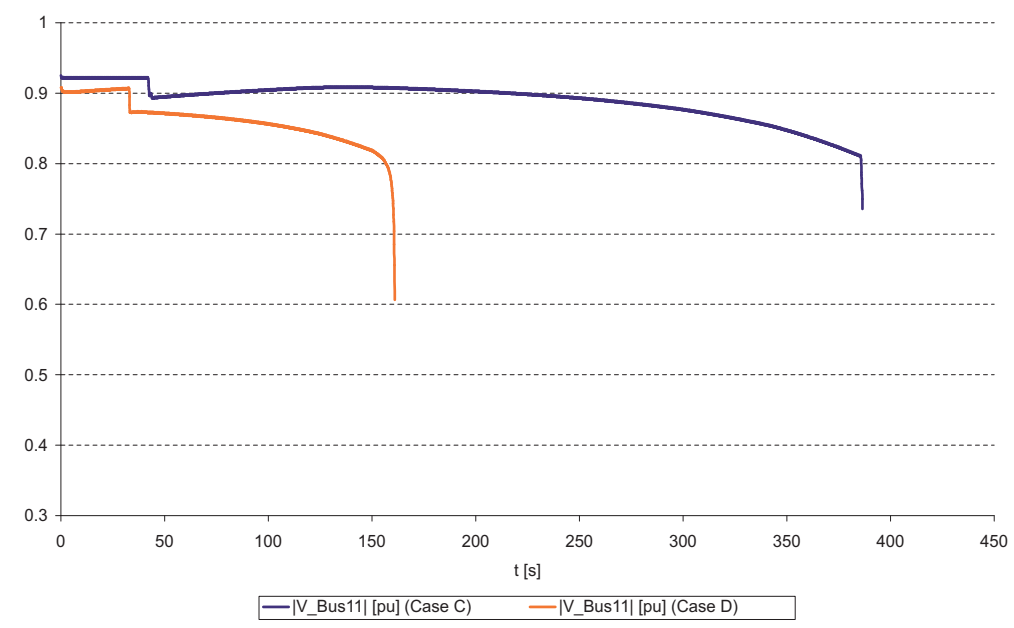

Figura 4.15: Tensão na barra 11 - casos C e D.

As figs. 4.16 e 4.17 mostram a alta sensibilidade dos motores com a tensão de alimentação. Nas figs. 4.16 e 4.17, observa-se o aumento progressivo da corrente absorvida pelo motor a medida que sua velocidade rotórica diminui. Não há variação no torque mecânico na 
fig. 4.16, uma vez que admite-se torque constante para a carga mecânica.

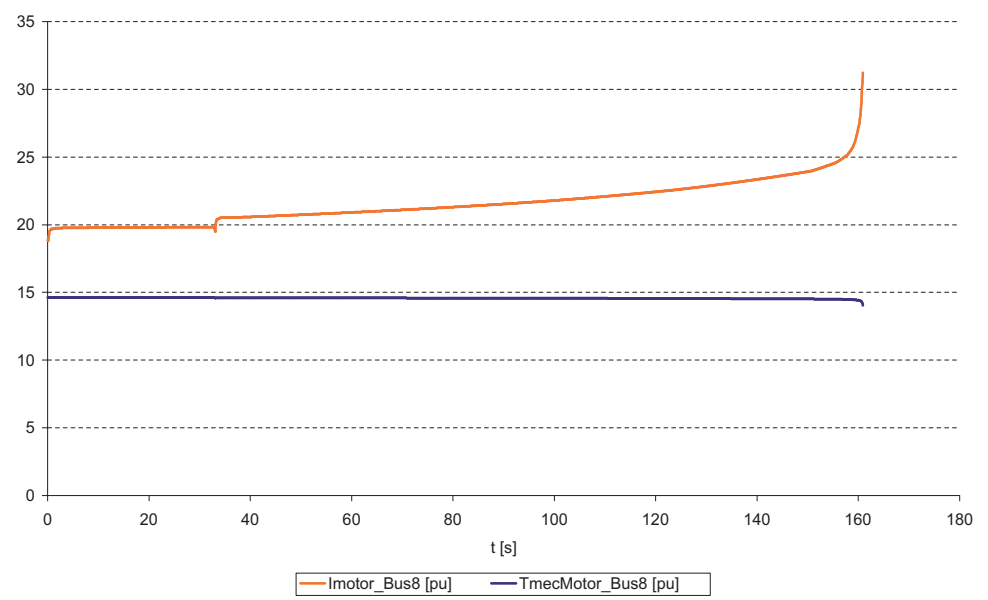

Figura 4.16: Torque e corrente do motor - caso D.

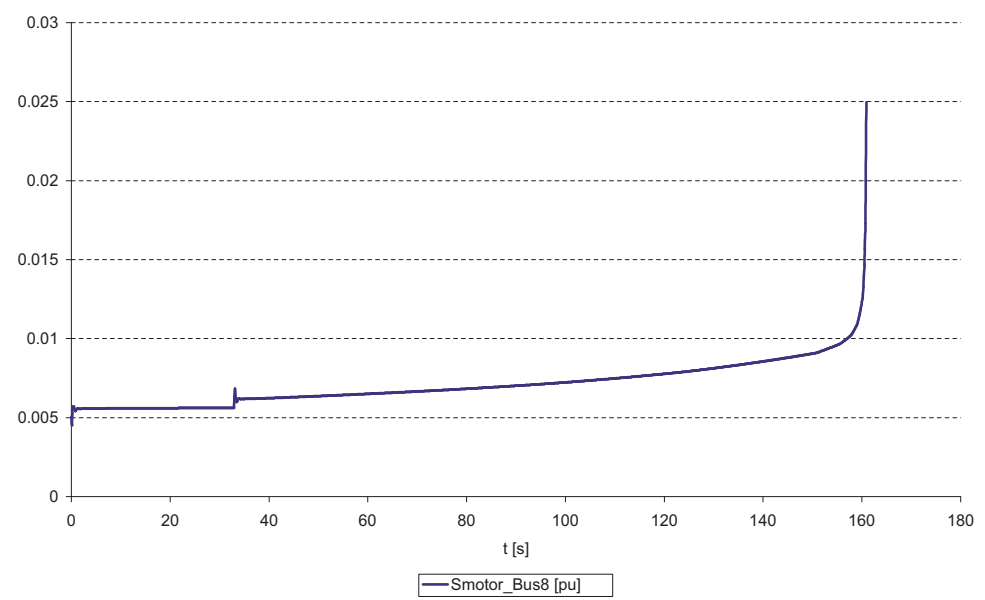

Figura 4.17: Escorregamento do motor - caso D.

Convém ressaltar que os resultados apresentados são próximos aos publicados em (CIGRE, 1995). As principais diferenças entre os resultados desse trabalho e os publicados relacionam-se aos intervalos de tempo entre os eventos, fato esse observado também entre os próprios simuladores dinâmicos contemplados em (CIGRE, 1995). Convém ressaltar que esse fato não invalida o simulador dinâmico implementado, uma vez que esse mostra-se capaz de reproduzir de forma satisfatória a dinâmica observada em fenômenos de instabilidade de tensão. 


\section{Análise de estabilidade de tensão utilizando modelos de carga estáticos e dinâmicos}

\subsection{Objetivos}

Este capítulo tem por objetivo avaliar a influência atribuída à interação entre os dispositivos existentes no sistema elétrico e os modelos de carga apresentados no item 4.2.3 sobre a estabilidade de tensão do sistema. Inicialmente, utilizam-se sistemas de apenas duas e três barras para apresentar alguns aspectos relacionados ao comportamento da carga e como cada um deles pode impactar de forma favorável ou não para a melhoria da estabilidade do sistema. Posteriormente, essa análise é estendida para o sistema de 14 barras do IEEE.

\subsection{Alguns aspectos sobre o comportamento da carga}

Sabe-se que o comportamento da carga analisado a partir de um transformador de subestação reflete a ação de um grande número de cargas individuais, alimentadas através de troncos e ramais de distribuição, além de uma série de outros equipamentos, como: transformadores de distribuição, capacitores chaveados, reguladores de tensão entre outros, conforme ilustrado na figura 5.1.

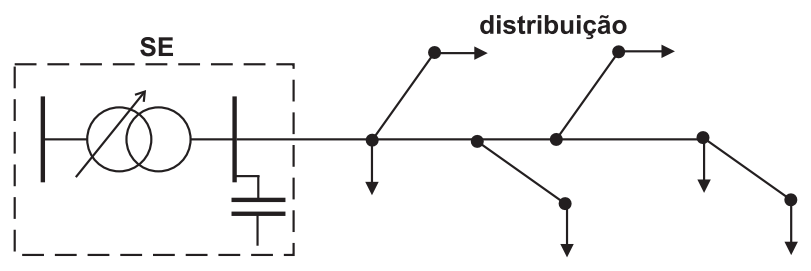

Figura 5.1: Diagrama unifilar simplificado de um transformador de subestação. 
A presença dessa diversidade de dispositivos, aliada ao fato de que o comportamento da carga é sensível a fatores como: estações do ano, situação do clima, hábitos de consumo durante dias de semana e finais de semana ou durante o dia e a noite entre outros, tornam a modelagem da carga um problema bastante difícil de ser resolvido. Apesar dessas dificuldades, o trabalho proposto por Hill (HILL, 1993) identifica a dependência dinâmica entre as potências ativa e reativa consumidas pela carga e sua tensão de alimentação, conforme ilustrado na figura $5.2^{1}$.

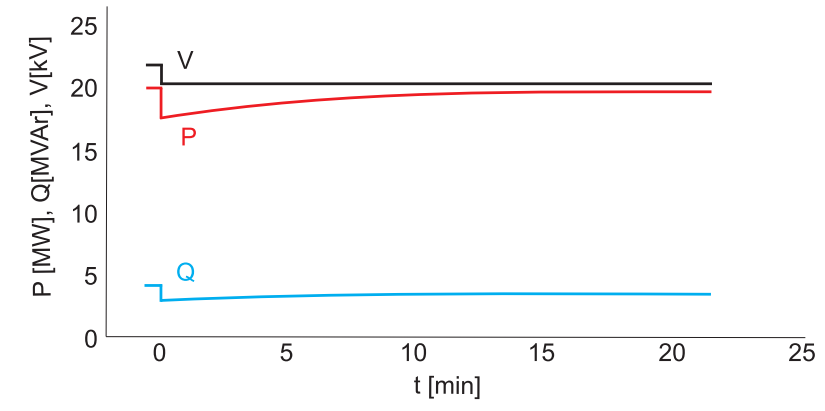

Figura 5.2: Comportamento dinâmico da carga.

A figura 5.2 ilustra uma tendência exponencial para os consumos de potência ativa e reativa da carga quando a mesma é submetida a um degrau de tensão. Baseado nesse fato, Hill propôs um modelo, vide equações (4.17) e (4.19), capaz de reproduzir esse comportamento utilizando como parâmetros as seguintes sensibilidades: potência ativa-tensão em regime permanente $\left(\alpha_{S}\right)$, potência ativa-tensão transitória $\left(\alpha_{T}\right)$, potência reativa-tensão em regime permanente $\left(\beta_{S}\right)$ e potência reativa-tensão transitória $\left(\beta_{T}\right)$. Estas sensibilidades, expressas através das equações (5.1) e (5.2), são obtidas através de medições de campo. Basicamente o processo consiste em aplicar diversos degraus de tensão na carga, através da mudança gradual do tape de um dos transformadores da subestação, e realizar medições a fim de determinar as sensibilidades e constantes de tempo definidas nas equações (4.17) e (4.19).

$$
\begin{aligned}
& \alpha=\frac{d P / P_{0}}{d V / V_{0}} \\
& \beta=\frac{d Q / Q_{0}}{d V / V_{0}}
\end{aligned}
$$

onde: $V_{0}, P_{0}$ e $Q_{0} \quad$ são, respectivamente, a tensão e as potências ativa e reativa da carga em sua condição normal de operação;

$d V, d P$ e $d Q$ são, respectivamente, a variação de tensão aplicada na carga e as variações de potência ativa e reativa medidas.

\footnotetext{
${ }^{1}$ Fonte: (KARLSSON, 1992).
} 
Uma vez determinados todos esses parâmetros, a dependência dinâmica entre as potências ativa e reativa consumidas pela carga, conhecida na literatura por load recovery, é aproximada pelo modelo Hill através de uma tendência exponencial, detalhada na figura 5.3.

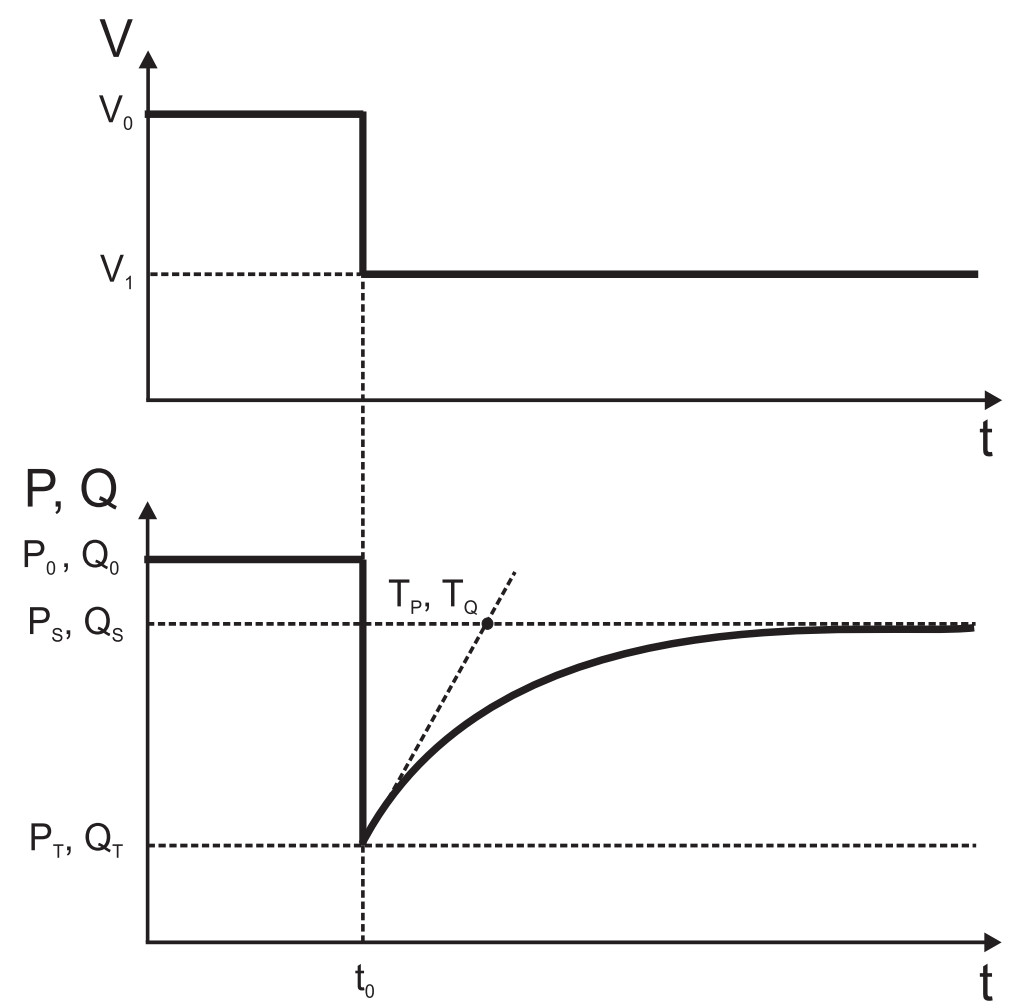

Figura 5.3: Load Recovery - Modelo Hill.

A figura 5.3 mostra uma carga, representada pelo modelo Hill, inicialmente alimentada em um nível de tensão $V_{0}$ e consumindo as potências ativa e reativa $P_{0}$ e $Q_{0}$. Quando a tensão que alimenta a carga sofre uma queda para $V_{1}$, as potências ativa e reativa consumidas assumem, instantaneamente, os valores transitórios $P_{T}$ e $Q_{T}$, segundo o comportamento definido pelas sensibilidades $\alpha_{T}$ e $\beta_{T}$. Somente decorridos cerca de dois terços de $T_{P}$ e $T_{Q}$, as potências ativa e reativa consumidas pela carga estabilizam-se nos valores $P_{S}$ e $Q_{S}$, segundo o comportamento definido pelas sensibilidades $\alpha_{S}$ e $\beta_{S}$. Assim, por exemplo, torna-se possível simular cargas que comportam-se transitoriamente como corrente constante $\left(\alpha_{T}=\beta_{T}=1\right)$ porém, devido às diferentes dinâmicas dos dispositivos existentes no sistema de distribuição, têm seus consumos de potência ativa e reativa restaurados segundo um comportamento de impedância constante $\left(\alpha_{S}=\beta_{S}=2\right)$.

Nesse ponto convém ressaltar que o fenômeno de load recovery, anteriormente descrito, não é necessariamente observado em todas as barras de carga do sistema de transmissão. 
Assim, existem também cargas que apresentam resposta instantânea a eventuais quedas ou aumentos de tensão, como por exemplo cargas compostas predominantemente por lâmpadas incandescentes e florescentes, fornos elétricos a arco, processos industriais que envolvem eletrólise entre outros (TAYLOR, 1994; CUTSEM; VOURNAS, 1998). Tais tipos de carga são bem representadas pelos modelos de carga estáticos ZIP, vide equações (4.15) e (4.16), e exponencial, vide equações (4.13) e (4.14), apresentados no item 4.2.3.1.

Recentemente, o trabalho de Navarro (NAVARRO, 2005) deu continuidade ao trabalho de Hill (KARLSSON, 1992) analisando a adequação desse modelo para representar o comportamento das cargas em sistemas de potência. As principais contribuições de (NAVARRO, 2005) são: a proposição de uma metodologia automática para identificar os parâmetros dos modelos dinâmicos de carga através de medições, a constatação da inadequação do modelo proposto por Hill para representar o comportamento da carga quando sua tensão de alimentação apresenta afundamentos superiores a $5 \%$ e a recomendação do modelo proposto por Ihara, vide equações (4.21), (4.22), (4.23) e (4.24), para afundamentos de tensão entre $5 \%$ e $30 \%$. Nesse contexto, o presente trabalho contribui com a literatura analisando eventuais diferenças nas avaliações de estabilidade de tensão decorrentes da aplicação de cada um dos dois modelos citados.

As figuras 5.4 e 5.5 mostram, respectivamente, as respostas desses dois modelos para um degrau na tensão de alimentação igual a 30\%. Os parâmetros utilizados nos cenários apresentados são típicos, vide (IHARA; TANI; TOMIYAMA, 1994) e (NAVARRO, 2005), e encontram-se na tabela 5.1.

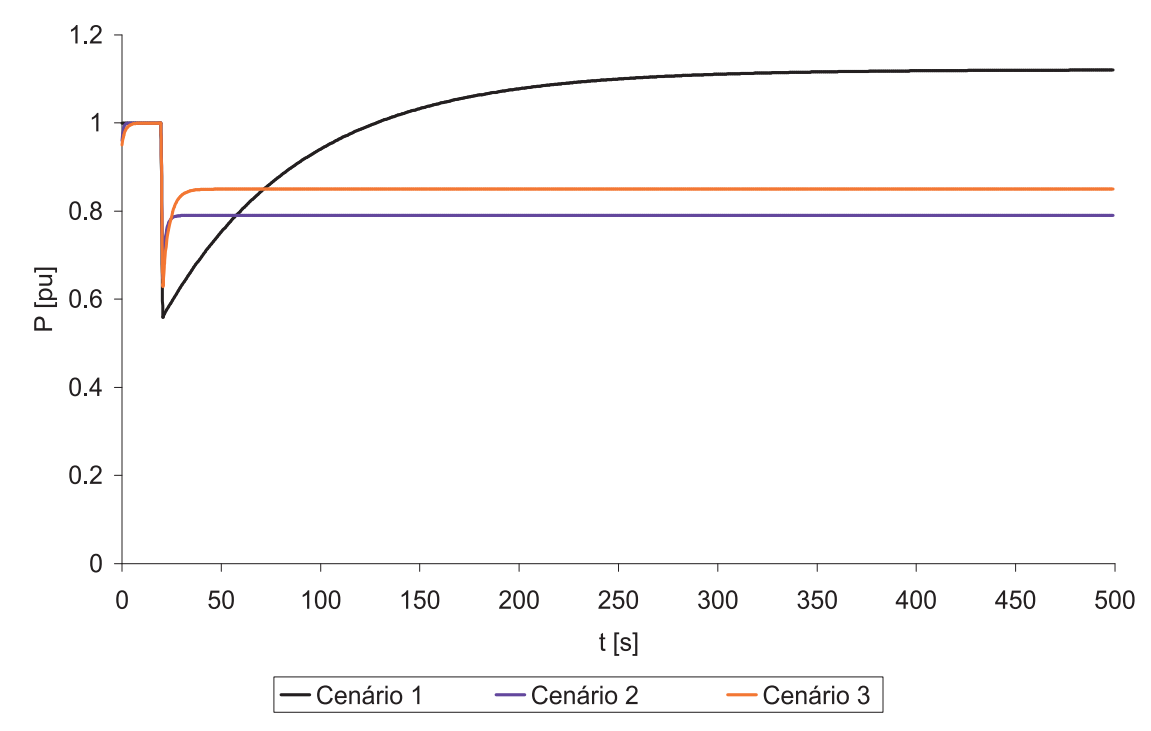

Figura 5.4: Comportamento da Potência ativa para $\Delta \mathrm{V}=30 \%$ 


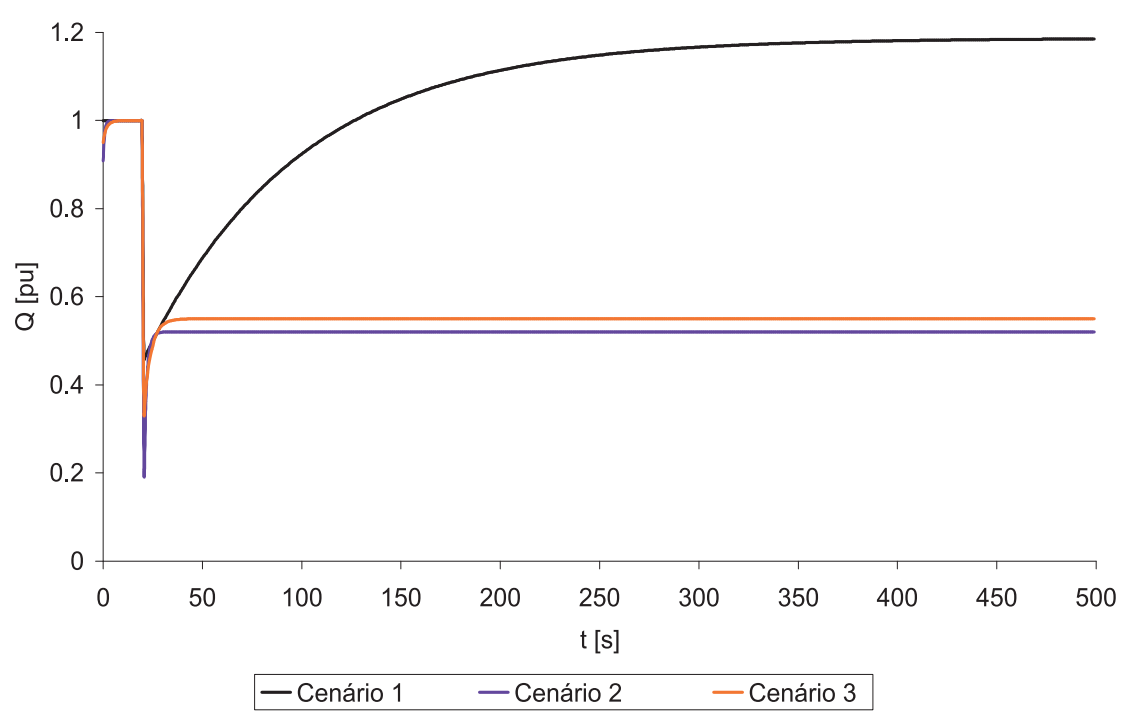

Figura 5.5: Comportamento da Potência reativa para $\Delta \mathrm{V}=30 \%$

Tabela 5.1: Parâmetros utilizados nos modelos Hill e Ihara.

\begin{tabular}{|c|c|c|c|c|c|c|c|}
\hline Cenário & Modelo & $T_{p}[\mathrm{~s}]$ & $\alpha_{S}$ ou $K_{p}$ & $\alpha_{T}$ ou $P_{d y n}$ & $T_{q}[\mathrm{~s}]$ & $\beta_{S}$ ou $K_{q}$ & $\beta_{T}$ ou $Q_{\text {dyn }}$ \\
\hline 1 & Hill & 70 & -0.32 & 1.65 & 78 & -0.48 & 2.22 \\
\hline 2 & Ihara & 0.7 & 0.7 & 0.4 & 0.7 & 1.6 & 0.917 \\
\hline 3 & Ihara & 1.7 & 0.5 & 0.5 & 1.7 & 1.5 & 0.5 \\
\hline
\end{tabular}

Segundo (NAVARRO, 2005), o modelo Hill é inadequado para representar o comportamento da carga nessa situação. De fato, vê-se claramente nas figuras 5.4 e 5.5 que o modelo Ihara apresenta constantes de tempo bem inferiores ao modelo Hill. Além disso, após alguns testes efetuados com ambos os modelos, contatou-se que, dentro da faixa de parâmetros típicos, o modelo Ihara é capaz de representar quedas transitórias mais acentuadas na potência reativa absorvida pela carga, fato esse observado em cargas compostas por uma porcentagem significativa de motores quando submetidas a quedas de tensão severas.

\subsection{Impacto das sensibilidades da carga sobre a esta- bilidade de tensão}

Nesse item analisa-se o impacto das sensibilidades em regime permanente e transitória da carga sobre a estabilidade de tensão do sistema. Para isso, utiliza-se a rede de transmissão ilustrada na figura 5.6 e verifica-se o comportamento da carga frente à ocorrência de uma contingência simples. Os parâmetros elétricos dessa rede encontram-se no item A.3. 


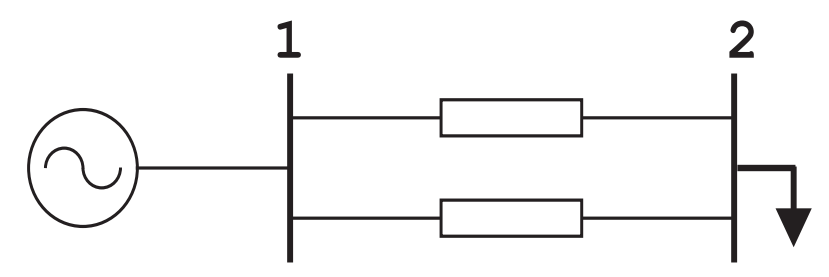

Figura 5.6: Sistema de duas barras.

\subsubsection{Impacto das sensibilidades em regime permanente $\left(\alpha_{S}\right.$ e $\left.\boldsymbol{\beta}_{S}\right)$}

Para essa análise, utiliza-se o modelo estático exponencial, vide equações (4.13) e (4.14), e traça-se a sua resposta em regime permanente ${ }^{2}$ para diferentes valores de $\alpha_{S}$ sobre as curvas PV da rede para as situações de pré e pós-contingência. A figura 5.7 sintetiza os resultados obtidos.

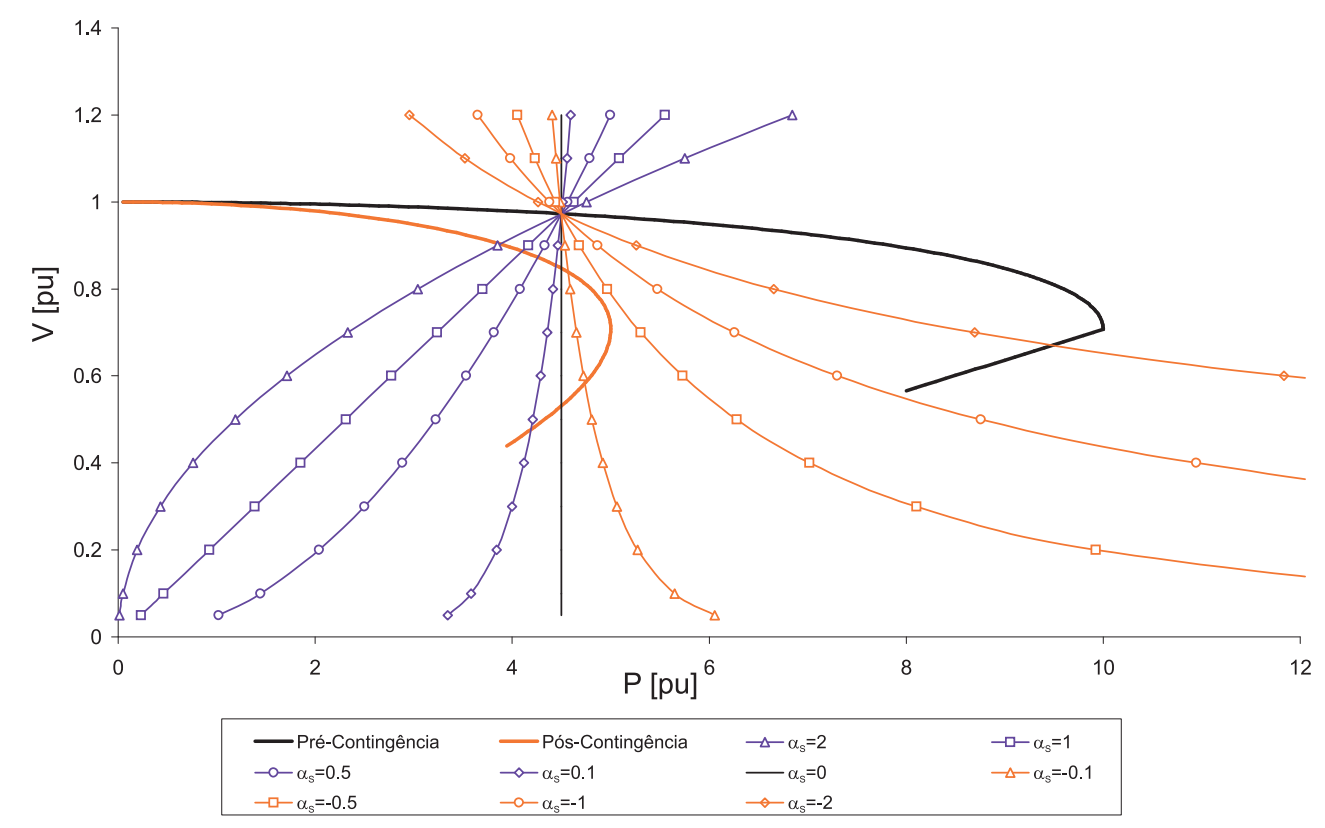

Figura 5.7: Impacto das sensibilidades em regime permanente $\left(\alpha_{S}\right)$.

Analisando a figura 5.7, percebe-se que as respostas da carga correspondentes aos $\alpha_{S}$ positivos (em azul) correspondem a cenários mais estáveis, uma vez que sempre existe um ponto de equilíbrio que intercepta a curva PV na situação de pós-contingência. O mesmo não se verifica para os $\alpha_{S}$ negativos (em vermelho), uma vez que somente a resposta correspondente a $\alpha_{S}=-0.1$ intercepta a curva PV. Essa observação pode ser generalizada para todos os modelos de carga, uma vez que valores negativos de $\alpha_{S}$ e $\beta_{S}$ correspondem

\footnotetext{
${ }^{2}$ Funções: $P(V)=P_{0} \cdot\left(\frac{V}{V_{0}}\right)^{\alpha_{S}}$
} 
a situações em que a potência restaurada pós-distúrbio possui magnitude superior ao valor consumido antes do distúrbio. Normalmente, valores negativos de $\alpha_{S}$ e $\beta_{S}$ estão relacionados à existência de um ou mais dispositivos para restauração da carga (como LTCs e reguladores de tensão) na rede de distribuição.

\subsubsection{Impacto das sensibilidades transitórias $\left(\alpha_{T}\right.$ e $\left.\beta_{T}\right)$}

Para essa análise, utiliza-se o modelo dinâmico de Hill, fixando $\alpha_{S}$ em -0.1 (curva azul "lisa" da figura 5.8). A seguir, traça-se a sua resposta em regime transitório ${ }^{3}$ para diferentes valores de $\alpha_{T}$ sobre as curvas PV de pré e pós-contingência e a curva $\alpha_{S}=-0.1$, que corresponde ao ponto de equilíbrio pós-distúrbio. A figura 5.8 apresenta os resultados obtidos.

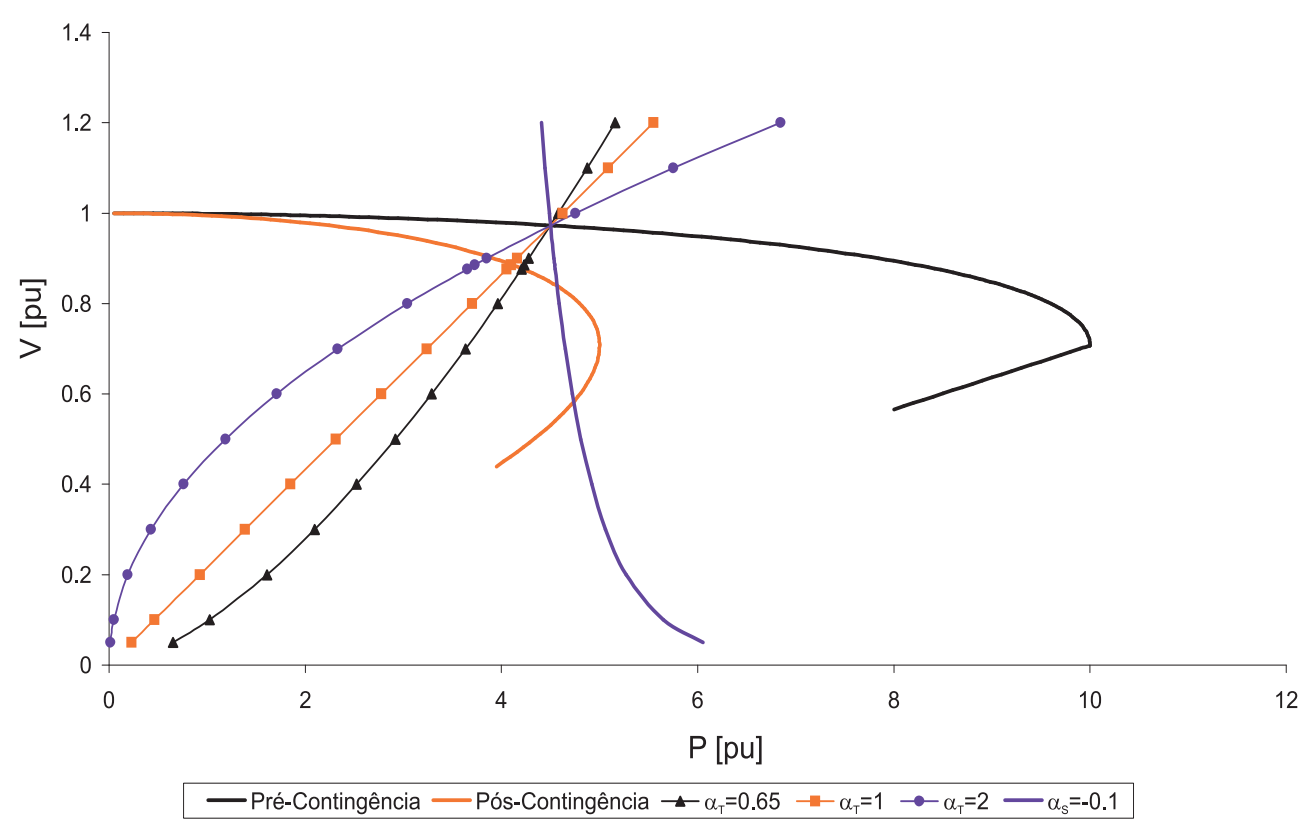

Figura 5.8: Impacto das sensibilidades em regime transitório $\left(\alpha_{T}\right)$.

Observando a figura 5.8 percebe-se que, instantaneamente após a contingência, o ponto de operação do sistema é definido pela intersecção das respostas transitórias da carga $\left(\alpha_{T}=0.65, \alpha_{T}=1\right.$ e $\left.\alpha_{T}=2\right)$ com a curva PV de pós-contingência. Durante a constante de tempo $T_{P}$, o ponto de operação desloca-se sobre a curva PV pós-contingência até atingir o ponto de operação em regime permanente, definido pela intersecção dessa com a curva $\alpha_{S}=-0.1$. Observa-se que quando mais o valor de $\alpha_{T}$ se aproxima do valor de $\alpha_{S}$, menor é a queda transitória da potência absorvida pela carga, vide figura 5.9.

\footnotetext{
${ }^{3}$ Funções: $P(V)=P_{0} \cdot\left(\frac{V}{V_{0}}\right)^{\alpha_{T}}$
} 


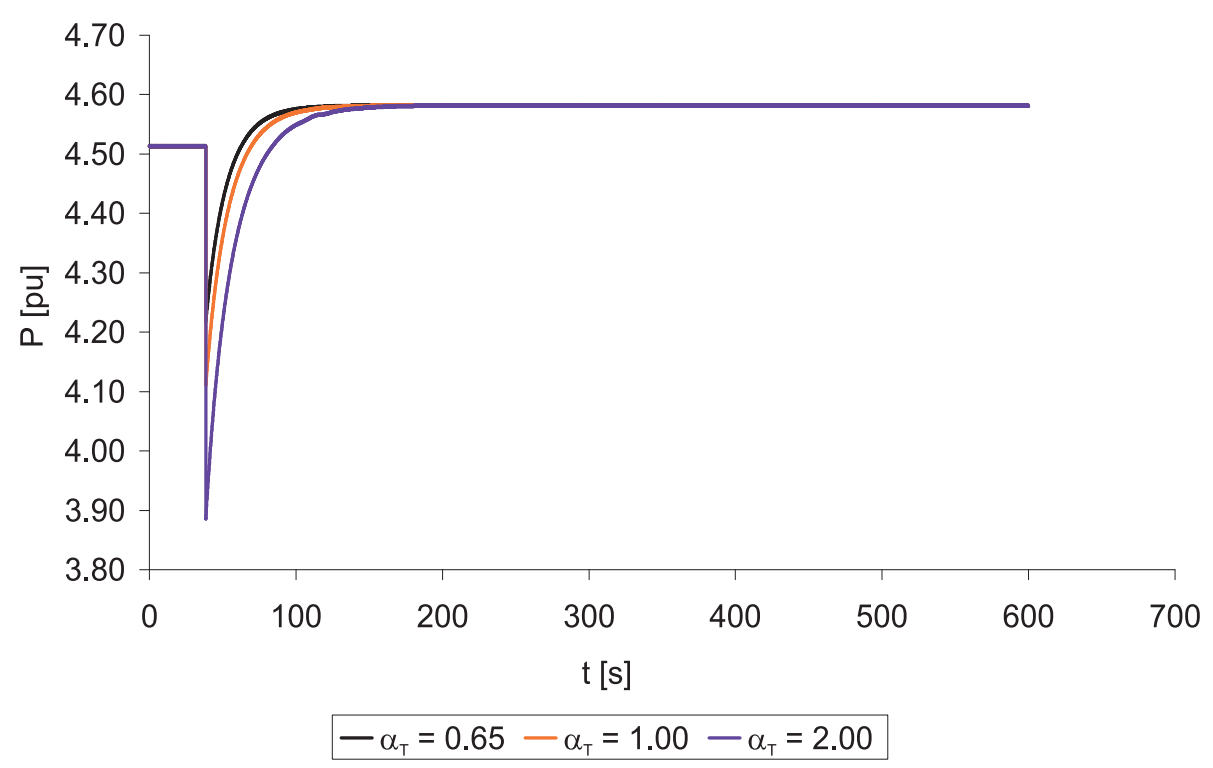

Figura 5.9: Potência absorvida pela carga para diferentes valores de $\alpha_{T}$.

Esse fato ilustra a dificuldade em se definir critérios para a tomada de ações preventivas e/ou corretivas, como por exemplo: corte de parte da carga ou adição de suporte reativo local, frente a um cenário de instabilidade de tensão. Vê-se, claramente, que a característica da carga é capaz de influenciar o comportamento do sistema de tal forma que uma situação de colapso pode ser atingida sem que alguns sintomas típicos de sua deterioração (no caso, a queda repentina da potência consumida pelas cargas) sejam observados pelos operadores. Neste ponto convém ressaltar que, independentemente dos indicadores utilizados para detectar a aproximação de um colapso de tensão, qualquer ação preventiva ou corretiva deve garantir a existência de um ponto de operação em regime permanente (intersecção da curva $\alpha_{S}$ com a curva PV pós-contingência). Considerações relacionadas à velocidade de disparo dessas ações são completamente ineficazes caso essa condição não seja satisfeita.

Com o intuito de aferir a análise discutida nesse item, simulou-se dinamicamente uma contingência simples no sistema de duas barras da figura 5.6 utilizando o modelo Ihara com os seguintes parâmetros $K_{P}=-0.1, P_{d y n}=0.8$ e $P_{d r o p}=0$. A figura 5.10 mostra o resultado obtido para essa simulação sobre um diagrama similar ao da figura 5.8. Convém ressaltar que calcularam-se as sensibilidades $\alpha_{S}=-0.09$ e $\alpha_{T}=1.55$ para o modelo Ihara utilizando a equação (5.1) sobre as respostas $V(t)$ e $P(t)$ da carga obtidas da simulação dinâmica. 


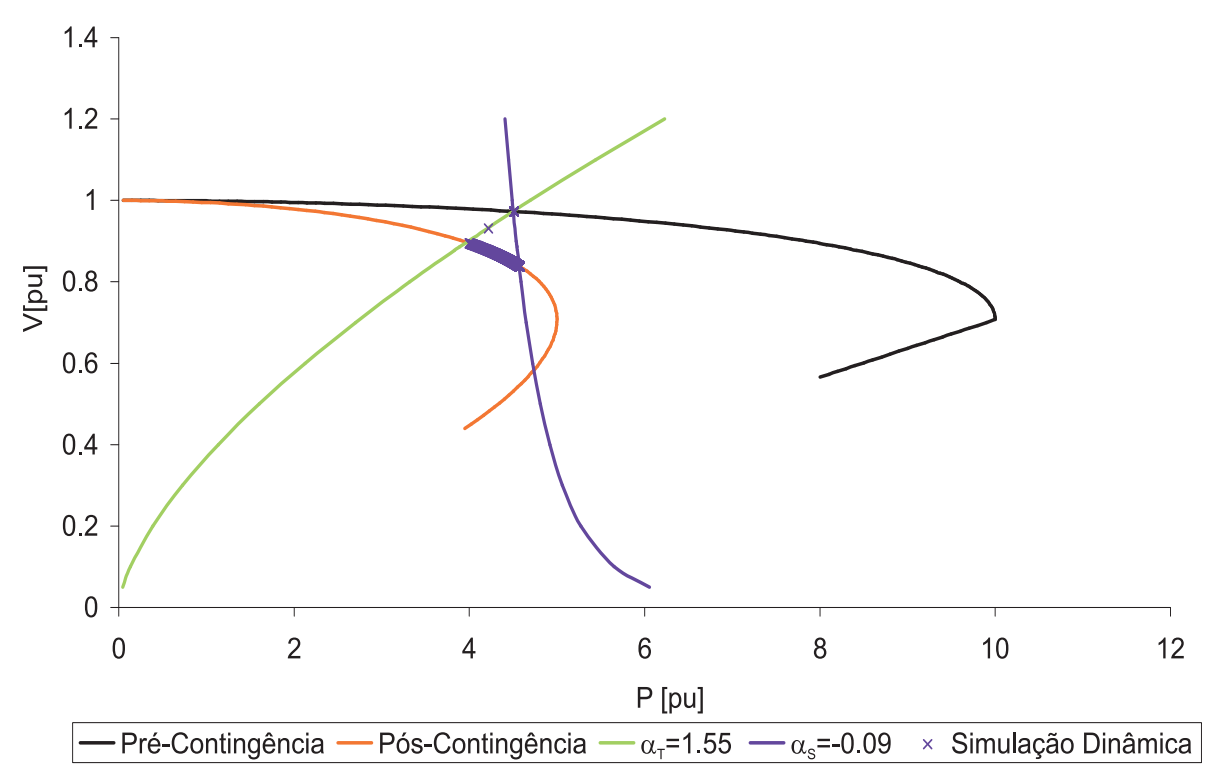

Figura 5.10: Análise estática vs dinâmica do mecanismo de load recovery.

\subsection{Impacto dos controles sobre a resposta transitória da carga}

Nessa seção discute-se o impacto dos controles existentes no sistema sobre a interação entre a carga e a rede elétrica. Para isso, utiliza-se o sistema de três barras, apresentado na seção 2.3 (vide figura 2.1), e procede-se a uma análise similar à apresentada na seção 5.3. Para essa análise utiliza-se um modelo dinâmico de carga Hill com os seguintes parâmetros: $\alpha_{S}=-0.1, \alpha_{T}=2.0, \beta_{S}=0.4, \beta_{T}=3.0$ e $T_{P}=T_{Q}=10 \mathrm{~s}$.

As figuras 5.11, 5.12, 5.13 e 5.14 ilustram as comparações entre as análises estáticas e as simulações dinâmicas para uma contingência em uma das linhas situadas entre as barras 1 e 3 supondo os dois cenários: no primeiro o gerador situado na barra 2 fornece reativos para a carga normalmente e no segundo há uma limitação no fornecimento de reativos do gerador devido aos limites de operação do AVR. Nesse ponto convém ressaltar que:

- as curvas identificadas como "Pré-contingência" e "Pós-contingência" são provenientes de um fluxo de potência continuado (utilizando o programa UWPFLOW) adotando um modelo de impedância constante para a carga localizada na barra 4;

- as curvas identificadas como "Pré-FLOW" e "Pós-FLOW" resultam das simulações de fluxos de potência sucessivos (utilizando o programa FLOW) adotando um modelo tipo exponencial, com $\alpha_{S}=-0.1$ e $\beta_{S}=0.4$, para a carga localizada na barra 4 . 
As figuras 5.11 e 5.12 mostram as curvas PV e QV na barra 4, obtidas para uma situação em que o AVR mantém o controle sobre a tensão na barra 2. Observa-se nas duas figuras que, imediatamente após a contingência, as potências ativa e reativa consumidas pela carga seguem as trajetórias definidas pela sua característica transitória $\left(\alpha_{T}\right.$ e $\left.\beta_{T}\right)$ e pela curva "Pós-FLOW".

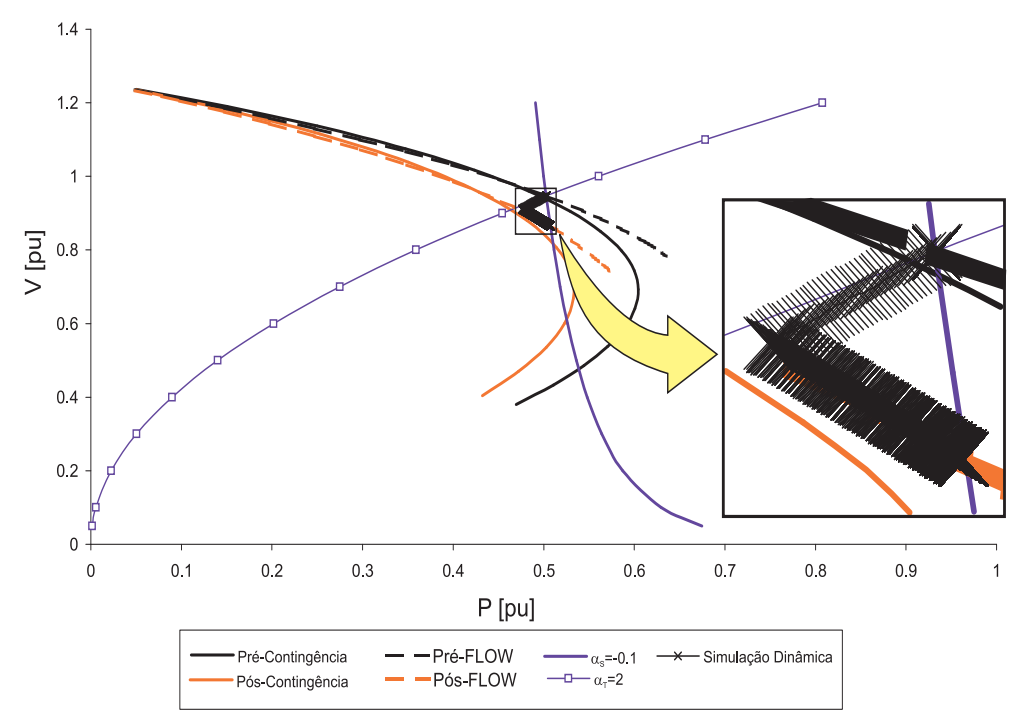

Figura 5.11: Mecanismo de load recovery da potência ativa - ação irrestrita do AVR.

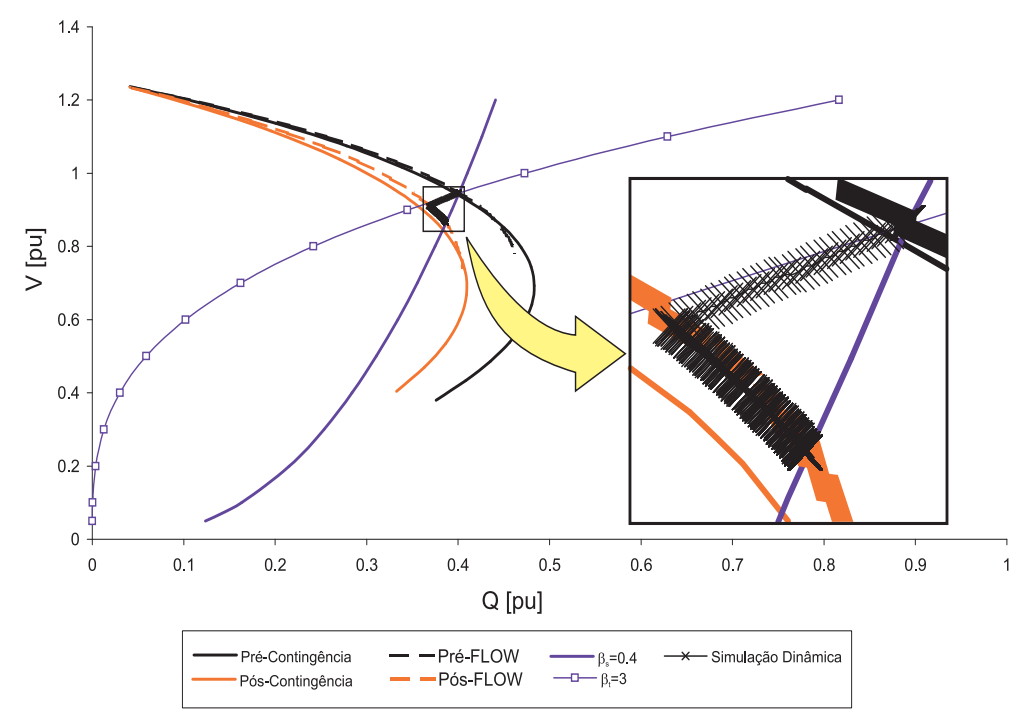

Figura 5.12: Mecanismo de load recovery da potência reativa - ação irrestrita do AVR.

Esse comportamento é esperado uma vez que a carga "enxerga" uma tensão fixa na barra do gerador, e assim os sucessivos pontos de equilíbrio calculados na simulação dinâmica equivalem ao resultado de um fluxo de potência que contempla um modelo de carga exponencial suprido por uma barra PV e uma barra swing. 
As figuras 5.13 e 5.14 mostram as curvas PV e QV na barra 4, para uma situação em que o AVR perde o controle sobre a tensão na barra 2, devido a uma restrição de seus limites operacionais. Observa-se nas duas figuras que, imediatamente após a contingência, as potências ativa e reativa consumidas pela carga seguem as trajetórias definidas pela sua característica transitória ( $\alpha_{T}$ e $\left.\beta_{T}\right)$ e pela curva "Pós-contingência".

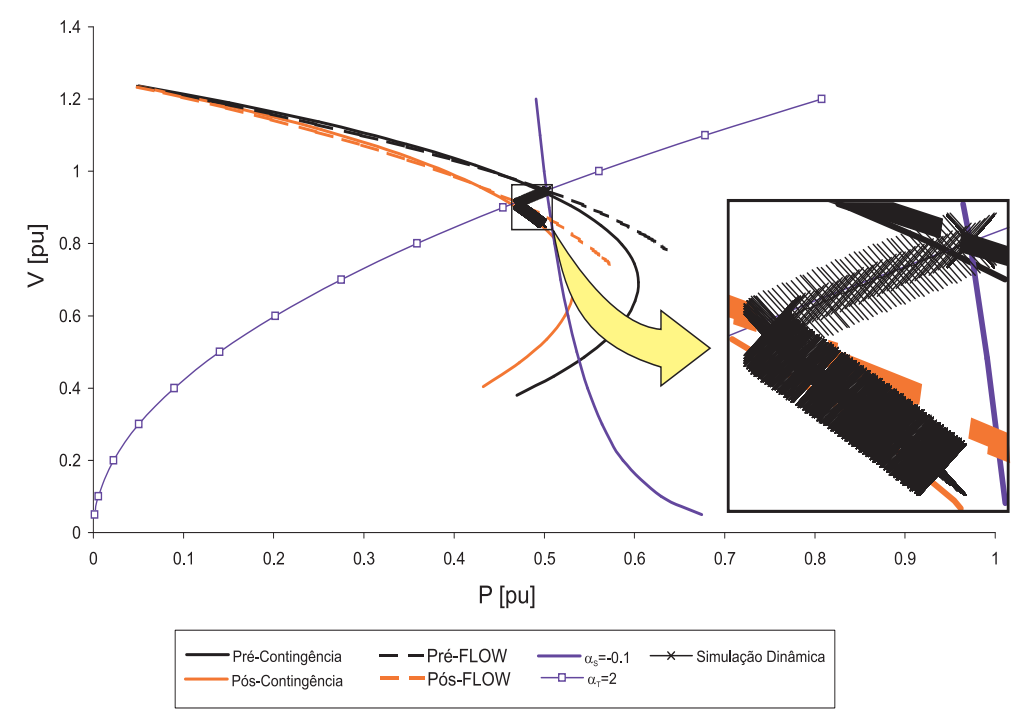

Figura 5.13: Mecanismo de load recovery da potência ativa - ação limitada do AVR.

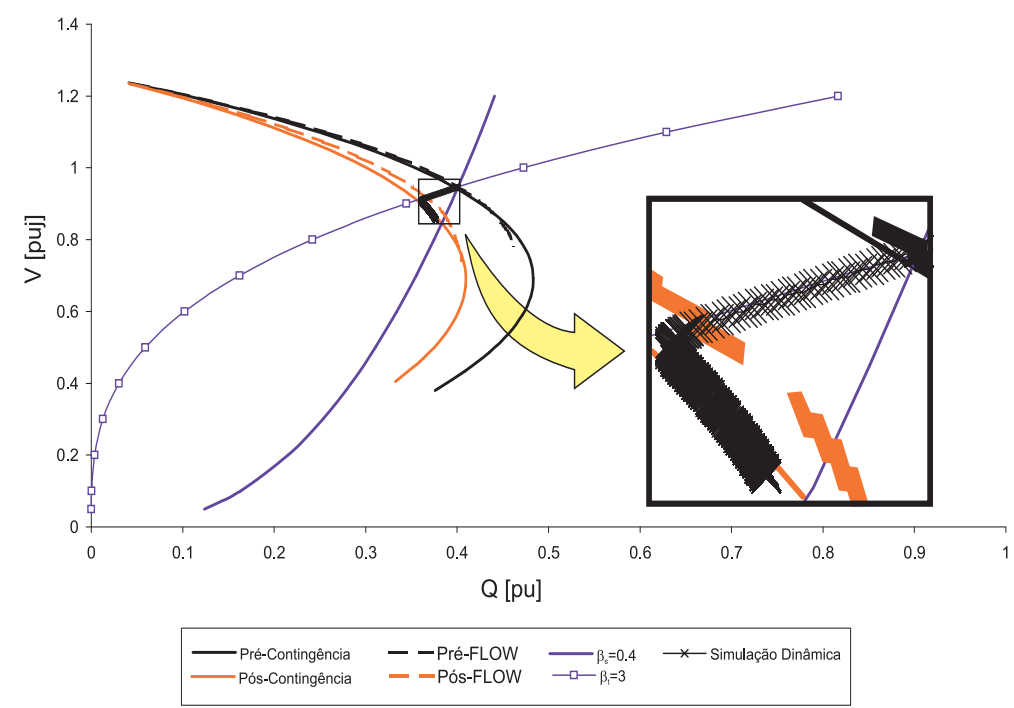

Figura 5.14: Mecanismo de load recovery da potência reativa - ação limitada do AVR.

Esse comportamento é similar ao comentado na seção 5.3.2. Nesse caso, a carga "enxerga" o gerador como uma barra que fornece potências ativa e reativas fixas, e assim os sucessivos pontos de equilíbrio calculados na simulação dinâmica equivalem ao resultado de um fluxo de potência que contempla um modelo de carga exponencial suprido por uma barra PQ 
e uma barra swing.

Nesse ponto convém ressaltar que, apesar dos resultados apresentados nos itens 5.3 e 5.4, a análise estática baseada no modelo do fluxo de potência é incapaz de prever o comportamento da carga durante o período transitório. A título de exemplo, a trajetória descrita pelas potências ativas e reativas consumidas pela carga não seguem as curvas "Pós-contingência" ou "Pós-FLOW" caso as constantes de tempo $T_{P}$ e $T_{Q}$ utilizadas no modelo de carga Hill possuíssem valores distintos. Entretanto, esse fato não invalida a metodologia aqui apresentada, uma vez que ela apresenta resultados bastante satisfatórios para determinar o ponto de operação do sistema pós-evento.

\subsection{Impacto das cargas dinâmicas sobre a estabili- dade de tensão}

Nesse item, analisa-se o impacto em se adotar os modelos dinâmicos discutidos no item 4.2.3.2 sobre alguns dos principais indicadores adotados para avaliar estaticamente a estabilidade de tensão do sistema, a citar: o ponto de máximo carregamento e o limite de carregamento pós-contingência. Para isso, utiliza-se o sistema de 14 barras do IEEE e admite-se que as cargas dinâmicas estão localizadas na barra mais crítica, identificada através da analise modal (GAO; MORISON; KUNDUR, 1992). Adicionalmente, faz-se uma análise comparativa entre os incrementos obtidos na margem de estabilidade para diferentes modelos de carga quando se adota o "alívio de carga" como ação corretiva.

A tabela 5.2 e a figura 5.15 apresentam os resultados da análise modal sobre a matriz $\boldsymbol{J}_{\boldsymbol{R} Q \boldsymbol{V}}$ do fluxo de potência. A tabela 5.2 apresenta os três menores autovalores provenientes dessa análise, permitindo identificar o modo mais crítico EigJRQV1. Já a figura 5.15 apresenta os fatores de participação(FP) para o modo EigJRQV1 permitindo identificar, através da propriedade ilustrada no item 4.5.1.2, as barras 14, 10 e 9 como sendo as mais críticas associadas a esse modo.

Tabela 5.2: Autovalores JRQV - IEEE 14 barras.

\begin{tabular}{|c|c|}
\hline Modo & Autovalor \\
\hline EigJRQV1 & $(0.0312,0.0000)$ \\
\hline EigJRQV2 & $(1.9185,0.0000)$ \\
\hline EigJRQV3 & $(3.3306,0.0000)$ \\
\hline
\end{tabular}




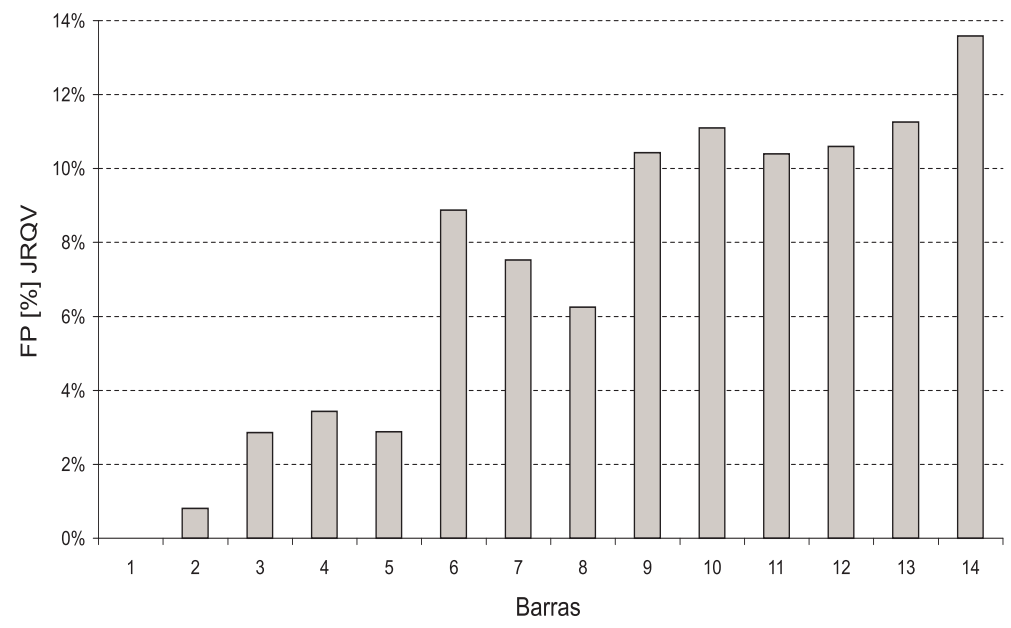

Figura 5.15: Fatores de participação - modo EigJRQV1 (IEEE 14 barras).

Com base no resultado da análise modal, seleciona-se a barra 14 para colocar os modelos dinâmicos de carga. Os parâmetros desses modelos encontram-se na tabela 5.3.

Tabela 5.3: Modelos dinâmicos para carga localizada na barra 14 .

\begin{tabular}{|c|c|c|c|c|c|c|c|}
\hline Modelo & $T_{p}[\mathrm{~s}]$ & $\alpha_{S}$ ou $K_{p}$ & $\alpha_{T}$ ou $P_{d y n}$ & $T_{q}[\mathrm{~s}]$ & $\beta_{S}$ ou $K_{q}$ & $\beta_{T}$ ou $Q_{d y n}$ & - \\
\hline Hill & 61 & -0.16 & 1.31 & 88 & -0.77 & 2.08 & - \\
\hline Ihara & 1.7 & 0.7 & 0.4 & 1.7 & 1.6 & 0.5 & - \\
\hline - & $S n[M V A]$ & $R s[p u]$ & $X s[p u]$ & $X m[p u]$ & $R r[p u]$ & $X r[p u]$ & $H[s]$ \\
\hline Motor & 15 & 0.035 & 0.094 & 2.80 & 0.048 & 0.163 & 0.93 \\
\hline
\end{tabular}

\subsubsection{Avaliação do ponto de máximo carregamento}

Nesta seção comparam-se os resultados das simulações dinâmicas, para os modelos de carga listados na tabela 5.3 e o modelo de potência constante, com o resultado proveniente do fluxo de potência continuado (pressupondo todas as cargas tipo potência constante).

A figura 5.16 mostra as margens de carregamento, calculadas em função do parâmetro de stress $Z^{4}$ (vide item 3.5.5), para os diferentes tipos de carga alocados na barra 14 . Observa-se que, conforme esperado, a simulação dinâmica que emprega apenas o modelo de carga tipo potência constante resulta no ponto de máximo carregamento mais conservativo. As demais cargas, cujos consumos de potências ativa e reativa dependem da tensão de alimentação, apresentam margens de carregamento mais otimistas. Convém ressaltar

\footnotetext{
${ }^{4}$ Conceitualmente o parâmetro de stress é definido através da expressão (3.2) no item 3.5.2. Nesse trabalho, essa expressão é particularizada para os modelos de carga abordados através das relações $P(t)=$ $P_{0} \cdot\left(1+Z . k_{p} \cdot\left(t-t_{0}\right)\right)$ e $Q(t)=Q_{0} \cdot\left(1+Z . k_{q} \cdot\left(t-t_{0}\right)\right)$. Para os motores, adotou-se $T_{m e c}(t)=T_{0} \cdot\left(1+Z .\left(t-t_{0}\right)\right)$.
} 
que o emprego dos modelos dinâmicos Ihara e Hill resultam em margens de carregamento praticamente idênticas.

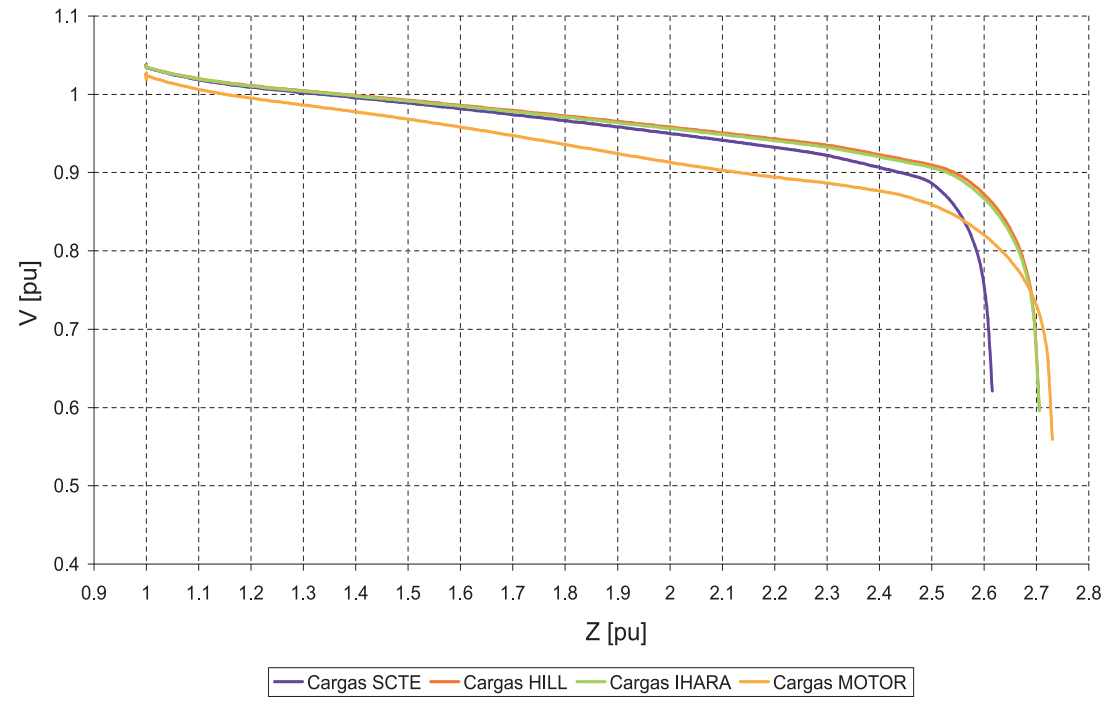

Figura 5.16: PMC - barra14: diferentes modelos de carga.

As figuras 5.17 e 5.18 mostram as curvas PV e QV resultantes das mesmas simulações. Estas curvas ilustram a dependência das potências ativa e reativas nas cargas dinâmicas com sua tensão de alimentação. Percebe-se que, utilizando os parâmetros típicos, as potências ativa e reativa consumidas pelo modelo Ihara são mais sensíveis com relação à variações de tensão quando comparadas com o modelo Hill. Conforme ilustrado na figura 5.16, esse fato não resulta em um aumento significativo na margem de carregamento.

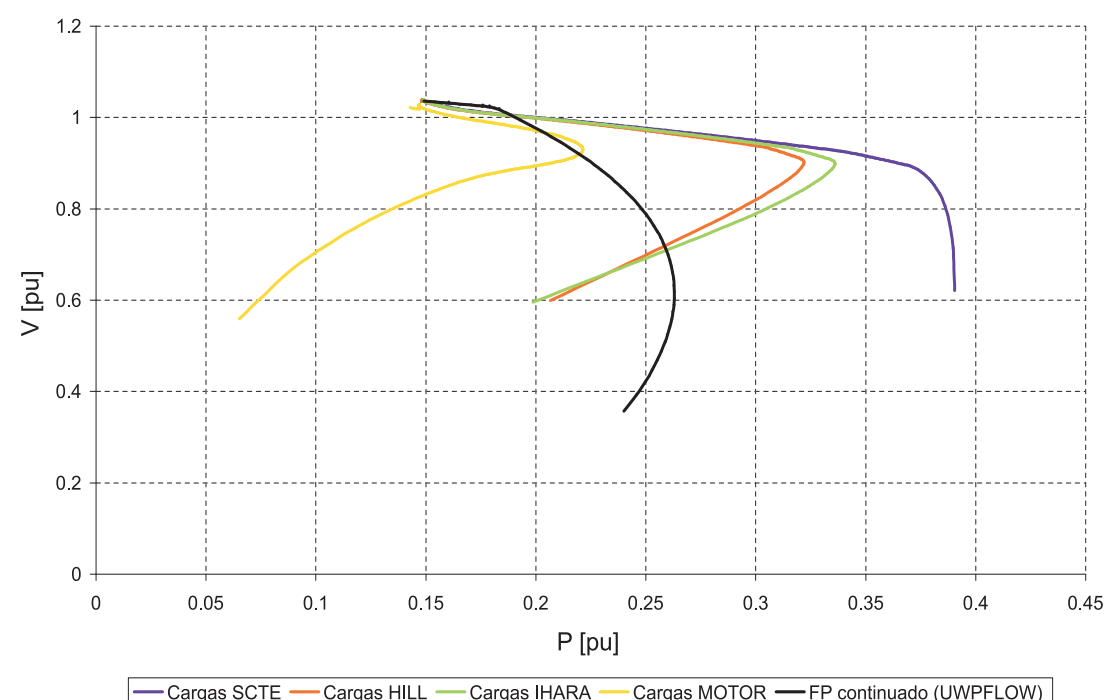

Figura 5.17: Curvas PV - barra14: diferentes modelos de carga. 


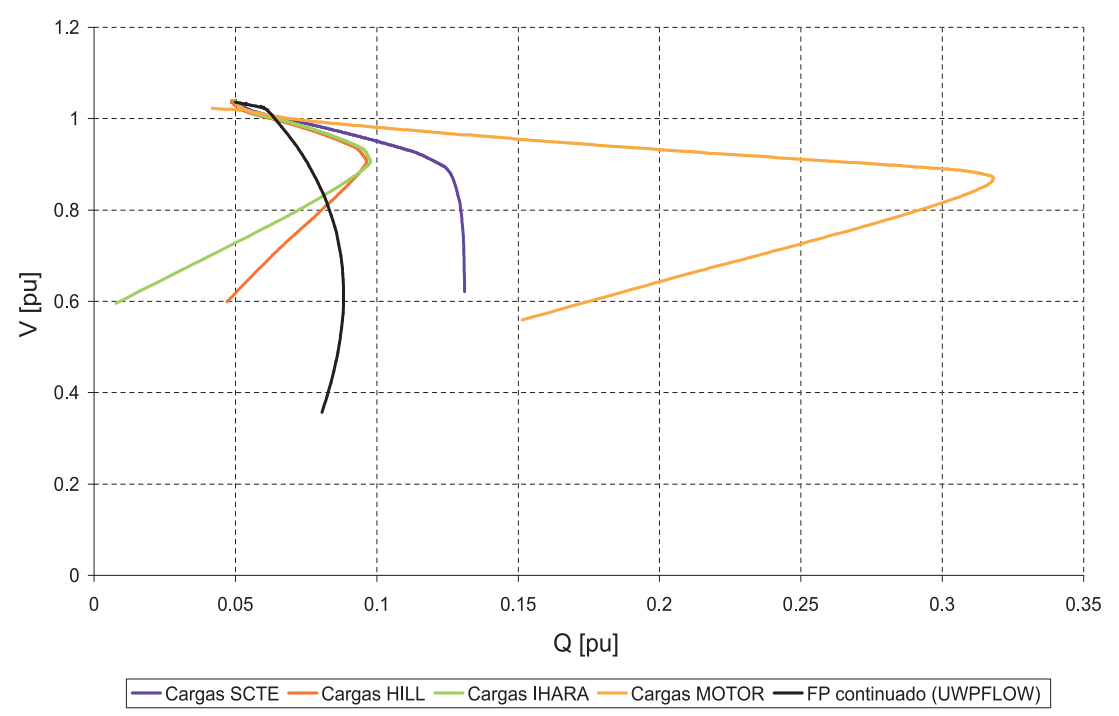

Figura 5.18: Curvas QV - barra14: diferentes modelos de carga.

Adicionalmente observa-se nas figuras 5.17 e 5.18 que o resultado oriundo do fluxo de potência continuado (com os limites de despacho de potência reativa nas barras PV) é bem mais conservativo em relação aos demais. Essa discrepância deve-se à representação dos limites de reativos nos geradores implementada no programa UWPFLOW. As figuras 5.19 e 5.20 ratificam essa afirmação apresentando as curvas PV e QV obtidas através da simulação dinâmica antes(em azul) e após(em vermelho) a redução dos limites operacionais das excitatrizes (AVRs) nos geradores. Adicionalmente essas figuras contêm simulações, oriundas do UWPFLOW, em que os limites nos geradores são considerados(em preto) e são desprezados(em verde).

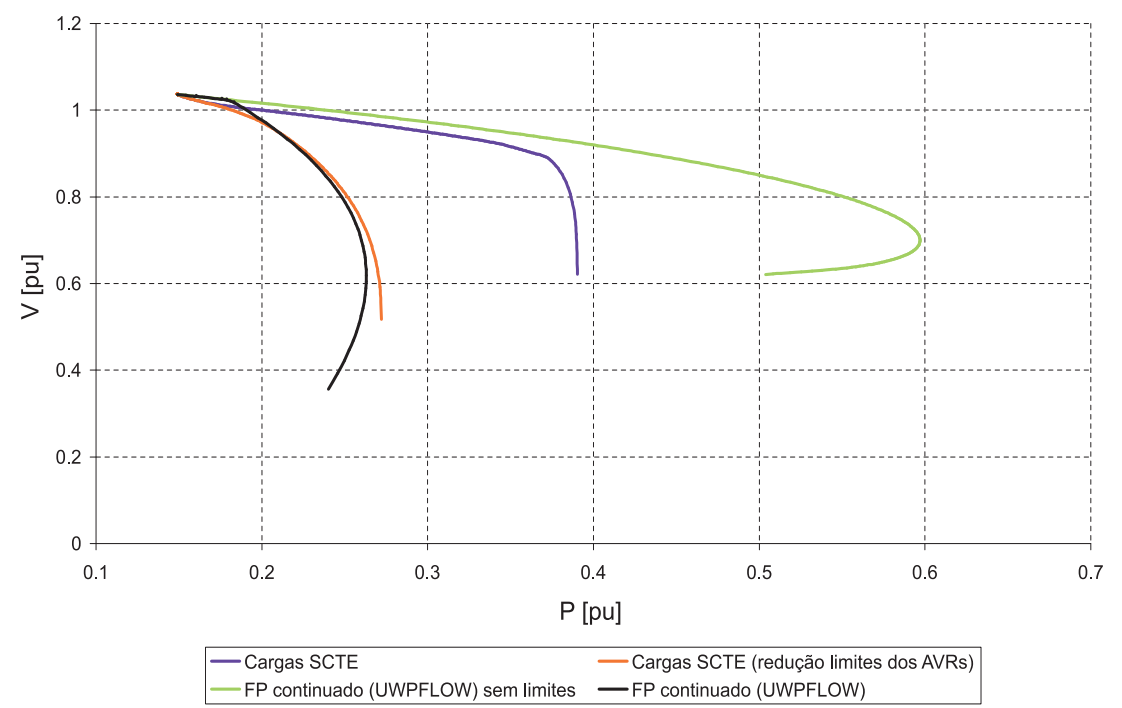

Figura 5.19: Curvas PV - barra14: impacto dos limites nos AVRs 


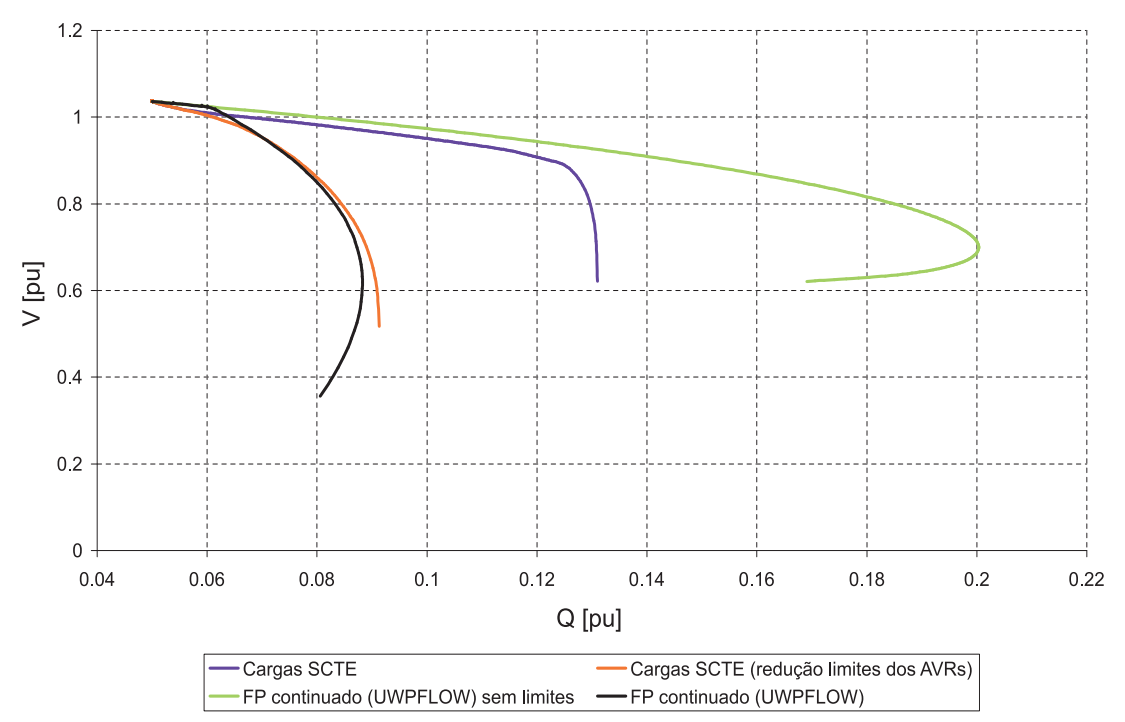

Figura 5.20: Curvas QV - barra14: impacto dos limites nos AVRs

Com o intuito de explicar o comportamento do motor, observado nas figuras 5.17 e 5.18, utiliza-se o diagrama apresentado na figura 5.21.

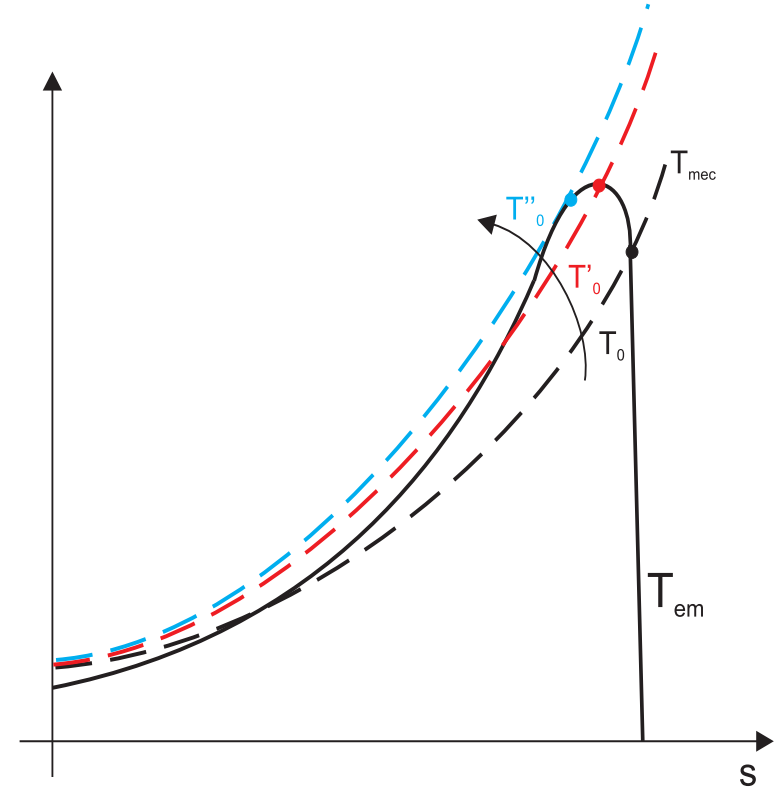

Figura 5.21: Motor (barra 14): Relação entre os torques eletromagnético e mecânico.

Nesse, observa-se a variação do escorregamento $\boldsymbol{s}$ e do torque eletromagnético $\boldsymbol{T}_{\boldsymbol{e}}$ do motor frente a um aumento do torque mecânico $\boldsymbol{T}_{\boldsymbol{m e c}}$ quando admite-se uma relação quadrática deste último com o escorregamento. Verifica-se que ao incrementar o valor do torque mecânico de $\boldsymbol{T}_{\mathbf{0}}$ a $\boldsymbol{T}_{\mathbf{0}}^{\prime}$ há um um aumento do torque eletromagnético e uma diminuição gradual do escorregamento do motor. Em $\boldsymbol{T}_{\mathbf{0}}^{\prime}$ o motor atinge o seu conjugado eletromagnético máximo e, a partir desse instante, qualquer incremento no torque 
mecânico resulta em uma redução abrupta do torque eletromagnético e um aumento significativo do escorregamento. Esse estado persiste até o ponto $\boldsymbol{T}_{\mathbf{0}}^{\prime \prime}$ ser atingido, a partir daí qualquer incremento no torque mecânico resulta no stall do motor de indução e o sistema perde a estabilidade.

A figura 5.21 mostra a evolução temporal das grandezas associadas ao comportamento do motor. Percebe-se que o incremento da carga mecânica provoca, inicialmente, aumentos graduais no escorregamento e nos consumos de potência ativa (diretamente relacionada com o torque eletromagnético) e reativa acompanhada de uma queda de sua tensão de alimentação. A partir de um determinado instante, observa-se que o escorregamento passa a aumentar mais rapidamente enquanto a potência ativa consumida apresenta uma pequena redução. O cenário evolui para uma situação de colapso quando a tensão do motor atinge cerca de $0.65 \mathrm{pu}$.

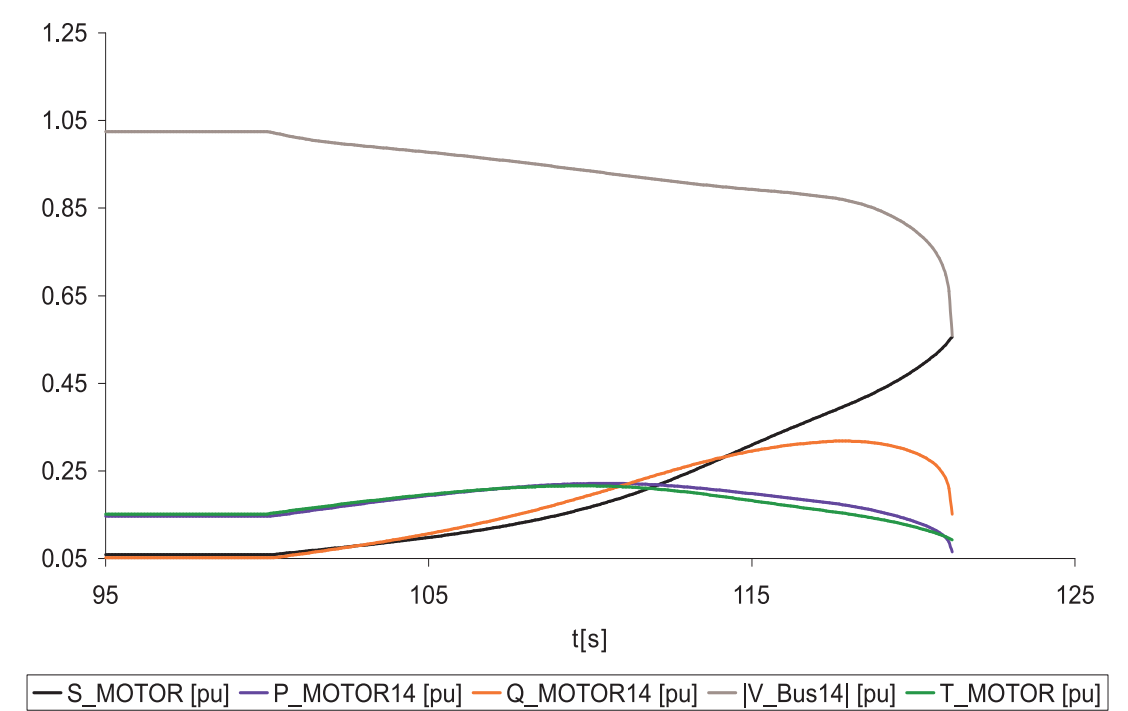

Figura 5.22: Motor (barra 14): Evolução temporal do comportamento.

Ironicamente, apesar do comportamento apresentado nas figuras 5.17 e 5.18, o motor de indução apresentou uma margem de carregamento ligeiramente maior que os demais tipos de carga analisados nas simulações apresentadas, vide figura 5.16.

Ao fim desse item pode-se concluir que a determinação precisa das margens de carregamento é bastante influenciada pela representação dos controles utilizada no fluxo de potência continuado. Além disso, verificou-se que os modelos dinâmicos propostos por Hill e Ihara apresentaram margens de carregamento similares frente a aumentos incrementais da carga. Nesse ponto, sugere-se uma investigação mais profunda no sentido de identificar um modelo estático capaz de reproduzir o comportamento apresentado pelo modelo proposto por Ihara após o período transitório de restauração da carga. Isso per- 
mitiria adaptar os programas de fluxos de potência continuado com o intuito de alcançar uma melhor precisão na determinação em tempo real da margem de carregamento do sistema elétrico.

Adicionalmente, observou-se que as cargas compostas por motores de indução apresentam um comportamento dinâmico complexo. A representação adequada desse comportamento é bastante difícil em ferramentas baseadas no equacionamento do fluxo de potência. $\mathrm{Na}$ visão do autor, uma representação adequada dessa dinâmica para a determinação em tempo real da margem de carregamento do sistema pode ser alcançada através de uma abordagem quasi-estática, vide item 3.6.

\subsubsection{Avaliação do limite de carregamento pós-contingência}

Nesta seção analisa-se o desempenho do modelos dinâmicos de carga frente a ocorrência de contingências. Para isso, aplica-se a contingência mais severa para o sistema IEEE 14 barras e obtém-se a margem de carregamento pós-contingência para cada um dos modelos de carga listados na tabela 5.3 e o modelo de potência constante. A partir dos resultados apresentados na tabela 5.4, seleciona-se a contingência L02-03 para ser aplicada na análise apresentada a seguir.

Tabela 5.4: Avaliação das Contingências - IEEE 14 barras.

\begin{tabular}{|c|c|c|}
\hline ID & Contingência & Severidade \\
\hline 1 & L02-03 & 0.23615 \\
\hline 2 & L01-05 & 0.27734 \\
\hline 3 & L07-09 & 0.29764 \\
\hline 4 & L01-02 & 0.37704 \\
\hline 5 & L02-04 & 0.3989 \\
\hline 6 & L09-14 & 0.41708 \\
\hline 7 & L04-05 & 0.42282 \\
\hline 8 & L06-13 & 0.42529 \\
\hline 9 & L02-05 & 0.43565 \\
\hline 10 & L09-10 & 0.46697 \\
\hline
\end{tabular}

A figura 5.23 mostra os limites de carregamento pós-contingência, calculados em função do parâmetro de stress $Z$, para os diferentes tipos de carga situados na barra 14 . De forma similar ao ocorrido no item 5.5.1, observa-se que a simulação dinâmica que emprega apenas o modelo de carga tipo potência constante resulta no limite de carregamento mais conservativo. Novamente os limites de carregamento pós-contingência obtidos para os modelos de carga Hill e Ihara são idênticos. Convém mencionar que a contingência L02- 
03 faz com que o motor evolua rapidamente para o estado de stall devido à carência de um suporte reativo na barra 14 .

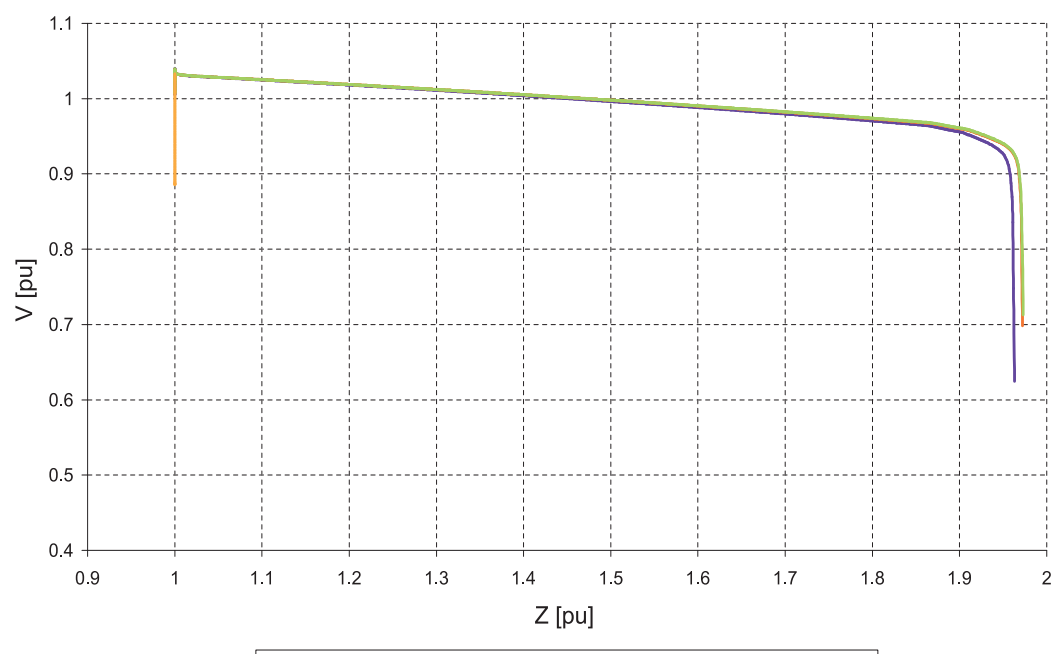

—Cargas SCTE — Cargas HILL — Cargas IHARA — Cargas MOTOR

Figura 5.23: Curvas ZV pós contingência (barra14).

As figuras 5.24 e 5.25 mostram as curvas PV e QV obtidas para os modelos de carga considerados. Nesse caso, percebe-se que as curvas PV e QV correspondentes à carga tipo potência constante são bastante similares às curvas PV e QV obtidas a partir do fluxo de potência continuado desconsiderando a representação dos limites nos controles, vide item 5.4.

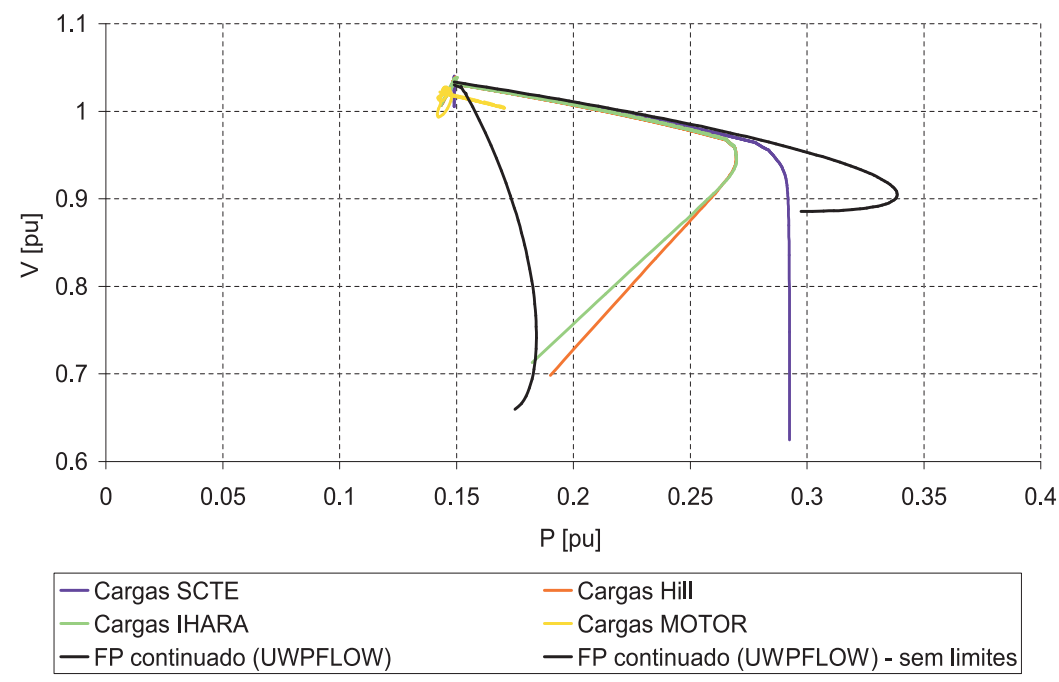

Figura 5.24: Curvas PV pós contingência (barra14). 


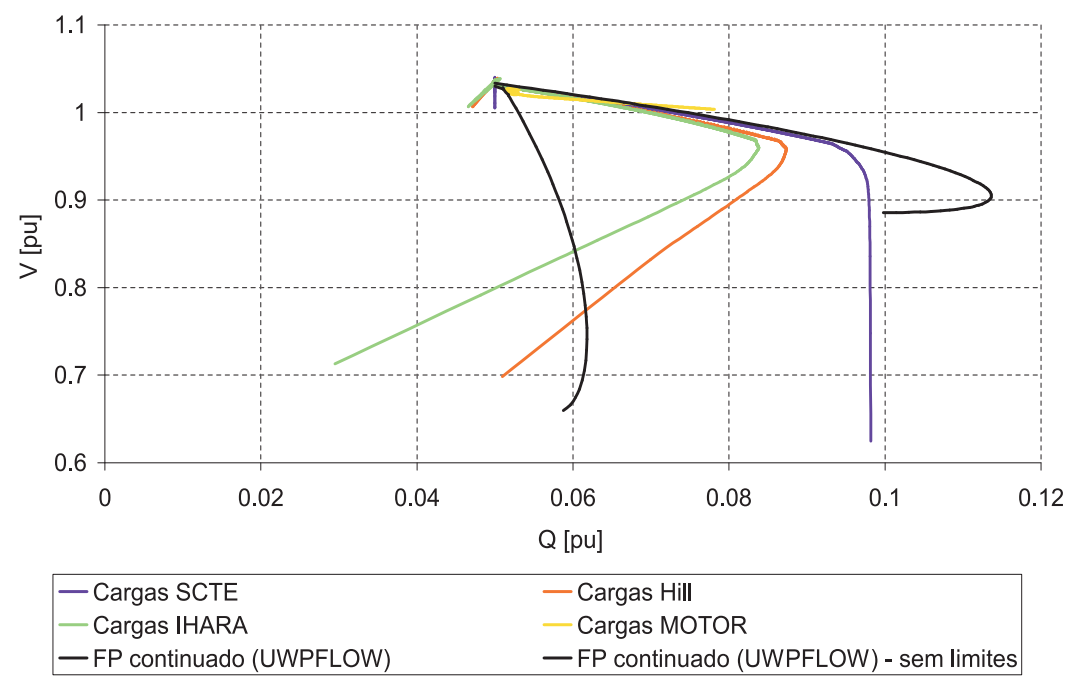

Figura 5.25: Curvas QV pós contingência (barra14).

Em relação aos modelos de carga Hill e Ihara, as figuras 5.24 e 5.25 ilustram a dependência das potências ativa e reativas com sua tensão de alimentação. Percebe-se que, utilizando os parâmetros típicos, as potências ativa e reativa consumidas pelo modelo Ihara são mais sensíveis com relação à variações de tensão quando comparadas com o modelo Hill. Conforme ilustrado na figura 5.23, esse fato não resulta em um aumento significativo do limite de carregamento.

Ao fim desse item pode-se concluir que a determinação dos limites de operação póscontingência não exige uma representação elaborada dos controles existentes no sistema elétrico. Além disso, verificou-se que os modelos dinâmicos propostos por Hill e Ihara apresentaram limites de operação similares frente a contingências simples.

\subsubsection{Impacto sobre o "alívio de carga"}

Nesta seção analisa-se o desempenho do modelos dinâmicos de carga frente a ocorrência de cortes de carga. Para isso, particiona-se a carga em cinco blocos de igual valor e agendamse eventos para desconexão de, respectivamente, $20 \%$, 40\% e $60 \%$ da carga situada na barra 14. Para cada um dos cortes efetuados, mede-se o incremento na margem de carregamento alcançado. Em função dessa métrica, avalia-se o impacto para cada um dos modelos de carga estudados, excetuando-se o motor, uma vez que sua desconexão causa interferência na estabilidade numérica das simulações realizadas no DSIM. 
A figura 5.26 apresenta os resultados obtidos a partir da análise descrita acima.

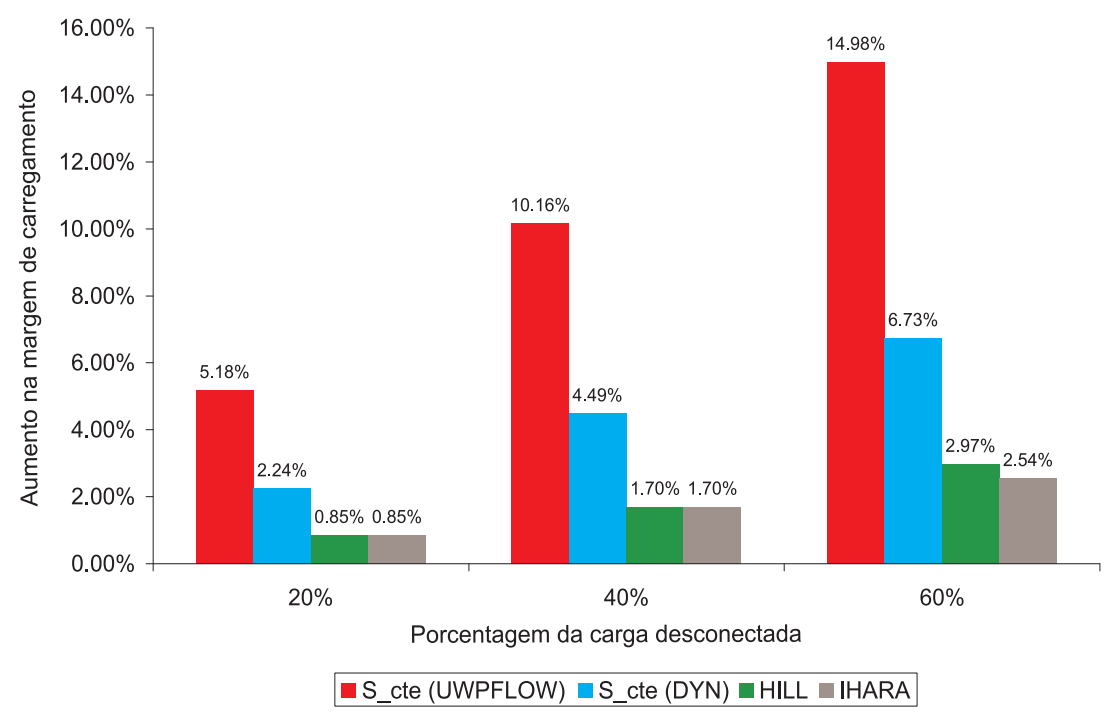

Figura 5.26: Aumento na margem de carregamento devido ao corte de carga (barra14).

A partir dos resultados obtidos pode-se concluir que o corte de carga apresenta maior eficácia quando é realizado sobre cargas que possuem uma característica de potência constante. Além disso, verifica-se que os ganhos auferidos para os modelos de carga Hill e Ihara são bastante próximos (verifica-se apenas uma pequena diferença em favor do modelo de carga Hill, quando há um corte de $60 \%$ da carga). Adicionalmente, constata-se que a estimativa no incremento da margem de carga obtida utilizando o fluxo de potência continuado é significativamente mais otimista que o resultante da simulação dinâmica. 


\section{Conclusões}

\subsection{Resumo geral}

Esse trabalho abordou o problema da estabilidade de tensão, sob o ponto de vista dinâmico, analisando o comportamento transitório e em regime permanente da carga. Para isso, procedeu-se a uma modelagem detalhada da rede elétrica com o intuito de representar adequadamente os principais eventos inerentes aos fenômenos de instabilidade e colapso de tensão relatados na literatura. A seguir, implementaram-se todos os modelos estudados em um programa de simulação multimáquina baseado no solver DASSLC. Finalmente, aplicou-se o programa desenvolvido para avaliar o impacto da interação dinâmica entre a carga e os controles existentes na rede elétrica sobre alguns dos principais índices empregados para a avaliação da estabilidade de tensão.

\subsection{Principais contribuições}

\subsubsection{Análise do impacto dos modelos de carga sobre as margens de estabilidade de tensão.}

As simulações realizadas no item 5.5 mostram que as diferenças entre os comportamentos dinâmicos dos modelos de carga propostos por Hill e Ihara não apresentaram impacto significativo sobre o ponto de máximo carregamento, vide figura 5.16, e o limite de carregamento pós-contingência, vide figura 5.23. Assim, com base nas simulações realizadas, pode-se afirmar que a aplicação indistinta de qualquer um dos dois modelos mencionados resulta em valores muito próximos para esses dois índices.

Nesse ponto convém ressaltar que a margem de estabilidade de tensão deve ser avaliada através de diagramas de bifurcação (CUTSEM; VOURNAS, 1998). Assim, apesar das diferenças observadas nas curvas PV e QV obtidas para os dois modelos de carga citados, verificou-se que ambos apresentaram diagramas de bifurcação idênticos. 
Em relação aos ganhos de margem de estabilidade de tensão auferidos quando se utiliza o "alívio de carga", observou-se também que a adoção indistinta dos modelos de carga Hill e Ihara também não impacta significativamente nos valores obtidos para esse índice, embora os resultados obtidos apontem o modelo Ihara como possível pivô de resultados mais conservativos. Adicionalmente observou-se que as margens estimadas a partir do fluxo de potência são consideravelmente mais conservativas que as oriundas das simulações dinâmicas.

Além das conclusões anteriores, verificou-se, através de simulações estáticas e dinâmicas, que a determinação do ponto de máximo carregamento é bastante sensível à representação dos controles utilizada no modelo do fluxo de potência, vide item 5.5.1. A representação "retangular", recomendada por alguns autores para representar a curva de capacidade dos geradores, é incapaz de fornecer resultados próximos aos provenientes das simulações dinâmicas.

\subsubsection{Aplicação do solver DASSLC para análise dinâmica da estabilidade de tensão}

Esse trabalho utiliza a versão 1.0 do solver DASSLC para solução numérica do sistema de equações algébrico-diferenciais descrito no item 4.2.5. Apesar de tratar-se de uma ferramenta não muito recente, não se identificaram aplicações da mesma para a solução de problemas relacionados à área de sistemas de potência. Convém ressaltar que na versão utilizada nesse trabalho observou-se que:

- A implementação de modelos discretos de dispositivos é bastante difícil uma vez que sua adição acarreta problemas de instabilidade numérica na DASSLC;

- A representação de limites de operação do controles existentes no sistema elétrico exige a aplicação de técnicas " anti-windup" sofisticadas, conforme descrito no item 4.5.2.2.

\subsubsection{Outras contribuições}

Além das contribuições anteriormente citadas, faz-se necessário citar os seguintes aspectos observados na implementação do fluxo de potência:

- Verificou-se que a solução de sistemas com muitas barras tipo PV (com limites de potência reativa) apresenta problemas de instabilidade numérica caso não se adote um critério para priorizar quantas e quais barras devem ser convertidas para o tipo 
PQ (e vice versa). O item 4.5.1 descreve uma heurística que apresentou excelentes resultados para o problema descrito;

- Verificou-se que a representação de motores como cargas tipo PQ não é adequada para inicialização das simulações dinâmicas. Nesse trabalho esse problema foi contornado adotando-se uma solução, bastante simples, que consiste em adicionar o suporte reativo correspondente à diferença entre o valor de potência reativa fornecida no fluxo e o valor de potência reativa obtido após o cálculo das condições iniciais do motor.

\subsection{Trabalhos futuros}

\subsubsection{Investigação de modelos de carga mais realistas}

Sabe-se que as sensibilidades para as potências ativa $(\alpha)$ e reativa $(\beta)$ apresentam uma correlação estreita com fatores como o clima, a temperatura, as estações do ano entre outros. As avaliações de estabilidade de tensão baseadas em valores específicos desses parâmetros são incapazes de abranger boa parte dos mecanismos de instabilidade que podem se manifestar nos sistemas de potência. Assim, pretende-se abordar esse problema através da adição de "incertezas" nos modelos estáticos e dinâmicos de carga implementados utilizando técnicas baseadas em redes neurais (identificou-se algumas publicações nesse sentido) ou através de uma modelagem estocástica.

\subsubsection{Inclusão de mais modelos de controle no simulador}

Com o intuito de representar a dinâmica presente em fenômenos de instabilidade e colapso de tensão com mais precisão, pretende-se adicionar ao simulador desenvolvido modelos de turbina, AVRs e PSSs entre outros.

\subsubsection{Determinação de ações corretivas}

Pretende-se utilizar a informação proveniente da análise modal estendida sobre a matriz de estados do sistema como ponto de partida para determinar as ações corretivas a serem tomadas nos diversos cenários de instabilidade possíveis. Nesse ponto convém ressaltar que essa investigação não foi realizada no presente trabalho pois o optou-se pela formulação retangular do sistema multimáquina (devido a razões de estabilidade numérica). Assim, 
antes de qualquer avanço messe sentido, faz-se necessário proceder a conversão da matriz de estados para a formulação polar. 


\section{Anexo A - Dados dos Sistemas Simulados}

\section{A.1 Sistema Exemplo - Capítulo 2}

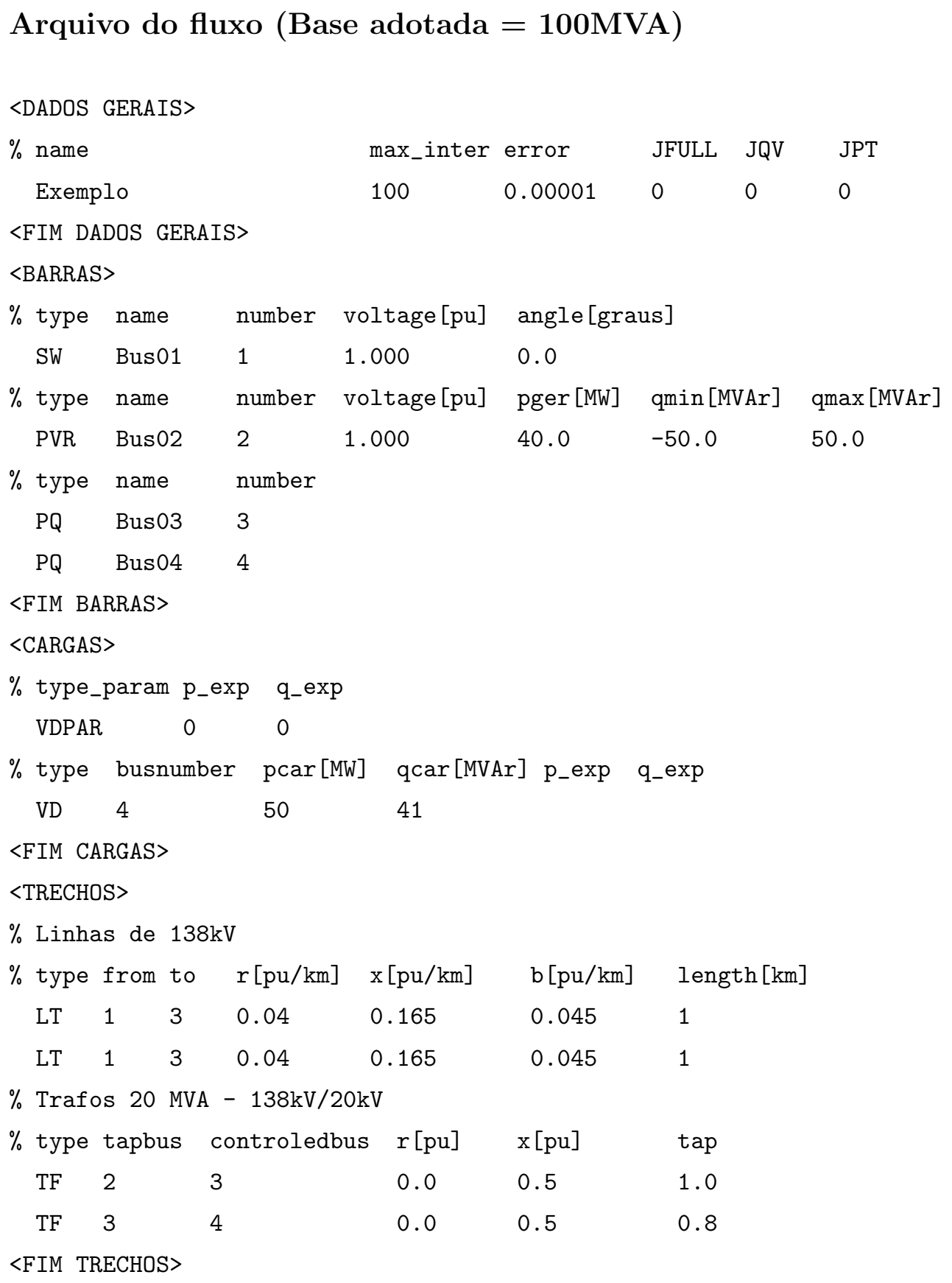




\section{Arquivo para simulação dinâmica}

$<$ ARQUIVO FLUXO>

Exemplo.flo

$<$ FIM ARQUIVO FLUXO>

<DADOS GERAIS>

$\begin{array}{llll}\% \text { step [s] } & \text { tf }[\mathrm{s}] & \text { rtol } & \text { atol } \\ 0.1 & 300 & 1 \mathrm{e}-2 & 1 \mathrm{e}-6\end{array}$

$<$ FIM DADOS GERAIS>

$<$ GERADORES>

\% Gerador Hidraulico H5 (pag 567 - Anderson \& Fouad) - 40MVA, $13.8 \mathrm{kV}, \mathrm{FP}=0.9$

$\%$ name num Sn[MVA] Tldo[s] Tlq0[s] $r s[p u] x d[p u] \quad x q[p u] x l d[p u] x l q[p u] H[s] D[p u]$

$\begin{array}{lllllllllll}\text { Bus02 } 2 & 40 & 5.3 & 0.53 & 0.0029 & 0.990 & 0.615 & 0.318 & 0.615 & 2.7 & 0.0001\end{array}$

<FIM GERADORES>

<EXCITATRIZES>

\% genbusnumber $\quad$ KA [pu $] \quad$ TA [s] VRMAX [pu $\quad$ VRMIN [pu $] \quad$ Vref [pu]

50

$1.8 \quad 1.71$

$-2.6$

1

<FIM EXCITATRIZES>

<EVENTOS>

$\begin{array}{llllll}\text { \% dispositivo barraFRoM } & \text { barraTo } & \text { input } & \text { comando } & \text { valor [pu] } & \text { tempo [ms] } \\ \text { Linha } & 1 & 3 & & \text { retirar } & 30 \\ \text { <FIM EVENTOS> } & & & & \end{array}$




\section{A.2 Sistema BPA de 10 barras - Capítulo 4}

\section{Arquivo do fluxo (Base adotada $=100 \mathrm{MVA})$}

$\%$ Task Force 38.02.08

<DADOS GERAIS>

$\%$ name

BPA10Bus_TestCase

max_inter error

$<$ FIM DADOS GERAIS>

<BARRAS>

$\begin{array}{lllllll}\text { \% type } & \text { name } & \text { number } & \text { voltage [pu] } & \text { angle [graus] } \\ \text { SW } & \text { Bus01 } & 1 & 0.98 & 0.0 & \\ \text { \% type } & \text { name } & \text { number } & \text { voltage [pu] } & \text { pger [MW] } & \text { qmin [MVAr] } & \text { qmax [MVAr] } \\ \text { PVR } & \text { Bus02 } & 2 & 0.9646 & 1736.0 & -200.0 & 727.0 \\ \text { PVR } & \text { Bus03 } & 3 & 0.9730 & 1155.0 & -100.0 & 700.0 \\ \% \text { type } & \text { name } & \text { number } & & & \\ \text { PQ } & \text { Bus05 } & 5 & & & \\ \text { PQ } & \text { Bus06 } & 6 & & & \\ \text { PQ } & \text { Bus07 } & 7 & & & \\ \text { PQ } & \text { Bus08 } & 8 & & & \\ \text { PQ } & \text { Bus09 } & 9 & & & \\ \text { PQ } & \text { Bus10 } & 10 & & & \\ \text { PQ } & \text { Bus11 } & 11 & & & \\ \end{array}$

$<$ FIM BARRAS>

<CARGAS>

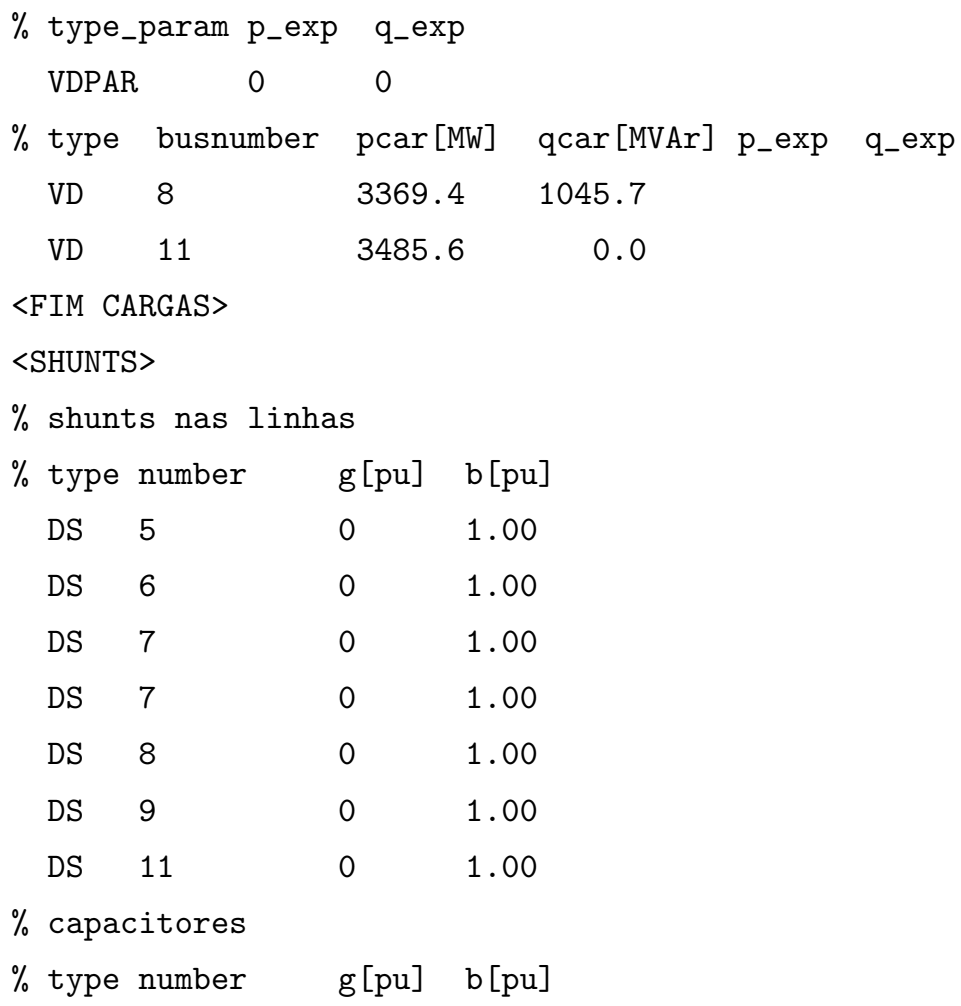




$\begin{array}{llll}\text { DS } & 7 & 0 & 7.63 \\ \text { DS } & 8 & 0 & 6.00 \\ \text { DS } & 9 & 0 & 3.00\end{array}$

<FIM SHUNTS>

$<$ TRECHOS>

$\%$ type tapbus controledbus $r[p u] \quad x[p u] \quad$ tap

$\begin{array}{llllll}\text { TF } & 1 & 5 & 0.0 & 0.0020 & 0.8857 \\ \text { TF } & 2 & 6 & 0.0 & 0.0045 & 0.8857 \\ \text { TF } & 3 & 7 & 0.0 & 0.0125 & 0.9024 \\ \text { TF } & 3 & 7 & 0.0 & 0.0125 & 0.9024 \\ \text { TF } & 7 & 8 & 0.0 & 0.0030 & 1.0664 \\ \text { TF } & 7 & 9 & 0.0 & 0.0026 & 1.0800 \\ \text { TF } & 10 & 11 & 0.0 & 0.0010 & 0.9600\end{array}$

$\%$ type frombus tobus $r[\mathrm{pu} / \mathrm{km}] \quad \mathrm{x}[\mathrm{pu} / \mathrm{km}] \quad \mathrm{b}[\mathrm{pu} / \mathrm{km}] \quad$ length $[\mathrm{km}]$

$\begin{array}{lllllll}\text { LT } & 5 & 6 & 0.0000 & 0.0040 & 0.0000 & 1\end{array}$

$\begin{array}{lllllll}\text { LT } & 6 & 7 & 0.0015 & 0.0288 & 1.1730 & 1\end{array}$

$\begin{array}{lllllll}\text { LT } & 6 & 7 & 0.0015 & 0.0288 & 1.1730 & 1\end{array}$

$\begin{array}{lllllll}\text { LT } & 6 & 7 & 0.0015 & 0.0288 & 1.1730 & 1\end{array}$

$\begin{array}{lllllll}\text { LT } & 6 & 7 & 0.0015 & 0.0288 & 1.1730 & 1\end{array}$

$\begin{array}{lllllll}\text { LT } & 6 & 7 & 0.0015 & 0.0288 & 1.1730 & 1\end{array}$

$\begin{array}{lllllll}\text { LT } & 9 & 10 & 0.0010 & 0.0030 & 0.0000 & 1\end{array}$

$<$ FIM TRECHOS>

\section{Arquivo para simulação dinâmica}

$<$ ARQUIVO FLUXO>

bpa10bus_TF_CaseD.flo

$<$ FIM ARQUIVO FLUXO>

<DADOS GERAIS>

$\%$ step $[\mathrm{s}]$ tf $[\mathrm{s}]$ rtol atol

$0.1 \quad 300 \quad 1 \mathrm{e}-2 \quad 1 \mathrm{e}-6$

$<$ FIM DADOS GERAIS>

$<$ GERADORES>

\% name num Sn[MVA] Tldo[s] Tlq0[s] $\mathrm{rs}[\mathrm{pu}] \mathrm{xd}[\mathrm{pu}] \mathrm{xq}[\mathrm{pu}] \mathrm{xld}[\mathrm{pu}] \mathrm{xlq}[\mathrm{pu}] \mathrm{H}[\mathrm{s}] \mathrm{D}[\mathrm{pu}]$ A $\quad$ B
Bus02 22200
$4.10 \quad 0.56$
$\begin{array}{lllll}0.0046 & 2.070 & 1.9900 & 0.2800\end{array}$
0.4900
$\begin{array}{lllllll}2.09 & 0.0001 & 0.05 & 0.1\end{array}$
Bus03 31600
$4.10 \quad 0.56$
$\begin{array}{llll}0.0046 & 2.070 & 1.9900 & 0.2800\end{array}$
0.4900
$\begin{array}{lllll}2.33 & 0.0001 & 0.05 & 0.1\end{array}$

<FIM GERADORES>

$<$ EXCITATRIZES>

$\%$ genbusnumber

$\begin{array}{llllc}\text { KA }[\mathrm{pu}] & \mathrm{TA}[\mathrm{s}] & \operatorname{VRMAX}[\mathrm{pu}] & \operatorname{VRMIN}[\mathrm{pu}] & \operatorname{Vref}[\mathrm{pu}] \\ 200 & 0.5 & 3.2 & -3.2 & 1 \\ 200 & 0.5 & 3 & -3 & 1\end{array}$

3

2

200

$<$ FIM EXCITATRIZES>

$<$ OXLS>

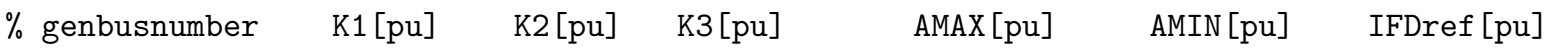




$\begin{array}{lllllll}2 & 100 & 0.08 & 1 & 0.01 & -0.01 & 2.25 \\ 3 & 100 & 0.08 & 1 & 0.01 & -0.01 & 2.3\end{array}$

<FIM OXLS>

$<$ LTCS>

$\%$ frombus tobus DB[pu nro_tapes TDO[s] TD [s] TMEC[s]

$\begin{array}{lllllll}10 & 11 & 0.03 & 32 & 30 & 5 & 2\end{array}$

$<$ FIM LTCS>

$<$ MOTORES>

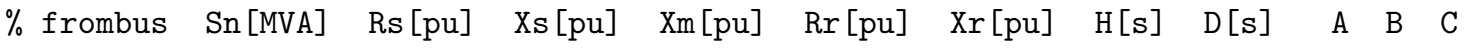

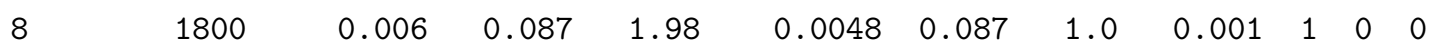

$<$ FIM MOTORES>

$<$ EVENTOS>

$\begin{array}{lllllll}\text { \% dispositivo } & \text { barraFROM } & \text { barraTO } & \text { input } & \text { comando } & \text { valor [pu] } & \text { tempo [ms] } \\ \text { Linha } & 6 & 7 & & \text { retirar } & 30\end{array}$

$<$ FIM EVENTOS> 


\section{A.3 Sistema de 2 barras - Capítulo 5}

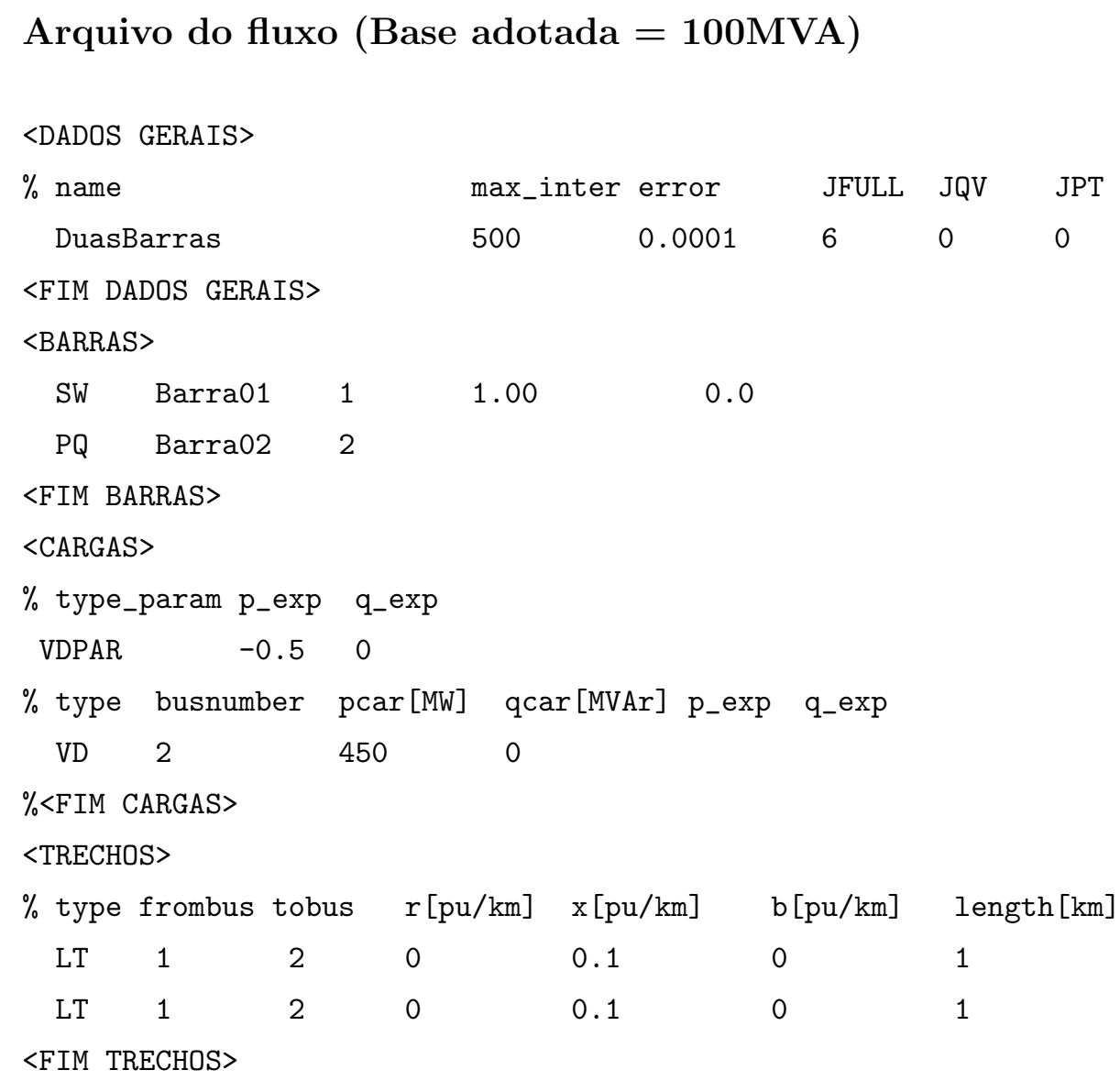

\section{Arquivo para simulação dinâmica}

$<$ ARQUIVO FLUXO>

duas_barras_flow.flo

$\langle$ FIM ARQUIVO FLUXO>

$<$ DADOS GERAIS $>$

$\begin{array}{clll}\% \text { step }[\mathrm{s}] & \mathrm{tf}[\mathrm{s}] & \mathrm{rtol} & \text { atol } \\ 0.1 & 600 & 1 \mathrm{e}-3 & 1 \mathrm{e}-6\end{array}$

<FIM DADOS GERAIS>

$<$ CARGAS DINAMICAS>

$\%$ frombus tipo TP[s] alpha_t $[\mathrm{pu}] \mathrm{TQ}[\mathrm{s}]$ beta_t $[\mathrm{pu}]-$ HILL

$\begin{array}{llllll}2 & \text { Hill } & 10 & 0.65 & 10 & 3.0\end{array}$

\% frombus tipo KP[pu] TP[s] Pdyn[pu] Pdrop[pu] KQ[pu] TQ[s] Qdyn[pu] Qdrop[pu] - IHARA
2
Ihara $-0.1 \quad 10$
$0.80 \quad 0$
2.3
$1.7 \quad 0.8$
0

$<$ FIM CARGAS DINAMICAS>

$<$ EVENTOS>
$\%$ dispositivo barraFRoM barraTo input comando valor [pu] tempo [ms]
$\begin{array}{lllll}\text { Linha } & 1 & 2 & \text { retirar } & 30\end{array}$

<FIM EVENTOS> 


\section{A.4 Sistema IEEE de 14 barras - Capítulo 5}

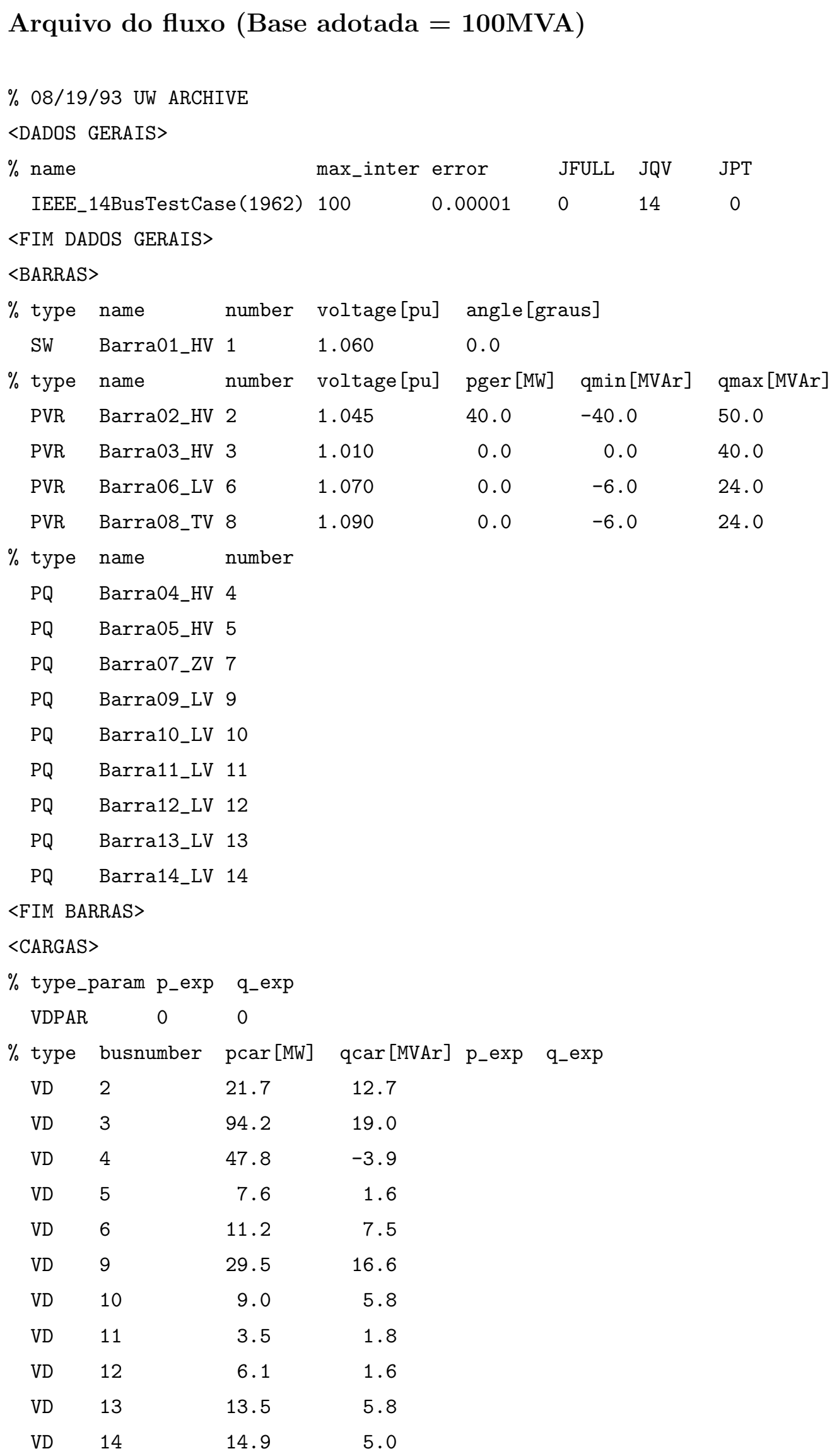


$<$ FIM CARGAS>

$<$ SHUNTS>

$\%$ type busnumber g[pu] $\mathrm{b}[\mathrm{pu}]$
DS 9
0
0.19

$<$ FIM SHUNTS $>$

$<$ TRECHOS $>$

\begin{tabular}{|c|c|c|c|c|c|c|c|}
\hline$\%$ type & frombus & tobus & $\mathrm{r}[\mathrm{pu} / \mathrm{k}$ & & $\mathrm{x}[\mathrm{pu} / \mathrm{km}]$ & $\mathrm{b}[\mathrm{pu} / \mathrm{km}]$ & length $[\mathrm{km}]$ \\
\hline LT & 1 & 2 & 0.0193 & & 0.05917 & 0.0528 & 1 \\
\hline LT & 1 & 5 & 0.0540 & & 0.22304 & 0.0492 & 1 \\
\hline LT & 2 & 3 & 0.0469 & & 0.19797 & 0.0438 & 1 \\
\hline LT & 2 & 4 & 0.0581 & & 0.17632 & 0.0374 & 1 \\
\hline LT & 2 & 5 & 0.0569 & & 0.17388 & 0.0340 & 1 \\
\hline LT & 3 & 4 & 0.0670 & & 0.17103 & 0.0346 & 1 \\
\hline LT & 4 & 5 & 0.0133 & & 0.04211 & 0.0128 & 1 \\
\hline LT & 6 & 11 & 0.0949 & & 0.19890 & 0.0 & 1 \\
\hline LT & 6 & 12 & 0.1229 & & 0.25581 & 0.0 & 1 \\
\hline LT & 6 & 13 & 0.0661 & & 0.13027 & 0.0 & 1 \\
\hline $\mathrm{LT}$ & 7 & 8 & 0.0 & & 0.17615 & 0.0 & 1 \\
\hline LT & 7 & 9 & 0.0 & & 0.11001 & 0.0 & 1 \\
\hline LT & 9 & 10 & 0.0318 & & 0.08450 & 0.0 & 1 \\
\hline $\mathrm{LT}$ & 9 & 14 & 0.1271 & & 0.27038 & 0.0 & 1 \\
\hline LT & 10 & 11 & 0.0820 & & 0.19207 & 0.0 & 1 \\
\hline LT & 12 & 13 & 0.2209 & & 0.19988 & 0.0 & 1 \\
\hline LT & 13 & 14 & 0.1709 & & 0.34802 & 0.0 & 1 \\
\hline$\%$ type & tapbus & contro] & edbus & $\mathrm{r}[\mathrm{pu}$ & $\mathrm{x}[\mathrm{pu}]$ & tap & \\
\hline $\mathrm{TF}$ & 4 & 7 & & 0.0 & 0.20912 & 0.978 & \\
\hline $\mathrm{TF}$ & 4 & 9 & & 0.0 & 0.55618 & 0.969 & \\
\hline $\mathrm{TF}$ & 5 & 6 & & 0.0 & 0.25202 & 0.932 & \\
\hline
\end{tabular}

\section{Arquivo para simulação dinâmica}

<ARQUIVO FLUXO>

ieee14.flo

<FIM ARQUIVO FLUXO>

<DADOS GERAIS>

$\%$ step [s] tf $[s]$ rtol atol

$0.1 \quad 600 \quad 1 \mathrm{e}-6 \quad 1 \mathrm{e}-6$

$<$ FIM DADOS GERAIS >

$<$ GERADORES>

\% busname busnumber Sn[MVA] TldO[s] TlqO[s] rs[pu $\mathrm{xd}[\mathrm{pu}] \mathrm{xq}[\mathrm{pu}] \mathrm{xld}[\mathrm{pu}] \mathrm{xlq}[\mathrm{pu}] \mathrm{H}[\mathrm{s}] \mathrm{D}[\mathrm{pu}]$

\begin{tabular}{|c|c|c|c|c|c|c|c|c|c|}
\hline Barra02_HV 2 & 60 & 6.10 & 0.30 & 0.0031 & 1.05 & 0.98 & 0.1850 & 0.36 & 6.540 .001 \\
\hline 3_HV & 60 & 6.10 & 0.30 & 0.0031 & 1.05 & 0.98 & 0.1850 & 0.36 & 6.54 \\
\hline arra06_LV & 25 & 4.75 & 1.50 & 0.0014 & 1.25 & 1.22 & 0.232 & 0.715 & 5.06 \\
\hline
\end{tabular}




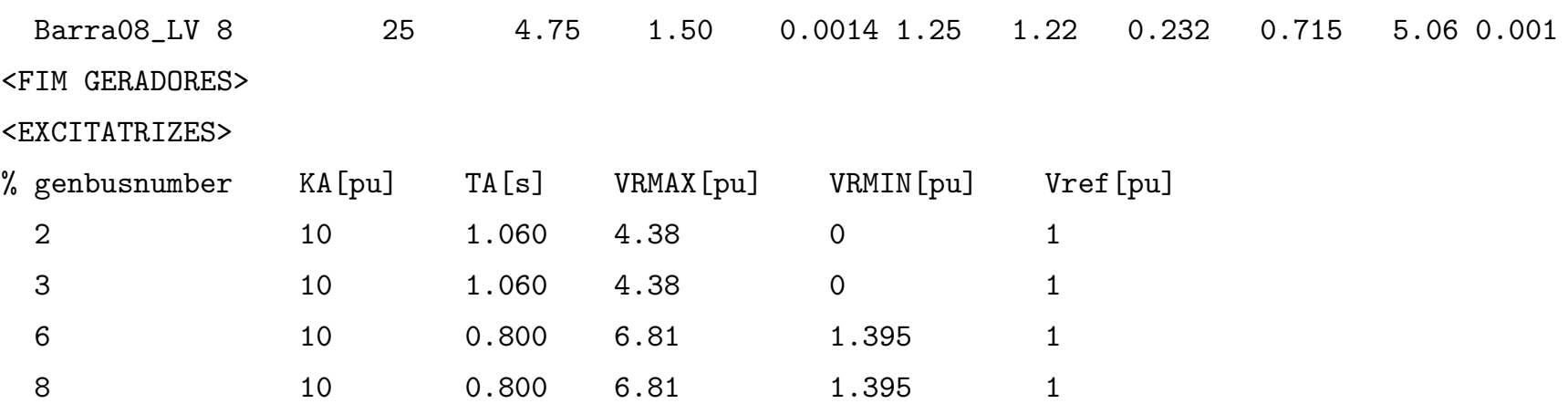

$<$ FIM EXCITATRIZES>

$<$ CARGAS DINAMICAS>

$\%$ Hill

$\begin{array}{llllll}\% \text { frombus } & \text { tipo } & \text { TP }[\mathrm{s}] & \text { alpha_t }[\mathrm{pu}] & \mathrm{TQ}[\mathrm{s}] & \text { beta_t }[\mathrm{pu}] \\ 14 & \text { Hill } & 61 & 1.31 & 88 & 2.08\end{array}$

$\%$ Ihara

\% frombus tipo KP [pu] TP[s] Pdyn[pu] Pdrop[pu] KQ[pu] TQ[s] Qdyn[pu] Qdrop[pu]
14
Ihara
0.7
1.7
0.4
$\begin{array}{lll}1.6 & 1.7 & 0.5\end{array}$
0

<FIM CARGAS DINAMICAS>

<MOTORES>

$\%$ agregado residencial + industrial (20 hp)- tipo 6 (torque quadratico)

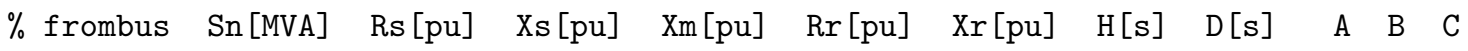

$\begin{array}{llllllllllll}14 & 15 & 0.035 & 0.094 & 2.80 & 0.048 & 0.163 & 0.93 & 0.001 & 1 & 0 & 0\end{array}$

$<$ FIM MOTORES>

$<$ EVENTOS>

$\begin{array}{lllllllll}\% \text { dispositivo } & \text { barraFROM } & \text { comando } & \text { valor }[\mathrm{pu} / \mathrm{s}] & \text { to }[\mathrm{s}] & \text { tf }[\mathrm{s}] & \mathrm{kp} & \mathrm{kq} & \\ \text { Carga } & 2 & \text { aumentar } & 0.082 & 100 & 130 & 1 & 1 & 1 \\ \text { Carga } & 3 & \text { aumentar } & 0.082 & 100 & 130 & 1 & 1 & 1 \\ \text { Carga } & 4 & \text { aumentar } & 0.082 & 100 & 130 & 1 & 1 & 1 \\ \text { Carga } & 5 & \text { aumentar } & 0.082 & 100 & 130 & 1 & 1 & 1 \\ \text { Carga } & 6 & \text { aumentar } & 0.082 & 100 & 130 & 1 & 1 & 1 \\ \text { Carga } & 9 & \text { aumentar } & 0.082 & 100 & 130 & 1 & 1 & 1 \\ \text { Carga } & 10 & \text { aumentar } & 0.082 & 100 & 130 & 1 & 1 \\ \text { Carga } & 11 & \text { aumentar } & 0.082 & 100 & 130 & 1 & 1 \\ \text { Carga } & 12 & \text { aumentar } & 0.082 & 100 & 130 & 1 & 1 \\ \text { Carga } & 13 & \text { aumentar } & 0.082 & 100 & 130 & 1 & 1 \\ \text { CargaDin } & 14 & \text { aumentar } & 0.082 & 100 & 130 & 1 & 1\end{array}$

<FIM EVENTOS> 


\section{Anexo B - Uma introdução breve à DASSLC}

As equações (B.1) e (B.2) descrevem uma DAE ${ }^{1}$ em que $d=-0.01$ e $e=0.01$.

$$
\begin{aligned}
& \dot{y}_{0}-d . y_{0}-\frac{y_{1}}{e}=0 \\
& \dot{y}_{1}+\frac{y_{1}}{e}=0
\end{aligned}
$$

A solução numérica dessa DAE entre $t_{0}=0 \mathrm{~s}$ e $t_{f}=6.9 \mathrm{~s}$, admitindo-se um $\Delta t=0.1 \mathrm{~s}$, é obtida a partir do código a seguir. Admite-se os valores iniciais de $y_{0}=1$ e $y_{1}=1$. Os valores iniciais das derivadas $\dot{y_{0}}$ e $\dot{y_{1}}$ são desconhecidos.

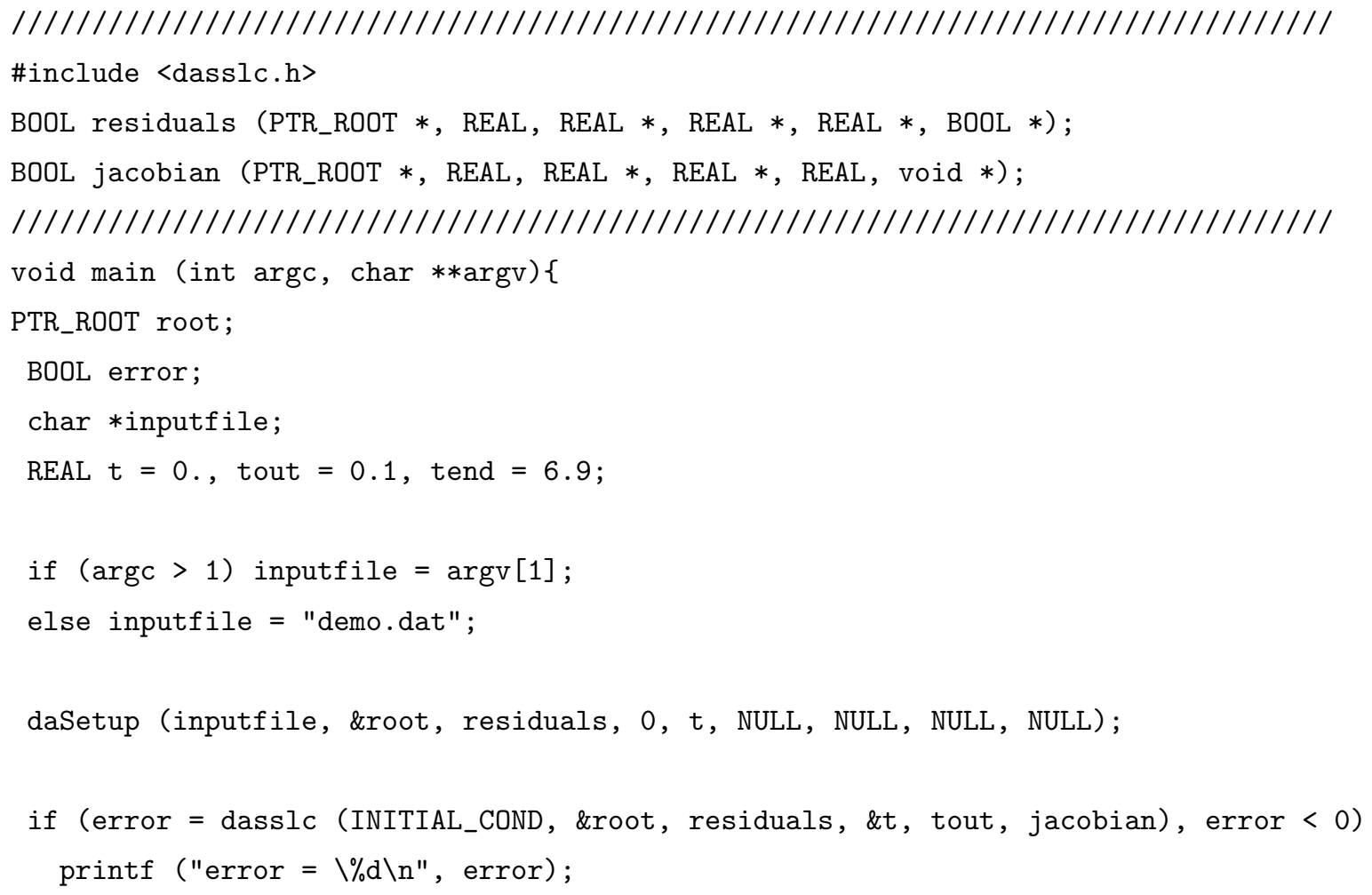

${ }^{1} \mathrm{O}$ exemplo aqui abordado foi retirado de (SECCHI, 1992). 


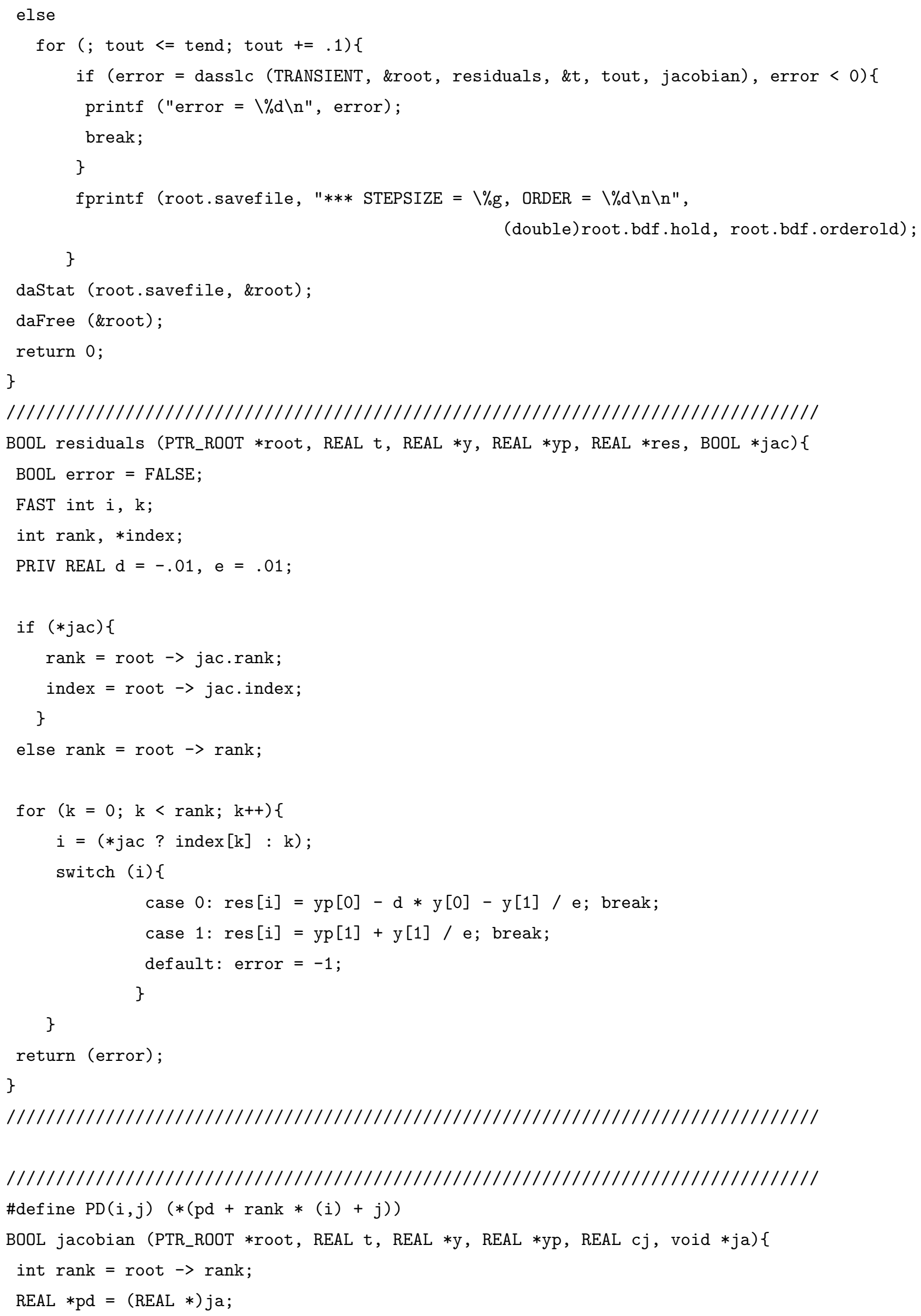


PRIV REAL $\mathrm{d}=-.01, \mathrm{e}=.01$;

$\operatorname{PD}(0,0)=c j-d ;$

$\operatorname{PD}(0,1)=-1.0 / \mathrm{e}$;

$\operatorname{PD}(1,1)=c j+1.0 / e ;$

return FALSE;

\}

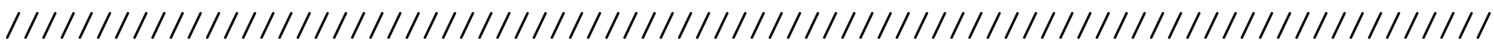

A função daSetup() é responsável pela inicialização da $D A S S L C$ (leitura do arquivo de setup, ajuste dos parâmetros do solver, alocação dinâmica de memória, entre outras tarefas). A função daSetup() quando chamada com o parâmetro INITIAL_COND obriga o solver a determinar os valores iniciais das derivadas $\dot{y}$ quando essas não são fornecidas. A chamada à função daSetup() com o parâmetro TRANSIENT resolve numericamente a DAE entre os instantes $t$ e tout. O laço existente no código apresentado faz com que a solução numérica seja determinada entre $t_{0}=0 \mathrm{~s}$ e $t_{f}=1 \mathrm{~s}$. A função daStat() mede o tempo de simulação e a função daFree() desaloca toda a memória previamente alocada.

Para a solução numérica da DAE, a função daSetup() utiliza as funções residuals() e jacobian() que contêm, respectivamente, as descrições de seu resíduo e jacobiano. As condições iniciais da DAE e alguns ajustes da DASSLC estão contidas no arquivo demo.dat, apresentado a seguir:

rank 2

option savefile demo.save

option !istall !stol

option maxlen 3000

option maxorder 5

print

data initial

time 0 .

$0: 1$.

1: 1 .

endata

O comando rank define a dimensão da DAE. O comando option savefile indica o arquivo que a DASSLC deve utilizar para salvar o resultado da simulação. O comando print solicita a impressão dos resultados no arquivo selecionado. Finalmente, o comando data initial ... endata permite especificar as seguintes condições iniciais para a solução da DAE: 


$$
\begin{aligned}
t & =0 \\
y_{0}(0) & =1 \\
y_{1}(0) & =1
\end{aligned}
$$

A seguir apresenta-se o resultado impresso pela DASSLC no arquivo demo.save.

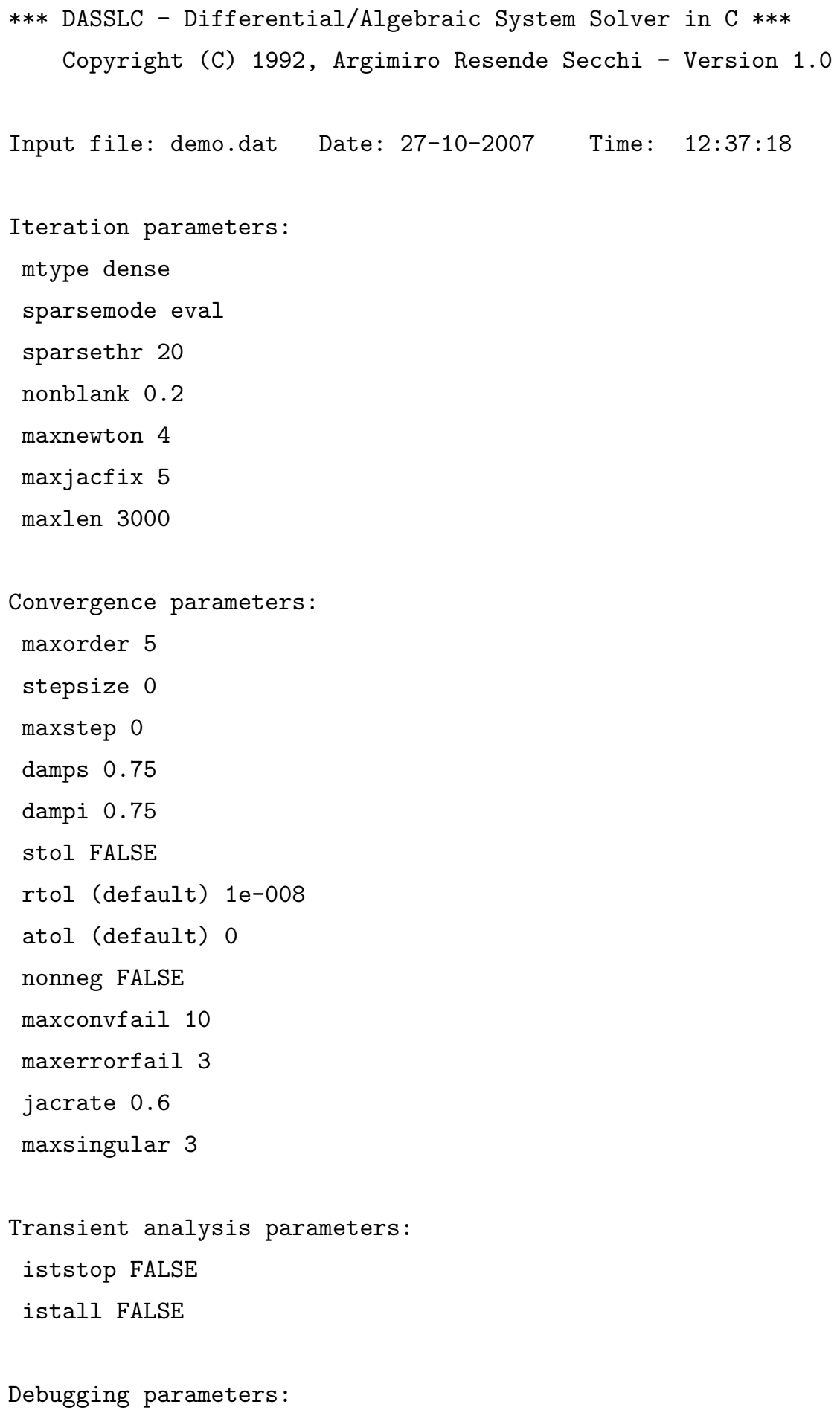


print TRUE

newton FALSE

bdf FALSE

conv FALSE

matrix FALSE

$t=0.000 e+000$ index value derivative index value derivative

( 0 ) $1.00000 \mathrm{e}+0009.528 \mathrm{e}+001$ ( 1) $1.00000 \mathrm{e}+000-9.529 \mathrm{e}+001$

$t=1.000 \mathrm{e}-001$ index value derivative index value derivative ( 0$) 1.99806 \mathrm{e}+000-1.544 \mathrm{e}-002$ ( 1) $4.53999 \mathrm{e}-005-4.540 \mathrm{e}-003$

$* * *$ STEPSIZE $=0.000417244$, ORDER $=5$

$t=2.000 \mathrm{e}-001$ index value derivative index value derivative

( 0) $1.99610 \mathrm{e}+000-1.996 \mathrm{e}-002$ ( 1) $2.06115 \mathrm{e}-009-2.061 \mathrm{e}-007$

$* * *$ STEPSIZE $=0.000417244$, ORDER $=5$

$\mathrm{t}=3.000 \mathrm{e}-001$ index value derivative index value derivative

( 0 ) $1.99411 \mathrm{e}+000-1.994 \mathrm{e}-002$ ( 1) $9.35763 \mathrm{e}-014-9.358 \mathrm{e}-012$

$* * *$ STEPSIZE $=0.000417244$, ORDER $=5$

$\mathrm{t}=4.000 \mathrm{e}-001$ index value derivative index value derivative

( 0 ) $1.99212 \mathrm{e}+000-1.992 \mathrm{e}-002$ ( 1) $4.24836 \mathrm{e}-018-4.248 \mathrm{e}-016$

$* * *$ STEPSIZE $=0.000417244$, ORDER $=5$

$\mathrm{t}=5.000 \mathrm{e}-001$ index value derivative index value derivative

( 0) $1.99012 \mathrm{e}+000-1.990 \mathrm{e}-002$ ( 1) $1.92875 \mathrm{e}-022-1.929 \mathrm{e}-020$

$* * *$ STEPSIZE $=0.000417244$, ORDER $=5$

$\mathrm{t}=6.000 \mathrm{e}-001$ index value derivative index value derivative

( 0$) 1.98814 \mathrm{e}+000-1.988 \mathrm{e}-002$ ( 1) $8.75652 \mathrm{e}-027-8.757 \mathrm{e}-025$

$* * *$ STEPSIZE $=0.000417244$, ORDER $=5$

$t=7.000 e-001$ index value derivative index value derivative

( 0) $1.98615 \mathrm{e}+000-1.986 \mathrm{e}-002$ ( 1) $3.97546 \mathrm{e}-031-3.975 \mathrm{e}-029$

STEPSIZE $=0.000417244$, ORDER $=5$ 


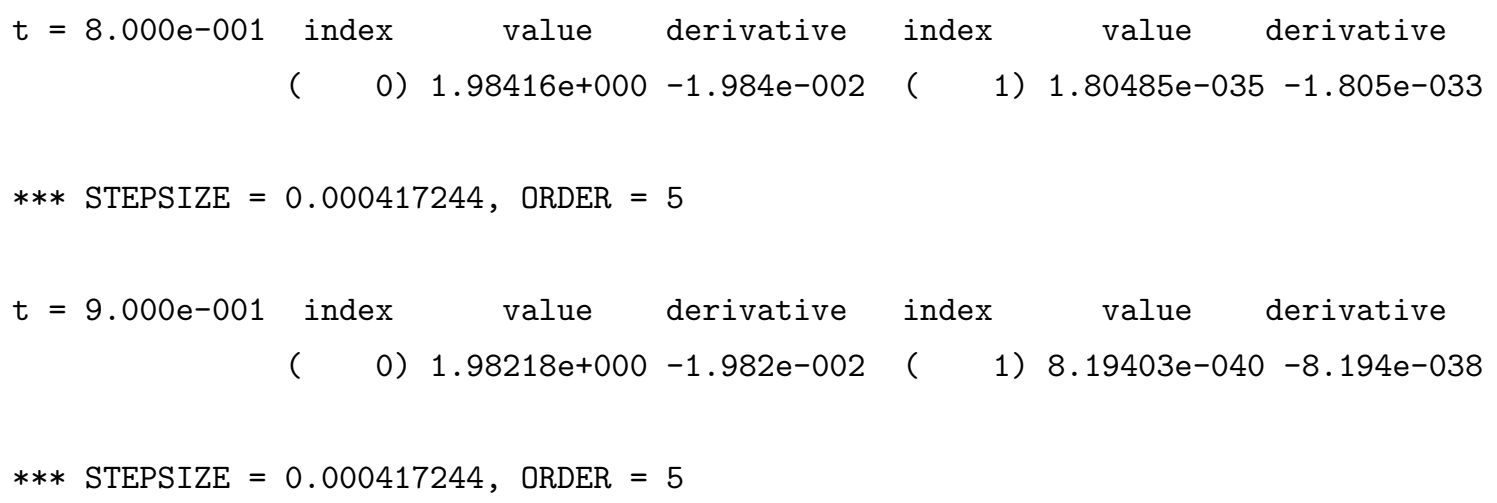




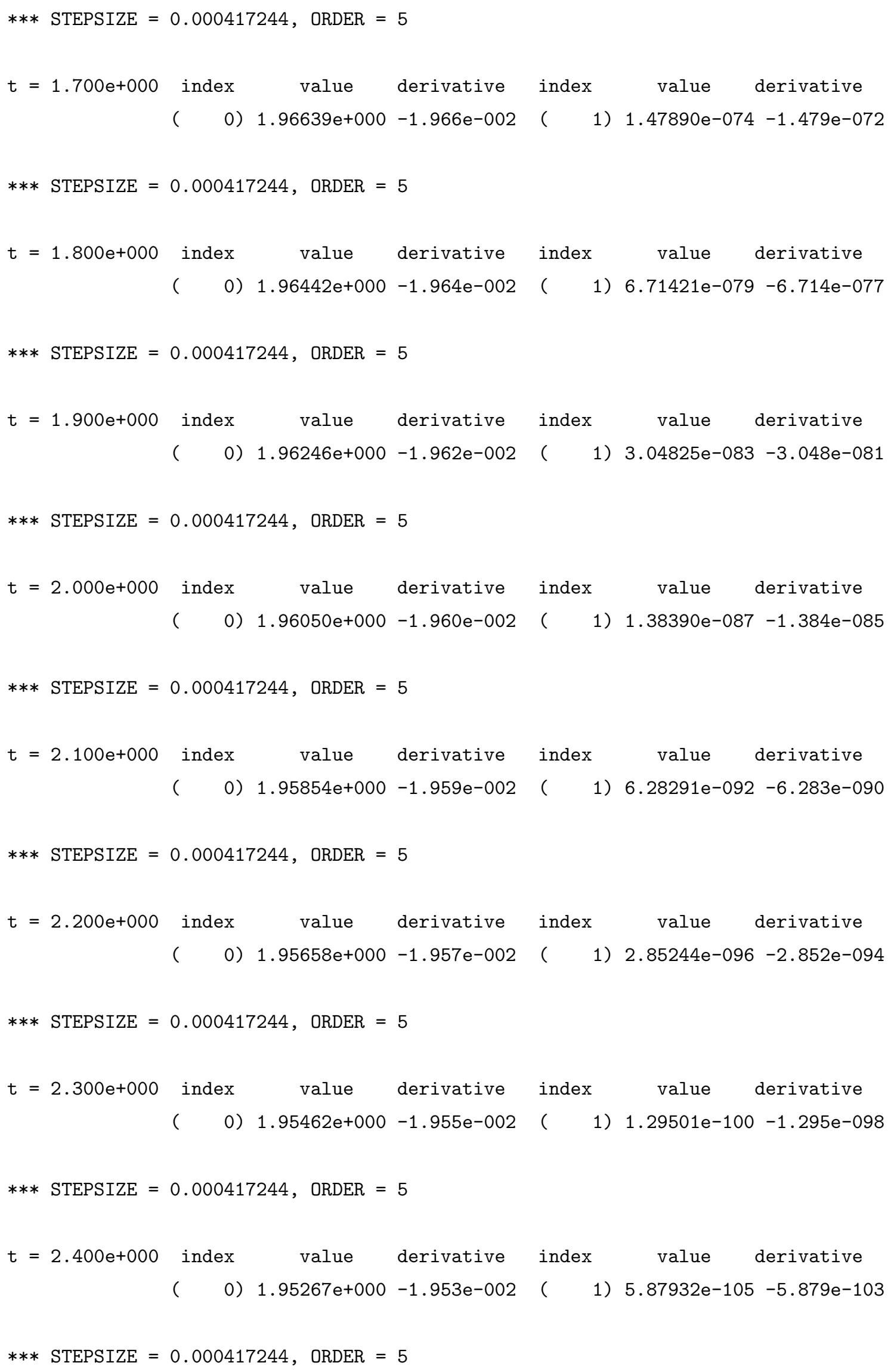


$t=2.500 \mathrm{e}+000$ index value derivative index value derivative

$* * *$ STEPSIZE $=0.000417244$, ORDER $=5$

$\mathrm{t}=2.600 \mathrm{e}+000$ index value derivative index value derivative

0) $1.94877 \mathrm{e}+000-1.949 \mathrm{e}-002$ ( $\quad$ 1) $1.21182 \mathrm{e}-113-1.212 \mathrm{e}-111$

$* * *$ STEPSIZE $=0.000417244$, ORDER $=5$

$t=2.700 e+000$ index value derivative index value derivative

( 0$) 1.94682 e+000-1.947 e-002$ ( 1) $5.50165 e-118-5.502 e-116$

$* * *$ STEPSIZE $=0.000417244$, ORDER $=5$

$t=2.800 e+000$ index value derivative index value derivative

0) $1.94487 e+000-1.945 e-002$ ( 1) $2.49774 e-122-2.498 e-120$

$* * *$ STEPSIZE $=0.000417244$, ORDER $=5$

$t=2.900 \mathrm{e}+000$ index value derivative index value derivative ( 0$) 1.94293 e+000-1.943 e-002$ ( 1) $1.13397 e-126-1.134 e-124$

$* * *$ STEPSIZE $=0.000417244$, ORDER $=5$

$t=3.000 e+000$ index value derivative index value derivative ( 0$) 1.94099 \mathrm{e}+000-1.941 \mathrm{e}-002$ ( 1) $5.14824 \mathrm{e}-131-5.148 \mathrm{e}-129$

$* * *$ STEPSIZE $=0.000417244$, ORDER $=5$

$t=3.100 e+000$ index value derivative index value derivative

( 0$) 1.93905 e+000-1.939 e-002$ ( 1) $2.33730 e-135-2.337 e-133$

STEPSIZE $=0.000417244$, ORDER $=5$

$\mathrm{t}=3.200 \mathrm{e}+000$ index value derivative index value derivative ( 0$) 1.93711 \mathrm{e}+000-1.937 \mathrm{e}-002$ ( 1) $1.06113 \mathrm{e}-139-1.061 \mathrm{e}-137$

STEPSIZE $=0.000417244$, ORDER $=5$

$t=3.300 e+000$ index value derivative index value derivative ( 0$) 1.93517 e+000-1.935 e-002$ ( 1) $4.81753 e-144-4.818 e-142$ 


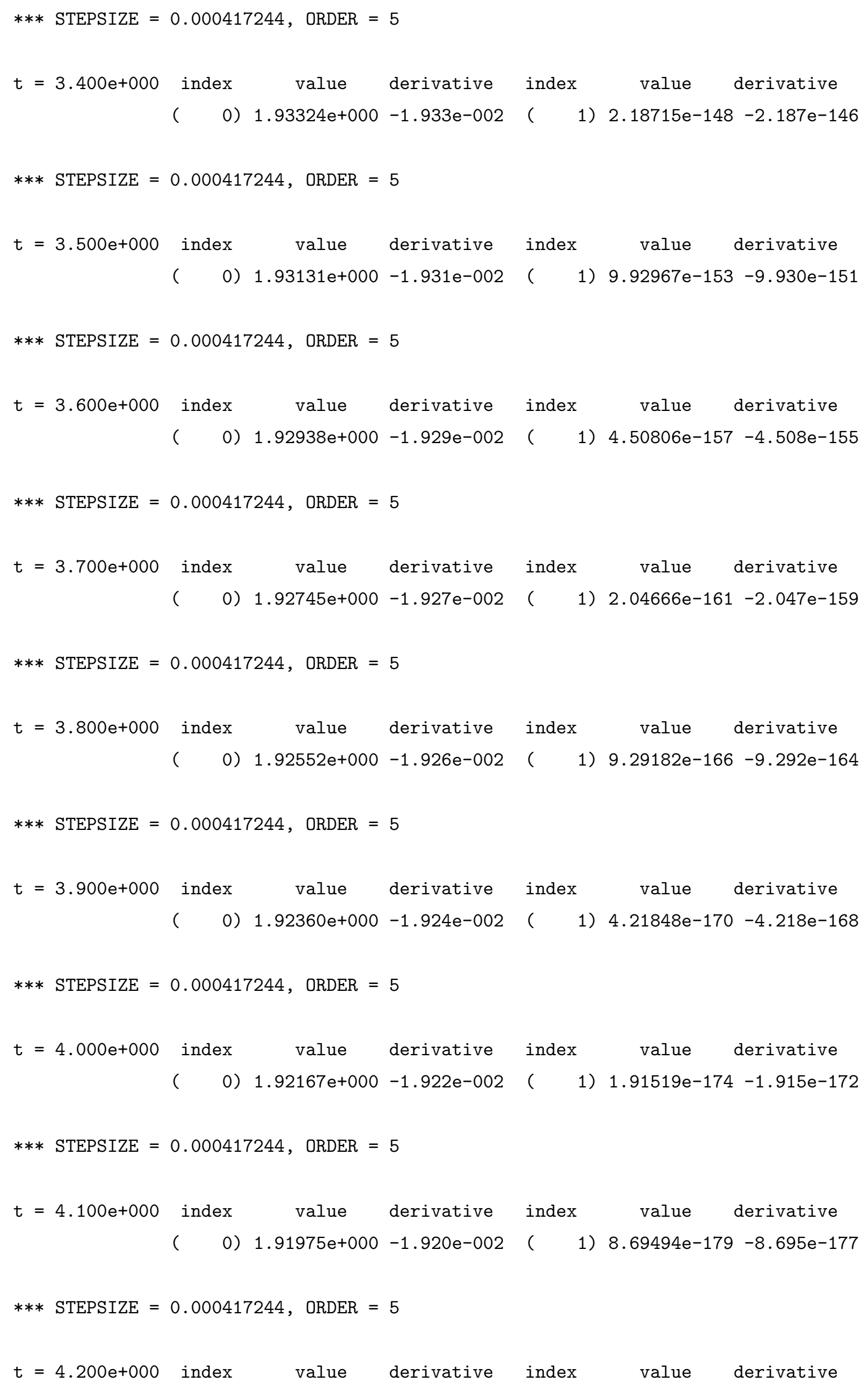




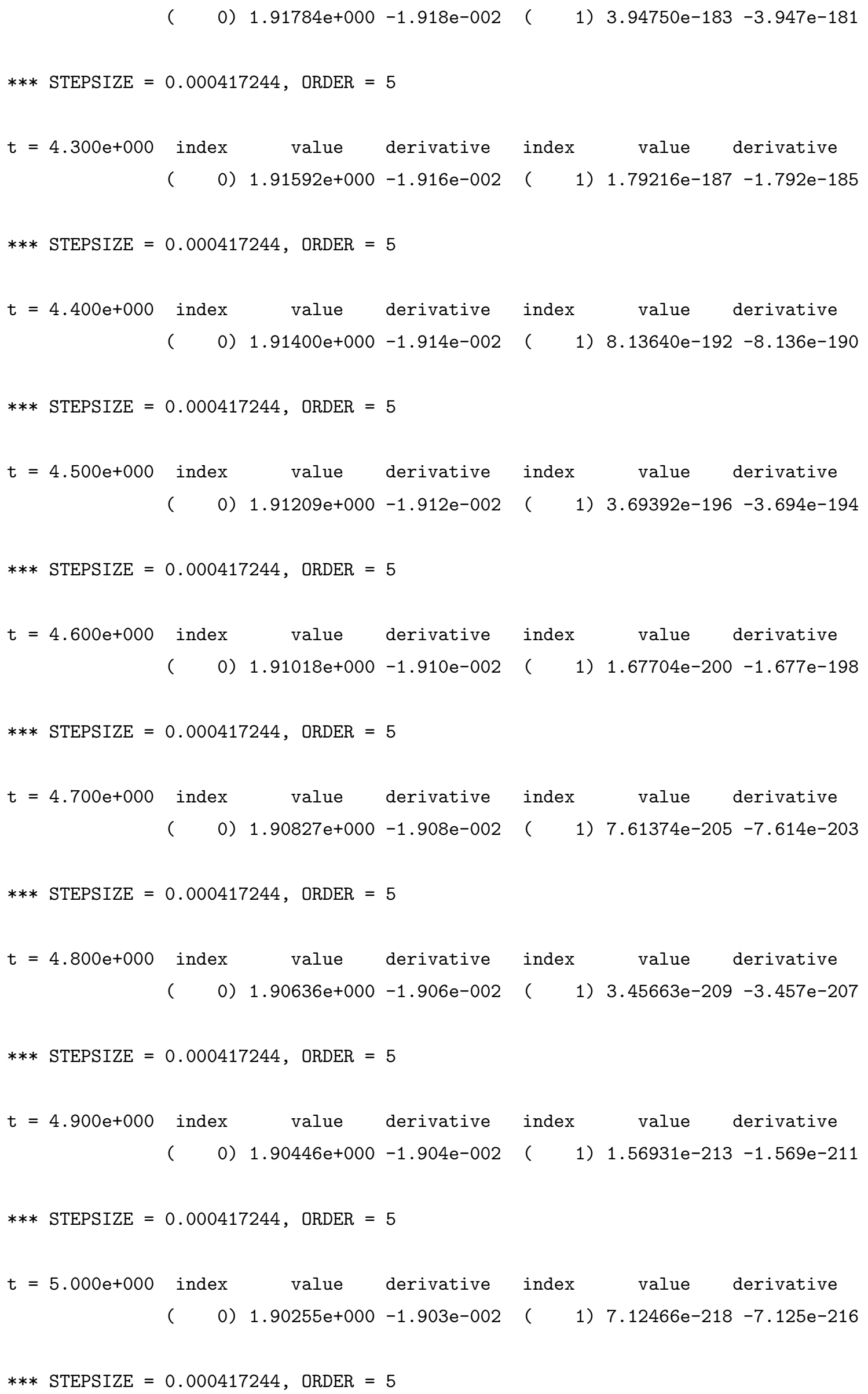




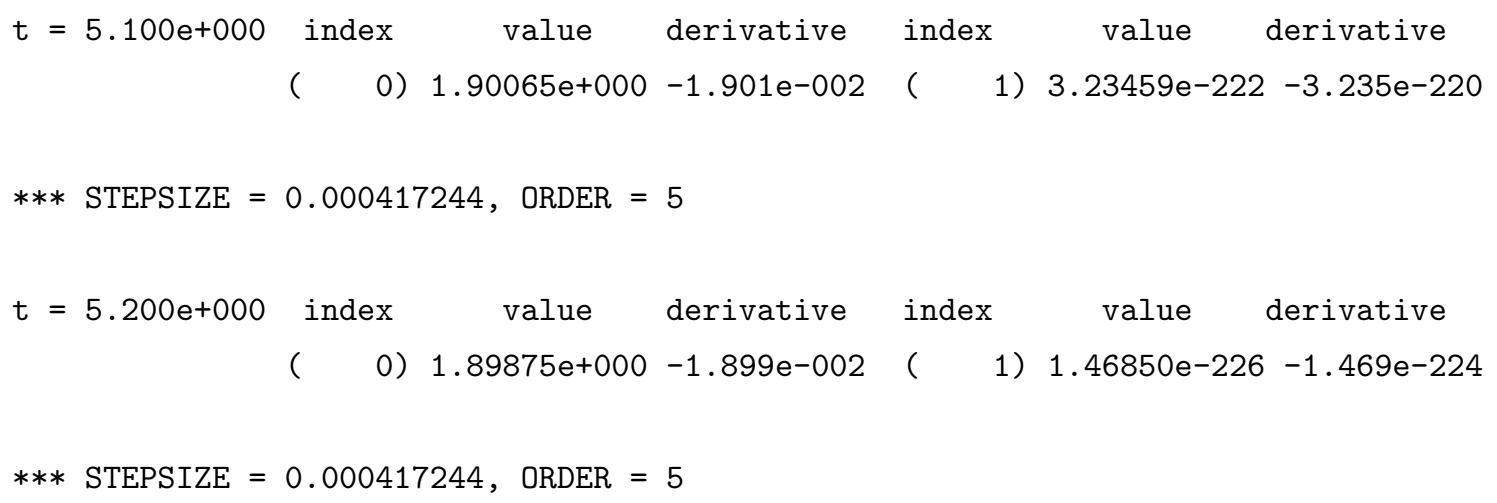




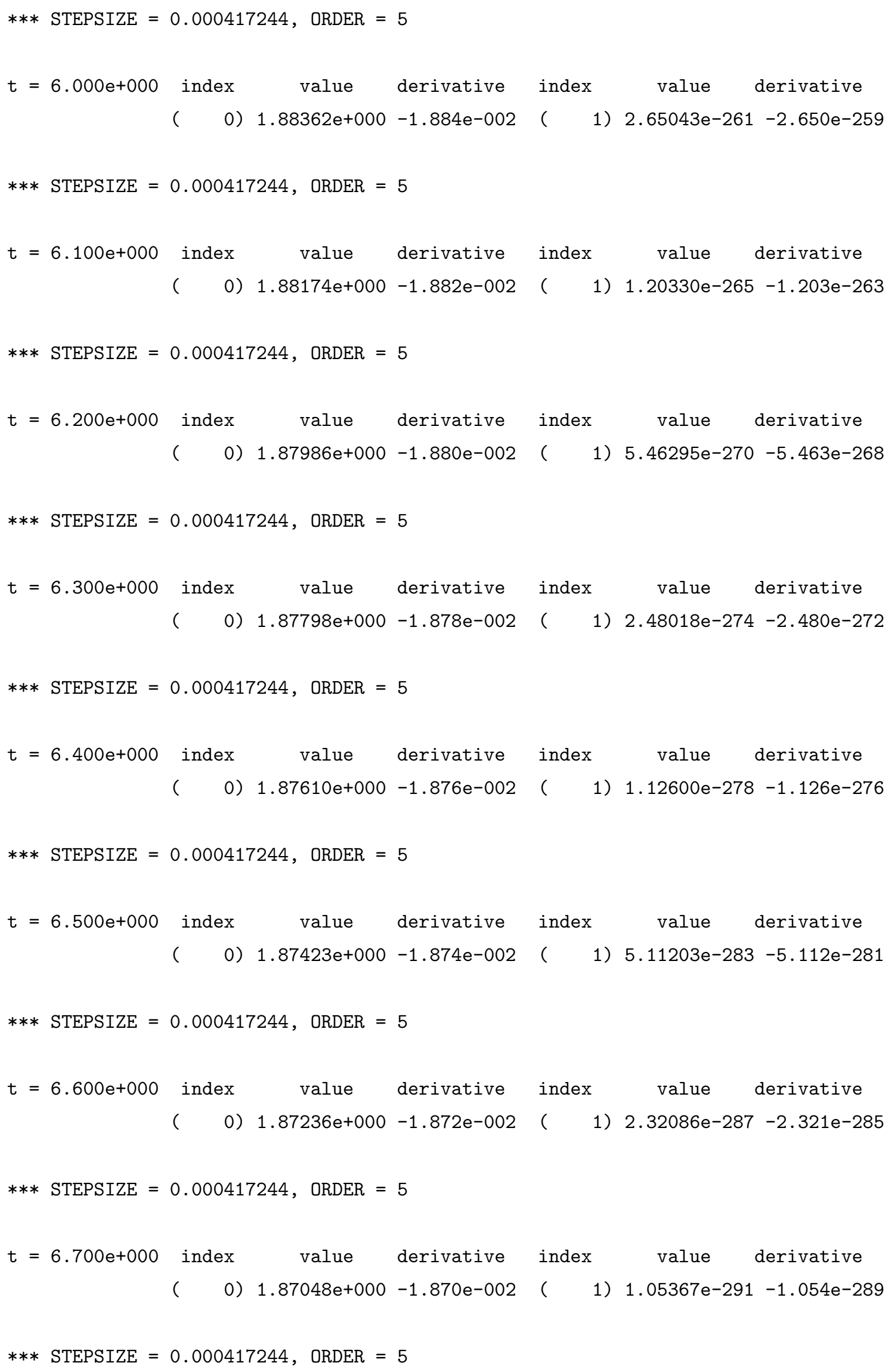




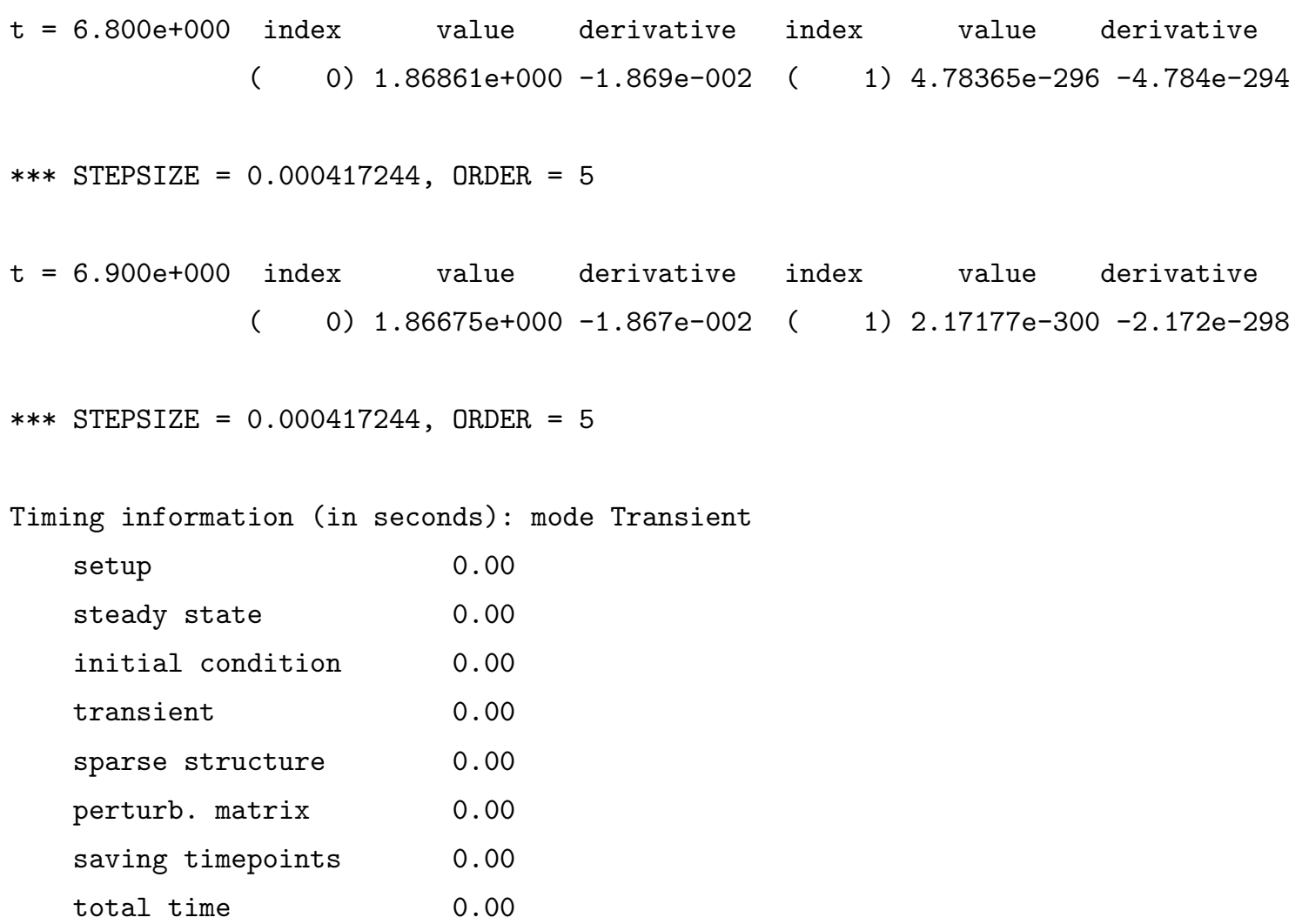

Total number of time-points: 16583

Total number of evaluation of residuals: 16674

Total number of evaluation of jacobian: 34

Total number of Newton-Raphson iterations: 83

Total number of error test failures: 7

Total number of convergence test failures: 0

Total number of rejected time-points: 7

Total number of rejected Newton-Raphson iterations: 36

Roundoff: $2.220446049250313100 e-016$

Total CPU-time (Setup + Simulation): $0.00 \mathrm{sec}$

Simulation time: $0.00 \mathrm{sec}$

Esse arquivo apresenta respectivamente: os ajustes da DASSLC utilizados na simulação, os resultados da simulação e um relatório contendo o tempo de execução e detalhes relacionados à simulação numérica.

Na seção correspondente aos resultados da simulação, observa-se que para cada instante de tempo $t$, situado entre $t_{0}=0 s$ e $t_{f}=6.9 s$, a DASSLC imprime, respectivamente, os valores de $y_{0}(t), y_{0}(t), y_{1}(t)$ e $\dot{y_{1}}(t)$. Além disso também são impressos o tamanho do passo de integração e ordem da série BDF empregados. 
Para mais detalhes sobre o uso da DASSLC, recomenda-se a leitura da referência (SECCHI, 1992). 


\section{Referências}

ADKINS, B. The General Theory of Electrical Machines. [S.l.]: John Wiley \& Sons, 1967.

AJJARAPU, V.; CHRISTY, C. The continuation power flow: a tool for steady state voltage stability analysis. Power Systems, IEEE Transactions on, v. 7, n. 1, p. 416-423, Feb. 1992.

AJJARAPU, V.; LEE, B. Bifurcation theory and its application to nonlinear dynamical phenomena in an electrical power system. Power Systems, IEEE Transactions on, v. 7, n. 1, p. 424-431, Feb. 1992.

ANDERSON, E.; BAI, Z.; BISCHOF, C.; BLACKFORD, L. S.; DEMMEL, J.; DONGARRA, J.; CROZ, J. D.; GREENBAUM, A.; HAMMARLING, S.; MCKENNEY, A.; SORENSEN, D. LAPACK Users' Guide. [S.l.]: Society for Industrial and Applied Mathematics, 1999.

ANDERSON, P. M.; FOUAD, A. A. Power System Control and Stability. 2nd edition. ed. [S.1.]: Wiley-IEEE Press, 2002. 672 p.

ASCHER, U. M.; PETZOLD, L. R. Computer methods for ordinary differential equations and differential-algebraic equations. [S.l.]: SIAM: Society for Industrial and Applied Mathematics, 1998. 332 p.

ASTIC, J.; BIHAIN, A.; JEROSOLIMSKI, M. The mixed adams-bdf variable step size algorithm to simulate transient and long term phenomena in power systems. Power Systems, IEEE Transactions on, v. 9, n. 2, p. 929-935, May 1994.

BERIZZI, A.; BRESESTI, P.; MARANNINO, P.; GRANELli, G.; MONTAGNA, M. System-area operating margin assessment and security enhancement against voltage collapse. Power Systems, IEEE Transactions on, v. 11, n. 3, p. 1451-1462, Aug. 1996.

CANIZARES, C. Voltage stability assessment : concepts, practices and tools. [S.1.], 2002.

CANIZARES, C.; ALVARADO, F. Point of collapse and continuation methods for large ac/dc systems. Power Systems, IEEE Transactions on, v. 8, n. 1, p. 1-8, Feb. 1993.

CANIZARES, C.; ALVARADO, F.; DEMARCO, C.; DOBSON, I.; LONG, W. Point of collapse methods applied to ac/dc power systems. Power Systems, IEEE Transactions on, v. 7, n. 2, p. 673-683, May 1992.

CANIZARES C. A.; ALVARADO, F. L. UWPFLOW software: continuation and direct methods to locate fold bifurcations in AC/DC power systems. [S.l.], 1991. 
CARPENTIER, J.; GIRARD, R.; SCANO, E. Voltage collapse proximity indicators computed from an optimal load flow. In: the 8th PSCC Conference, Proceedings of,. [S.l.: s.n.], 1984. p. 671-678.

CHEIMANOFF, A.; CURROYER, C. The power failure of december 19, 1978. de l'electricite, Revue Generale, v. 89, p. 280-320, 1980.

CHIANG, H.-D.; FLUECK, A.; SHAH, K.; BALU, N. Cpflow: a practical tool for tracing power system steady-state stationary behavior due to load and generation variations. Power Systems, IEEE Transactions on, v. 10, n. 2, p. 623-634, May 1995.

CHOWDHURY, B.; TAYLOR, C. Voltage stability analysis: V-q power flow simulation versus dynamic simulation. Power Systems, IEEE Transactions on, v. 15, n. 4, p. 1354-1359, Nov. 2000.

CIGRE. Task Force 38-02-08: Long Term Dynamics Phase II - Final Report. [S.1.], 1995.

COUnAn, C.; TROTIGNON, M.; CORRADI, E.; BORTONI, G.; STUBBE, M.; DEUSE, J. Major incidents on the french electric system: potentiality and curative measures studies. Power Systems, IEEE Transactions on, v. 8, n. 3, p. 879-886, Aug. 1993.

CUTSEM, T. V. A method to compute reactive power margins with respect to voltage collapse. Power Systems, IEEE Transactions on, v. 6, n. 1, p. 145-156, Feb. 1991.

CUTSEM, T. V. Voltage instability: phenomena, countermeasures, and analysis methods. Proceedings of the IEEE, v. 88, n. 2, p. 208-227, Feb. 2000.

CUTSEM, T. V.; JACQUEMART, Y.; MARQUET, J.-N.; PRUVOT, P. A comprehensive analysis of mid-term voltage stability. Power Systems, IEEE Transactions on, v. 10, n. 3, p. 1173-1182, Aug. 1995.

CUTSEM, T. V.; MAILHOT, R. Validation of a fast voltage stability analysis method on the hydro-quebec system. Power Systems, IEEE Transactions on, v. 12, n. 1, p. 282-292, Feb. 1997.

CUTSEM, T. V.; MOISSE, C.; MAILHOT, R. Determination of secure operating limits with respect to voltage collapse. Power Systems, IEEE Transactions on, v. 14, n. 1, p. 327-335, Feb. 1999.

CUTSEM, T. V.; MOORS, C.; LEFEBVRE, D. Design of load shedding schemes against voltage instability using combinatorial optimization. In: Power Engineering Society Winter Meeting, 2002. IEEE. [S.l.: s.n.], 2002. v. 2, p. 848-853vol.2.

CUTSEM, T. V.; VOURNAS, C. Voltage stability analysis in transient and mid-term time scales. Power Systems, IEEE Transactions on, v. 11, n. 1, p. 146-154, Feb. 1996.

CUTSEM, T. V.; VOURNAS, C. Voltage stability analysis of electric power systems. [S.l.]: Kluwer Academic Publishers, 1998. 396 p.

DANDENO, P. L.; AGRAWAL, B.; HANNETT, L. N.; SALON; BAKER, D. H.; HARLEY, R. G.; SCHUlZ, R. P.; CONCORDIA, C.; LEE D. C., S. H. R.; EDMONDS, J. S.; MINNICH, S. H.; UMANS, S. IEEE Guide for synchronous generator modelling practices in stability analyses, IEEE Std. 1110-1991. [S.l.], 1991. 
DEMARCO, C.; OVERBYE, T. An energy based security measure for assessing vulnerability to voltage collapse. Power Systems, IEEE Transactions on, v. 5, n. 2, p. 419-427, May 1990.

DEUSE, J.; STUBBE, M. Dynamic simulation of voltage collapses. Power Systems, IEEE Transactions on, v. 8, n. 3, p. 894-904, Aug. 1993.

DOBSON, I.; LU, L. Computing an optimum direction in control space to avoid stable node bifurcation and voltage collapse in electric power systems. Automatic Control, IEEE Transactions on, v. 37, n. 10, p. 1616-1620, Oct. 1992.

E. CAMPBELL S. L., P. L. R. B. K. Numerical Solution of Initial-Value Problems in Differential-Algebraic Equations. [S.l.]: Society for Industrial and Applied Mathematics (SIAM), 1996.

F. VIEIRA R. C., S. A. R. C. E. Dynamic simulation of high-index models of batch distillation processes. Lat. Am. Appl. Res., v. 33, p. 155-160, Apr./June 2003.

FERNANDES, L. A. P. Técnicas "anti-windup". Dissertação (Mestrado) — Escola Politécnica da Universidade de São Paulo, 2001.

GAO, B.; MORISON, G.; KUNDUR, P. Voltage stability evaluation using modal analysis. Power Engineering Review, IEEE, v. 12, n. 11, p. 41, November 1992.

GAO, B.; MORISON, G.; KUNDUR, P. Towards the development of a systematic approach for voltage stability assessment of large-scale power systems. Power Systems, IEEE Transactions on, v. 11, n. 3, p. 1314-1324, Aug. 1996.

GRANVILLE, S.; MELLO, J.; MELO, A. Application of interior point methods to power flow unsolvability. Power Systems, IEEE Transactions on, v. 11, n. 2, p. 1096-1103, May 1996.

GREENE, S.; DOBSON, I.; ALVARADO, F. Sensitivity of the loading margin to voltage collapse with respect to arbitrary parameters. Power Systems, IEEE Transactions on, v. 12, n. 1, p. 262-272, Feb. 1997.

HAKAVIK, B.; HOLEN, A. Power system modelling and sparse matrix operations using object-oriented programming. Power Systems, IEEE Transactions on, v. 9, n. 2, p. 1045-1051, May 1994.

HILL, D. Nonlinear dynamic load models with recovery for voltage stability studies. Power Systems, IEEE Transactions on, v. 8, n. 1, p. 166-176, Feb. 1993.

HISKENS, I.; GONG, B. Mpc-based load shedding for voltage stability enhancement. In: Decision and Control, 2005 and 2005 European Control Conference. CDC-ECC '05. 44th IEEE Conference on. [S.l.: s.n.], 2005. p. 4463-4468.

IBA, K.; SUZUKI, H.; EGAWA, M.; WATANABE, T. A method for finding a pair of multiple load flow solutions in bulk power systems. Power Systems, IEEE Transactions on, v. 5, n. 2, p. 582-591, May 1990.

IHARA, S.; TANI, M.; TOMIYAMA, K. Residential load characteristics observed at kepco power system. Power Systems, IEEE Transactions on, v. 9, n. 2, p. 1092-1101, May 1994. 
IRISARRI, G.; WANG, X.; TONG, J.; MOKHTARI, S. Maximum loadability of power systems using interior point nonlinear optimization method. Power Systems, IEEE Transactions on, v. 12, n. 1, p. 162-172, Feb. 1997.

IWAMOTO, S.; TAMURA, Y. A load flow calculation method for ill-conditioned power systems. Power Apparatus and Systems, IEEE Transactions on, v. 100, p. 1736-1743, 1981.

JARDIM, J. L. Utilização de ferramentas de simulação dinâmica de longa duração na análise de fenômenos de colapso de tensão e no treinamento de operadores. In: XIV SNPTEE. [S.l.: s.n.], 1997.

KARLSSON, D. Voltage Stability Simulations Using Detailed Models Based on Field Measurements. Dissertação (Mestrado) — Chalmers University of Technology, 1992.

KLUMP, R.; OVERBYE, T. Techniques for improving power flow convergence. In: Power Engineering Society Summer Meeting, 2000. IEEE. [S.l.: s.n.], 2000. v. 1, p. 598-603vol.1.

KUNDUR, P. Power System Stability and Control. 1. ed. [S.l.]: McGraw-Hill Professional, 1994. 1176 p.

KURITA, A.; OKUBO, H.; OKI, K.; AGEMATSU, S.; KLAPPER, D.; MILLER, N.; PRICE W.W., J.; SANCHEZ-GASCA, J.; WIRGAU, K.; YOUNKINS, T. Multiple time-scale power system dynamic simulation. Power Systems, IEEE Transactions on, v. 8, n. 1, p. 216-223, Feb. 1993.

KURITA, A.; SAKURAI, T. The power system failure on july 23, 1987 in tokyo. In: the 27th Conference on Decision and Control, Proceedings of. [S.l.: s.n.], 1988.

LEE, D. C.; BAKER, D. H.; GORDEN, D. I.; MELOY, G.; BESS, K. C.; HURLEY, J. D.; RIBEIRO, J. R.; CRENSHAW, M. L.; KUNDUR, P.; THOMAS, J. W.; DHIR, K.; LUINI, J. F.; TREBINCEVIC, I.; GISH, W. B.; WHITTEMORE, T. IEEE Recommended practice for excitation system models for power system stability studies, IEEE Std. 421.5-1992. [S.1.], 1992.

LEFEBVRE, D.; BERNARD, S.; CUTSEM, T. V. Undervoltage load shedding scheme for the hydro-quebec system. In: Power Engineering Society General Meeting, 2004. IEEE. [S.l.: s.n.], 2004. p. 1619-1624Vol.2.

LEFEBVRE, D.; MOORS, C.; CUTSEM, T. V. Design of an undervoltage load shedding scheme for the hydro-quebec system. In: Power Engineering Society General Meeting, 2003, IEEE. [S.l.: s.n.], 2003. v. 4.

LERM, A. Control of hopf bifurcation in power systems via a generation redispatch. In: Power Tech Proceedings, 2001 IEEE Porto. [S.l.: s.n.], 2001. v. 2, p. 6pp.vol.2.

LERM, A.; CANIZARES, C.; SILVA, A. Silveira e. Multiparameter bifurcation analysis of the south brazilian power system. Power Systems, IEEE Transactions on, v. 18, n. 2, p. 737-746, May 2003. 
LERM, A.; MORAES, C. Hopf bifurcation caused by dynamic load characteristics - a case study. In: Power Engineering Society General Meeting, 2003, IEEE. [S.l.: s.n.], 2003. v. 3.

LERM, A.; SILVA, A. Avoiding hopf bifurcations in power systems via set-points tuning. Power Systems, IEEE Transactions on, v. 19, n. 2, p. 1076-1084, May 2004.

MANSOUR, Y.; XU, W.; ALVARADO, F.; RINZIN, C. Svc placement using critical modes of voltage instability. Power Systems, IEEE Transactions on, v. 9, n. 2, p. 757-763, May 1994.

MILLER, N.; D'AQUILA, R.; JIMMA, K.; SHEEHAN, M.; COMEGYS, G. Voltage stability of the puget sound system under abnormally cold weather conditions. Power Systems, IEEE Transactions on, v. 8, n. 3, p. 1133-1142, Aug. 1993.

MONTICELLI, a. J. Fluxo de cargas em redes de energia elétrica. [S.l.]: Cepel, 1983. $164 \mathrm{p}$.

MORISON, G.; GAO, B.; KUNDUR, P. Voltage stability analysis using static and dynamic approaches. Power Systems, IEEE Transactions on, v. 8, n. 3, p. 1159-1171, Aug. 1993.

NAVARRO, I. Dynamic power system load estimation of parameters from operational data. Tese (Doutorado) — Lund University, 2005.

NOR, K.; MOKHLIS, H.; GANI, T. Reusability techniques in load-flow analysis computer program. Power Systems, IEEE Transactions on, v. 19, n. 4, p. 1754-1762, Nov. 2004.

OBADINA, O.; BERG, G. Determination of voltage stability limit in multimachine power systems. Power Systems, IEEE Transactions on, v. 3, n. 4, p. 1545-1554, Nov. 1988.

OLIVEIRA, A. C. C. Método para aumento da margem da estabilidade de tensão via redespacho ótimo da geração ativa. Tese (Doutorado) - COPPE - UFRJ, 2005.

ONG, C.-M. Dynamic Simulations of Electric Machinery: Using MATLAB/SIMULINK. [S.l.]: Prentice Hall PTR, 1997. 688 p.

ONS, O. N. d. S. Procedimentos de Rede: Diretrizes e critérios para estudos elétricos, submódulo 23.3. [S.l.], 2002.

OVERBYE, T. A power flow measure for unsolvable cases. Power Systems, IEEE Transactions on, v. 9, n. 3, p. 1359-1365, Aug. 1994.

OVERBYE, T. Computation of a practical method to restore power flow solvability. Power Systems, IEEE Transactions on, v. 10, n. 1, p. 280-287, Feb. 1995.

OVERBYE, T.; KLUMP, R. Effective calculation of power system low-voltage solutions. Power Systems, IEEE Transactions on, v. 11, n. 1, p. 75-82, Feb. 1996.

PAI, M.; SAUER, P.; LESIEUTRE, B. Static and dynamic nonlinear loads and structural stability in power systems. Proceedings of the IEEE, v. 83, n. 11, p. 1562-1572, Nov. 1995. 
PANDIT, S.; SOMAN, S.; KHAPARDE, S. Design of generic direct sparse linear system solver in c ++ for power system analysis. Power Systems, IEEE Transactions on, v. 16, n. 4, p. 647-652, Nov. 2001.

PANDIT, S.; SOMAN, S.; KHAPARDE, S. Object oriented set theoretic implementation of minimum degree algorithm. In: Proc. 14th Power System Computation Conference, Sevilla. [S.l.: s.n.], 2002.

PARKER, C.; MORRISON, I.; SUTANTO, D. Application of an optimisation method for determining the reactive margin from voltage collapse in reactive power planning. Power Systems, IEEE Transactions on, v. 11, n. 3, p. 1473-1481, Aug. 1996.

PEREIRA, R.; FERREIRA, C.; PINTO, J.; BARBOSA, F. Influence of the under load tap changers on the dynamic voltage collapse of an electric power system. In: Universities Power Engineering Conference, 2004. UPEC 2004. 39th International. [S.1.: s.n.], 2004. v. 3, p. 1106-1110vol.2.

PERFORMANCE, I. T. F. on Load Representation for D. Standard load models for power flow and dynamic performance simulation. Power Systems, IEEE Transactions on, v. 10, p. 1302-1313, 1995.

PERFORMANCE, I. Task Force on Load Representation for D. Load representation for dynamic performance analysis. Power Systems, IEEE Transactions on, v. 8, n. 2, p. 472-482, May 1993.

PETTERSON, N. M.; MEYER, W. S. Automatic ajustment of transformer and phase-shifter taps in newton power flow. Power Apparatus and Systems, IEEE Transactions on, PAS-90, n. 1, p. 103-108, January / February 1971.

POTAMIANAKIS E.G.; VOURNAS, C. Short-term voltage instability: effects on synchronous and induction machines. Power Systems, IEEE Transactions on, v. 21, p. $791-798,2006$.

POWELL, L. Power System Load Flow Analysis. [S.l.]: McGraw-Hill Education, 2005. $182 \mathrm{p}$.

SAUER, P.; PAI, M. Power system steady-state stability and the load-flow jacobian. Power Systems, IEEE Transactions on, v. 5, n. 4, p. 1374-1383, Nov. 1990.

SAUER, P. W.; PAI, M. A. Relationships between power system dynamic equilibrium, load-flow, and operating point stability. In: SAVULESCU, S. C. (Ed.). Real Time Stability in Power Systems - Techniques for Early Detection of the Risk of Blackout. [S.l.]: Springer Verlag, 2005. cap. 1, p. 1-30.

SAVULESCU, S. C. Real-Time Stability in Power Systems: Techniques for Early Detection of the Risk of Blackout. [S.l.]: Springer, 2005.

SCHMIDT, H. P. Analysis of the voltage stability problem in electric power system using neural networks. Tese (Doutorado) - Queen Mary and Westfield College - University of London, September 1994.

SECCHI, A. R. DASSLC: User's Manual, a Differencial Algebraic System Solver. [S.l.], 1992. 
SEDGEWICK, R. Algorithms in C++, Part 5: Graph Algorithms (3rd Edition). [S.1.]: Addison-Wesley, 2002.

SILVA, L. da; WANG, Y.; COSTA, V. da; XU, W. Assessment of generator impact on system power transfer capability using modal participation factors. In: Generation, Transmission and Distribution, IEE Proceedings-. [S.l.: s.n.], 2002. v. 149, n. 5, p. $564-570$.

SOUZA, A. Zambroni de; QUINTANA, V. New technique of network partitioning for voltage collapse margin calculations. In: Generation, Transmission and Distribution, IEE Proceedings-. [S.l.: s.n.], 1994. v. 141, n. 6, p. 630-636.

TAMURA, Y.; MORY, H.; IWAMOTO, S. Relationship between voltage instability and multiple load flow solutions. Power App. Syst., IEEE Transactions on, v. 102, p. 1115-1125, 1983.

TAMURA, Y.; SAKAMOTO, K.; TAYAMA, Y. Voltage instability proximity index (vipi) based on multiple load flow solutions in ill-conditioned power systems. In: Decision and Control, 1988., Proceedings of the 27th IEEE Conference on. [S.l.: s.n.], 1988. p. 2114-2119vol.3.

TARANTO, G.; MARTINS, N.; FALCAO, D.; MARTINS, A.; SANTOS, M. dos. Benefits of applying secondary voltage control schemes to the brazilian system. In: Power Engineering Society Summer Meeting, 2000. IEEE. [S.l.: s.n.], 2000. v. 2, p. 937-942vol.2.

TAYLOR, W. C. Power System Voltage Stability. [S.l.]: McGraw-Hill Education Europe, 1994. 272 p.

VAAHEDI, E.; FUCHS, C.; XU, W.; MANSOUR, Y.; HAMADANIZADEH, H.; MORISON, G. Voltage stability contingency screening and ranking. Power Systems, IEEE Transactions on, v. 14, n. 1, p. 256-265, Feb. 1999.

VOURNAS, C.; CUTSEM, T. V. On-line voltage security assessment. In: SAVULESCU, S. C. (Ed.). Real Time Stability in Power Systems - Techniques for Early Detection of the Risk of Blackout. [S.l.]: Springer Verlag, 2005. cap. 5, p. 119-146.

VOURNAS, C.; KARYSTIANOS, M. Load tap changers in emergency and preventive voltage stability control. Power Systems, IEEE Transactions on, v. 19, n. 1, p. 492-498, Feb. 2004.

VOURNAS, C.; MANOS, G.; KABOURIS, J.; CUTSEM, T. V. Analysis of a voltage instability incident in the greek power system. In: Power Engineering Society Winter Meeting, 2000. IEEE. [S.l.: s.n.], 2000. v. 2, p. 1483-1488vol.2.

YORINO, N.; HARADA, S.; CHENG, H. A method to approximate a closest loadability limit using multiple load flow solutions. Power Systems, IEEE Transactions on, v. 12, n. 1, p. 424-429, Feb. 1997.

ZHU, T.; TSO, S.; LO, K. An investigation into the oltc effects on voltage collapse. Power Systems, IEEE Transactions on, v. 15, n. 2, p. 515-521, May 2000. 